\title{
Beta-carotene and cancer risk : a trial in smokers using biomarkers as intermediate endpoints
}

Citation for published version (APA):

van Poppel, G. A. F. C. (1994). Beta-carotene and cancer risk : a trial in smokers using biomarkers as intermediate endpoints. [Doctoral Thesis, Maastricht University]. Rijksuniversiteit Limburg. https://doi.org/10.26481/dis.19940519gp

Document status and date:

Published: 01/01/1994

DOI:

10.26481/dis.19940519gp

Document Version:

Publisher's PDF, also known as Version of record

\section{Please check the document version of this publication:}

- A submitted manuscript is the version of the article upon submission and before peer-review. There can be important differences between the submitted version and the official published version of record.

People interested in the research are advised to contact the author for the final version of the publication, or visit the DOI to the publisher's website.

- The final author version and the galley proof are versions of the publication after peer review.

- The final published version features the final layout of the paper including the volume, issue and page numbers.

Link to publication

\footnotetext{
General rights rights.

- You may freely distribute the URL identifying the publication in the public portal. please follow below link for the End User Agreement:

www.umlib.nl/taverne-license

Take down policy

If you believe that this document breaches copyright please contact us at:

repository@maastrichtuniversity.nl

providing details and we will investigate your claim.
}

Copyright and moral rights for the publications made accessible in the public portal are retained by the authors and/or other copyright owners and it is a condition of accessing publications that users recognise and abide by the legal requirements associated with these

- Users may download and print one copy of any publication from the public portal for the purpose of private study or research.

- You may not further distribute the material or use it for any profit-making activity or commercial gain

If the publication is distributed under the terms of Article $25 \mathrm{fa}$ of the Dutch Copyright Act, indicated by the "Taverne" license above, 


\title{
Beta-carotene and cancer risk
}

a trial in smokers using biomarkers as intermediate endpoints

\author{
Proefschrift
}

ter verkrijging van de graad van doctor aan de Rijksuniversiteit te Maastricht, op gezag van de Rector Magnificus, Prof. Dr. H. Philipsen, volgens het besluit van het College van Dekanen, in het openbaar te verdedigen op donderdag, 19 mei 1994 om 14.00 uur

door

Gerardus Arnoldus Franciscus Catharina van Poppel 
Promotores:

Prof.dr.ir. R.J.J. Hermus

Prof.dr.ir. F.J. Kok (Landbouwuniversiteit Wageningen)

Beoordelingscommissie: Prof.dr. W.H.M. Saris (voorzitter)

Prof.dr. J.G.A.J. Hautvast (Landbouwuniversiteit Wageningen)

Prof.dr. J.C.S. Kleinjans

Prof.dr. P.G. Knipschild

Prof.dr. G.P. Vooijs (Katholieke Universiteit Nijmegen)

\section{CIP-GEGEVENS KONINKLIJKE BIBLIOTHEEK. DEN HAAG}

Poppel, Gerardus Amoldus Franciscus Catharina van

Beta-carotene and cancer risk : a trial in smokers using biomarkers as intermediate cndpoints / Gerardus Arnoldus Franciscus Catharina van Poppel. - IS.I : s.n.| (Utrecht: OM1). - 111 .

Thesis Maastricht. - With ref. - With summary in Dutch. ISBN $90-9007166-0$

Subject headings: beta-carotene / cancer / epidemiology.

Lay-out: Hanny Leezer

Omslag: La Momia, Montserrat, Spanje. Opname Ivo Claassen

Druk: OMI Offset, Utrecht

The studies in this thesis were carried out at the Department of Nutrition, TNO Nutrition and Food Research, and were financially supported by the Dutch Praeventiefonds, Hoffmann-La Roche Lid., the Dutch Ministry of Welfare, Public Health and Cultural Affairs and TNO Nutrition and Food Research. Financial support for the publication of this thesis was provided by Hoffmann-La Roche Ltd. 
Voor Lies en Noud 



\section{Contents}

1 Introduction

2 Carotenoids and cancer: an update with emphasis on human intervention studies. (Published in abbreviated form, European Journal of Cancer [993;29A/9:1335-1344).

3 Markers for cytogenetic damage in smokers: associations with plasma antioxidants and glutathione S-transferase $\mu$. (Cancer Epidemiology Biomarkers \& Prevention 1993;2:441-447).

4 Increased cytogenetic damage in smokers deficient in glutathione-S-transferase isozyme $\mu$. (Carcinogenesis 1992:13:303-305).

5 No influence of beta-carotene on smoking induced DNA damage as reflected by sister chromatid exchanges. (International Journal of Cancer 1992;51:355-358).

6 Beta-carotene supplementation in smokers reduces the frequency of micronuclei in sputum. (British Journal of Cancer 1992;66:1164-1168).

7 Effect of beta-carotene on immunological indices in healthy male smokers. (American Joumal of Clinical Nutrition 1993:57:402-407).

8 The effect of beta-carotene on sputum cytology in smokers; a preliminary study. (submitted for publication).

9 Epilogue

Summary

Samenvatting

Dankwoord

Bibliography

About the author 



\section{Introduction}

This thesis describes a number of studies on $\beta$-carotene and cancer risk in humans using biomarkers for exposure, susceptibility and biological effects or disease risk. Traditionally, epidemiological studies on cancer risk have focused on clinical outcome on the one hand, and assessment of exposure, often questionnaire-based, on the other. Such studies have been and will be indispensable for the study of human carcinogenesis, but they are as a rule large-scale, costly and lengthy. Moreover, such studies have to rely on extrapolations from animal experimental and in vitro work for inferences regarding mechanisms and biological plausibility. In this respect, a promising approach to strengthen epidemiological studies seems to be the application of biomarkers, sometimes referred to as "molecular epidemiology".' A biomarker can be described as an indicator on a biochemical, genetic or cellular level reflecting exposure, susceptibility or health status of a subject. ${ }^{2-5}$

The application of biomarkers in epidemiology has received special attention in the field of research on chemoprevention of cancer ${ }^{4-7}$ since biomarkers may function as intermediate endpoints or cancer surrogates. Though the predictive value of intermediate endpoints is often not yet established, they can indicate the pathways inhibited and the stages of carcinogenesis affected. Such studies may thus provide valuable information on mechanisms and on biological effectiveness of preventive interventions in humans. They may also be used to select promising agents and/or high-risk groups for full-scale intervention trials on cancer incidence. $^{5.6}$

The studies described in this thesis are focused around an intervention trial to evaluate the effect of $\beta$-carotene on several putative markers for cancer risk. The trial was performed in a group of cigarette smokers since they have, in comparison with non-smokers, a high risk for cancer, low plasma levels of $\beta$-carotene and increased levels for the biomarkers for cancer risk. The central question in this thesis is whether dietary $\beta$-carotene protects against cancer. A literature review (Chapter 2) gives the rationale for performing an intervention trial using $\beta$-carotene and summarizes the biological mechanisms by which $\beta$-carotene may beneficially influence carcinogenesis. Chapter 3 evaluates the application of biomarkers in a cross-sectional study involving both smokers and non-smokers. For the smokers group, this cross-sectional study provides also the baseline measurement of the intervention trial. The biological significance of one cross-sectional association, between a genetic susceptibility marker and a marker for DNA damage, is addressed in more detail in Chapter 4. The results of the $\beta$-carotene intervention trial are described in Chapters 5 to 8. Each of these Chapters addresses the effect of $\beta$-carotene on a separate biomarker for early biological effect or cancer risk, and the biological significance of this effect.

The epilogue (Chapter 9) evaluates the knowledge gained from the studies described in this thesis. First, the studies are evaluated in a methodological manner to address their validity for further interpretation. Second, the results of the studies are integrated and discussed in terms 
of their contribution to our understanding of the biological mechanisms of carcinogenesis and the involvement of $\beta$-carotene in this process. Finally, implications and expectations for future research are discussed.

\section{References}

1. Perera F. Molecular cancer epidemiology: a new tool in cancer prevention. J Natl Cancer Inst 1987;78:887-898.

2. Hulka BS, Wilcosky TC, Griffith JD, (eds). Biological markers in epidemiology, Oxford University Press, New York, Oxford, 1990

3. Kok FJ, Van ' $t$ Veer P (eds). Biomarkers of dietary exposure. Proceedings of the 3rd Meeting on Nutritional Epidemiology. Smith Gordon \& Company, London, 1991.

4. Van Poppel G, Verhagen H, Van '1 Veer P. Biomerkers in epidemiologisch en toxicologisch voedingsonderzoek. Voeding 1992;9:222-229.

5. Schatzkin A. Freedman LS, Schiffman $\mathrm{MH}$. Validation of intermediate end points in cancer research. J Nat] Cancer Inst 1990;82:1746-1752.

6. Greenwald P, Witkin KM, Malone WF, et al. The study of markers of biological effect in cancer prevention research trials. Int J Cancer 1992;52:189-196.

7. Lippman SM, Lee JS, Lotan R, et al. Biomarkers as intermediate end points in chemoprevention trial. J Natl Cancer Inst 1990;32:555-560. 


\section{Carotenoids and cancer: an update with emphasis on human intervention studies}

Geert van Poppel

\section{Abstract}

This article gives an overview of the current state of knowledge on the cancer preventive potential of carotenoids. Numerous retrospective and prospective epidemiologic studies have shown that a high intake of carotenoid-rich fruits and vegetables is associated with a decreased risk of cancer at a number of common sites. For several other cancer sites, however, the epidemiological evidence is not very consistent.

A number of mechanisms for the cancer preventive properties of carotenoids have been proposed. Conversion to retinol, possibly in post-hepatic tissues, would allow an effect on cellular differentiation and proliferation, and on cell to cell communication. Antioxidant functions could prevent free radical induced damage to cellular DNA and other macromolecules. Immunomodulatory effects could enhance immune surveillance in tumorigenesis. In addition, non-retinol mediated effects of carotenoids on metabolism of carcinogens and cell to cell communication have been shown.

Observational epidemiology cannot resolve whether associations are due to a specific carotenoid, or to an associated factor in fruits and vegetables, whereas interpretation of animal studies is hampered by uncertainties in extrapolation between species, more so because the metabolism of carotenoids in most animals differs noteably from that in humans. Human intervention studies on biomarkers related to cancer risk and on cancer incidence are therefore necessary. Human intervention studies performed so far suggest that $\beta$-carotene can affect carcinogenesis, though not at all stages and not at all cancer sites. Implications for future human intervention research are discussed.

\section{Introduction}

In 1981, Peto et al.' hypothesized that dietary carotenoids may reduce human cancer rates. Since then, a large number of epidemiologic studies have addressed this topic, and a flurry of experimental work has been aimed at unravelling the possible mechanisms of chemoprevention by carotenoids. This article will give an overview of the current state of knowledge regarding the cancer preventive potential of carotenoids. Firstly, an update on epidemiologic studies regarding carotenoids and cancer will be given. Subsequently, the current concepts on mechanisms of carcinogenesis will be addressed and possible mechanisms of action of 
carotenoids will be discussed. Finally, results of human intervention studies that have so far been performed will be addressed, and implications for future research will be given.

\section{Epidemiologic studies on carotenoids and cancer}

A large number of case-control studies have evaluated the association between intake of fruits and vegetables containing carotenoids and cancer. Likcwise, prospective cohort studies have evaluated the relation between prediagnostic consumption or blood levels of carotenoids and subsequent risk of cancer. Table 1 and 2 summarize the results for the retrospective and prospective studies.

The results of the case-control studies (table 1) show that high intake of fruits and vegetables that are rich in carotenoids has been associated with decreased risk of cancer at a number of common sites. This association appears to be most consistent for lung cancer and stomach cancer, and least consistent for breast, prostate, esophagal and oral cancer.

Table I. Retrospective studies on dielary intake of carotenoids and cancer, grouped by site.

\begin{tabular}{|c|c|c|c|c|c|}
\hline First author & $\begin{array}{l}\text { no of } \\
\text { cases }\end{array}$ & Exposure measure & $\begin{array}{l}\text { Ass } \\
\text { ocia } \\
\text { lion }\end{array}$ & $\begin{array}{l}\text { Relative risk } \\
\text { high vs } \\
\text { lowesi }\end{array}$ & Population \\
\hline \multicolumn{6}{|l|}{ Lung } \\
\hline Maclennan $1977^{\circ}$ & 233 & green veg.index & $\downarrow$ & 0.45 & $d^{n+7 .}$ Singapore Chinese \\
\hline Kolonel $1983^{5 i}$ & 267 & carotenoids & $\downarrow$ & 0.40 & ot+7. Multiethnic, Hawaii \\
\hline Hinds $1984^{(1)}$ & 364 & carotenoids & $\downarrow$ & 0.45 & $d^{\pi}+9$, Multiethnic, Hawaii \\
\hline Wu $1985^{61}$ & 216 & $\beta$-carotene & $\downarrow$ & 0.40 & White \&, LA County \\
\hline Samet $1985^{\circ 2}$ & 447 & carotenoids & n.s. & 0.76 & White o +9 , New Mexico \\
\hline Ziegler $1986^{67}$ & 763 & carotenoids & $\downarrow$ & 0.59 & White ${ }^{\prime \prime}$. New Jersey \\
\hline Pisani 1986 & 417 & carrots/green veg. & $\downarrow$ & 0.50 & on+\$, Northern Italy \\
\hline Bond $1987^{65}$ & 308 & carotenoids & n.s. & 0.42 & Chemical Employees. Texas \\
\hline Byers $1987^{x+1}$ & 450 & carotenoids & $\downarrow$ & 0.63 & of + , New York \\
\hline Pastorino $1987^{67}$ & 47 & carotenoids & n.s. & 0.34 & \&. Northern Italy \\
\hline Koo $1988^{t \times 8}$ & 88 & carotcnoid rich veg. & n.s. & 0.60 & Chinese o. Hong-Kong \\
\hline Fontham $1988^{(x)}$ & 1253 & carotenoids & n.s. & 0.88 & $\sigma+9$, Southern Louisiana \\
\hline Le Marchand $1989^{\circ}$ & 332 & $\beta$-carotene & $\downarrow$ & 0.53 & $a^{x}+9$, Multicthnic, Hawaii \\
\hline Jain $1990^{71}$ & 839 & $\beta$-carotene & n.s. & 0.89 & on+o , Toronto Area \\
\hline Dartiques $1990^{72}$ & 106 & carotenoids & $\downarrow$ & 0.25 & $\sigma^{\prime}+f$, South-Western France \\
\hline Harris $1991^{\circ}$ & 96 & carotenoids & $\downarrow$ & 0.45 & o, United Kingdom \\
\hline Wu-Williams $\left.199\right|^{24}$ & 965 & carotene-rich veg. & n.s. & 0.90 & \&. North-cast China \\
\hline \multicolumn{6}{|l|}{ Esophagus } \\
\hline Ziegler $1981^{75}$ & 120 & carotene & n.s. & 0.77 & Black ơ, Washington DC \\
\hline Tuyns $1987^{\circ}$ & 743 & carotene & $\downarrow$ & 0.47 & $\sigma^{x}+q$, Calvados, France \\
\hline Dccarli $1987^{37}$ & 105 & $\beta$-carotene & $\downarrow$ & 0.23 & $\phi^{\infty}+q$, Northern Italy \\
\hline Brown $1988^{*}$ & 209 & carolene & n.s. & 0.80 & $\sigma$, South Carolina \\
\hline Graham $1990^{\circ 0}$ & 178 & carotene & n.s. & 0.66 & $o+9$, New York \\
\hline
\end{tabular}


Table 1 , continued

\begin{tabular}{|c|c|c|c|c|c|}
\hline First author & $\begin{array}{l}\text { no of } \\
\text { cases }\end{array}$ & Exposure measure & $\begin{array}{l}\text { Ass } \\
\text { ocia } \\
\text { tion }\end{array}$ & $\begin{array}{l}\text { Relative risk } \\
\text { high vs } \\
\text { lowesi }\end{array}$ & Population \\
\hline \multicolumn{6}{|l|}{ Oral cavity, Pharynx } \\
\hline Winn $1984^{\text {sag }}$ & 227 & fruits \& veg. & $\downarrow$ & 0.5 & Black \& white \&, USA \\
\hline McLaughin $1988^{81}$ & 871 & carotene & n.s. & $0.9 ; 0.8$ & White on; $;,$ USA \\
\hline Rossing $1989^{\times 2}$ & 166 & carotenoids & n.s. & 1.0 & $d^{2}+9$, Washington State \\
\hline Ning $1990^{8.3}$ & 100 & carrots & n.s. & 0.4 & $d^{x}+9$, Tianjin, China \\
\hline \multicolumn{6}{|l|}{ Stomach } \\
\hline Correa $1985^{\mathrm{k}}$ & 391 & carotenoids & n.s. & $0.68 ; 1.08$ & $\sigma^{\pi}+8$, Louisiana (White; Black) \\
\hline Risch $1985^{x .5}$ & 246 & $\beta$-carotene & $\downarrow$ & 0.33 & $\sigma^{x}+8$, Canada \\
\hline Jedrichowski $1986^{86}$ & 110 & fruits \& veg. & $\downarrow$ & 0.24 & $\sigma^{\pi}+q$, Cracow, Poland \\
\hline La Vecchia $1987^{\circ 2}$ & 206 & $\beta$-carotene & $\downarrow$ & 0.39 & $\sigma^{\pi}+8$, Northern Italy \\
\hline You $1988^{* *}$ & 564 & carotene & $\downarrow$ & 0.50 & Chinese $\sigma^{n} ;$, Rural Shandong \\
\hline \multicolumn{6}{|l|}{ Pancreas } \\
\hline Gold $1985^{\text {颉 }}$ & 201 & raw fruits \& veg. & $\downarrow$ & 0.55 & $\sigma^{x}+9$, Baltimore area \\
\hline Norell $1986^{\circ 1}$ & 99 & vegetables & n.s. & 0.5 & $0^{2}+q$, Sweden \\
\hline Falk $1988^{1 / 1}$ & 363 & carotenoids & n.s. & $0.82 ; 1.65$ & $\sigma ; \%$. Louisiana \\
\hline Olsen $1989^{42}$ & 212 & vegetables & n.s. & 0.95 & White $\sigma^{n}$, Minneapolis area \\
\hline \multicolumn{6}{|l|}{ Colon, Rectum } \\
\hline Macquart-Moulin $1986^{1,3}$ & 399 & vegetables & $\downarrow$ & $0.42 ; 0.68$ & d: 7, Marscille Region \\
\hline Potter $1986^{2.4}$ & 419 & $\beta$-carotene & n.s. & $0.8 ; 2.2$ & $0^{n} ;$ F. S. Australian \\
\hline Kune $1987^{4,5}$ & 715 & $\beta$-carotene & $\downarrow$ & 0.45 & $\sigma+9$. Melbournc \\
\hline Graham $1988^{\text {ith }}$ & 428 & carotene & n.s. & - & $d+9$. New York \\
\hline La Vecchia $1988^{137}$ & 575 & green vegetables & $\downarrow$ & 0.5 & $d^{*}+9$. Northern Italy \\
\hline West $1989^{\circ x}$ & 231 & $\beta$-carotene & $\downarrow$ & $0.4 ; 0.6$ & $8 ; 9$. Utah \\
\hline Froudenheim $1990^{(x)}$ & 423 & carolenoids & $\downarrow$ & $0.59 ; 0.70$ & $8: 7$, New York \\
\hline Peters $1989^{1(x)}$ & 147 & raw fruils \& veg. & $\downarrow$ & 0.59 & $\sigma^{*}+9$, Los Angeles County \\
\hline Young $1988^{1111}$ & 353 & yellow vegetables & n.s. & 0.78 & White $\sigma^{\pi}+f$, Wisconsin \\
\hline Slattery $1988^{111:}$ & 231 & vegelables & n.s. & 0.6 & White of + . Utah \\
\hline Bidoli $1992^{10,3}$ & 148 & vegetables & n.s. & 0.6 & $o+q$, Northern Italy \\
\hline \multicolumn{6}{|l|}{ Bladder } \\
\hline Dunham $1968^{\mid(k)}$ & 493 & leafy \& yellow veg. & n.s. & - & Black \& white $\sigma^{*}+q$, Louisiana \\
\hline Mettlin $1979^{\text {iks }}$ & 569 & carrots & $\downarrow$ & 0.62 & $\sigma+q$, New York Statc \\
\hline La Vecchia $1989^{10}$ & 163 & carotenoids & $\downarrow$ & 0.41 & $\sigma^{n}+9$, Northern Italy \\
\hline Risch $1988^{1117}$ & 826 & $\beta$-carotenc & n.s. & 0.95 & Canadian $\delta^{n}+q$ \\
\hline Claude $1986^{116 x}$ & 431 & fruits \& vegetables & $\downarrow$ & $0.59 ; 0.90$ & 8; 9 , Northern Germany \\
\hline \multicolumn{6}{|l|}{ Cervix } \\
\hline Marshall $1983^{1(x)}$ & 513 & $\beta$-carolene & $\downarrow$ & 0.50 & White \&, New York \\
\hline Brock $1988^{110}$ & 117 & $\beta$-carotene & $\downarrow$ & 0.5 & \&, Sydney, Australia \\
\hline La Vecchia $1988^{11 \prime}$ & 392 & $\beta$-carotene & n.s. & $0.18 ; 1.09$ & \&, Italy (Invas;Intracpith) \\
\hline Verreault $1989^{112}$ & 189 & carotenoids & n.s. & 0.6 & \&. Washington State \\
\hline Ziegler $1990^{113}$ & 271 & carotenoids & n.s. & 0.98 & White 8 , USA \\
\hline VanEenwijk $1991^{114}$ & 102 & $\beta$-carotene & n.s. & 0.56 & 8, Chicago, USA \\
\hline
\end{tabular}


Table 1 , continued

\begin{tabular}{|c|c|c|c|c|c|}
\hline First author & $\begin{array}{l}\text { no of } \\
\text { cases }\end{array}$ & Exposure measure & $\begin{array}{l}\text { Ass } \\
\text { ocia } \\
\text { tion }\end{array}$ & $\begin{array}{l}\text { Relative risk } \\
\text { high vs } \\
\text { lowest }\end{array}$ & Population \\
\hline \multicolumn{6}{|l|}{ Breast } \\
\hline La Vecchia $1987^{115}$ & 1108 & green vegelables & $\downarrow$ & 0.42 & \$, Northern ltaly \\
\hline Iscovich $1989^{116}$ & 150 & $\beta$-carotene & n.s. & 0.92 & \$, Argentina \\
\hline Katsouyanni $1988^{117}$ & 120 & carotene & $\downarrow$ & 0.56 & \$, Greece \\
\hline Rohan $1988^{118}$ & 451 & $\beta$-carotene & $\downarrow$ & 0.76 & \&, South Australia \\
\hline Marubini $1988^{119}$ & 214 & $\beta$-carotene & n.s. & 1.20 & \$, Northern Italy \\
\hline Toniolo $1989^{120}$ & 250 & $\beta$-carolene & n.s. & 1.00 & 9, Northern ltaly \\
\hline Van 'I Veer $1990^{121}$ & 133 & $\beta$-carolene & n.s. & 0.73 & \$, Netherlands \\
\hline Potischman $1990^{122}$ & 83 & carotenoids & n.s. & 0.81 & $\$$, New York State \\
\hline Richardson $1991^{123}$ & 409 & $\beta$-carotene & n.s. & 1.0 & \$, Montpellier, France \\
\hline \multicolumn{6}{|l|}{ Ovary } \\
\hline Slattery $1989^{124}$ & 85 & $\beta$-carotene & $\downarrow$ & 0.50 & White \&, America \\
\hline Byers $1983^{125}$ & 274 & carotenoids & n.s. & 0.77 & ․, New York \\
\hline La Vecchia $1987^{126}$ & 455 & carotene & n.s. & 0.94 & ㅇ, Northern Italy \\
\hline Shu $1989^{127}$ & 172 & carotene & n.s. & 1.0 & $\$$, Shanghai, China \\
\hline \multicolumn{6}{|l|}{ Prostate } \\
\hline Ohno $1988^{128}$ & 100 & $\beta$-carotene & $\downarrow$ & 0.34 & or. Japan \\
\hline Ross $1987^{131}$ & 142 & $\beta$-carotene & n.s. & $0.6 ; 1.0$ & on (black: whites), California \\
\hline Mishina $1985^{13 n}$ & 100 & gr. \& yel. veg. & n.s. & 0.5 & $\sigma^{*}$ Japan \\
\hline Talamini $1986^{1,31}$ & 166 & green vegetables & n.s. & 1.20 & $\sigma$. Pordenone. ltaly \\
\hline Mellin $1989^{17:}$ & 371 & $\beta$-carotenc & $\downarrow$ & 0.60 & o. New York \\
\hline Oishi $19 \times 8^{1 " 1}$ & 100 & $\beta$-carotene & $\downarrow$ & 0.47 & $\sigma^{\prime}$, Japan \\
\hline Le Marchand $1991^{1.24}$ & 452 & $\beta$-carotenc & n.s. & - & ๙, Multicthic, Hawaii \\
\hline
\end{tabular}

n.s. $=$ not statistically significant. $\$=$ women: $\sigma^{n}=$ men.

The studies in table 1 may be hampered by misclassification through a rather crude assessment of dietary intake, especially in the older studies. Presumably, however, this misclassification will be nondifferential and will therefore only attenuate associations. Another caveat in the interpretation of these studies is that dietary information is collected retrospectively from diseased cases. This may potentially introduce differential misclassification since the disease process may have influenced dietary intake, or knowledge of the disease status may result in recall bias in the patient.

Problems of differential misclassification are avoided in prospective studies, since dietary information or blood samples are collected a number of years prior to diagnosis. The results of the prospective studies show a remarkable consistency for the association of increased lung cancer risk with either infrequent consumption of dark green and yellow fruits and vegetables, low levels of dietary carotenoids, or low plasma $\beta$-carotene levels. The studies using plasma levels, however, should be considered with some caution since plasma $\beta$-carotene levels may be lowered through a metabolic effect of smoking. Though all studies have adjusted their risk estimates for the number of cigarettes smoked, the crude adjustment may not have adequately 
accounted for the metabolic effects of smoking on $\beta$-carotene. ${ }^{2}$ In addition, it should be realized that epidemiological studies based on either dietary intake or plasma levels cannot resolve whether the observed effects are due to dietary carotenoids or to other components of fruits and vegetables.

For stomach cancer, the prospective evidence for a protective effect of consumption of dark green and yellow fruits and vegetables and possibly dietary carotenoids is rather consistent, and in line with the retrospective case control studies, though the magnitude and the number of studies are modest as compared to lung cancer. For breast and prostate cancer, the prospective studies are in line with the retrospective studies and do not indicate a clearly consistent association of plasma or dietary carotenes with reduced cancer risk. For the other cancer sites, the number of cases in the prospective studies are often small, implying that only very strong associations would have been detected in these studies.

Table 2. Prospective studies on dietary intake or blood levels of carotenoids and cancer, grouped by site.

\begin{tabular}{|c|c|c|c|c|c|}
\hline First author & $\begin{array}{l}\text { no of } \\
\text { cases }\end{array}$ & Exposure measure & $\begin{array}{l}\text { Ass } \\
\text { ocia } \\
\text { tion }\end{array}$ & $\begin{array}{l}\text { Relative risk } \\
\text { high vs } \\
\text { lowest }\end{array}$ & Population \\
\hline \multicolumn{6}{|l|}{ Lung } \\
\hline Shekclle $1981^{13.3}$ & 33 & carotenoid intake & $\downarrow$ & 0.14 & o', Western Electric Study \\
\hline Long-de $1985^{1 k}$ & 2952 & green salad + fruit & $\downarrow$ & 0.56 & of+7, China \\
\hline Hirayama $1986^{1:-}$ & 1917 & green \& ycllow veg. & $\downarrow$ & $0.79 ; 1.35$ & o; $q$, Japan \\
\hline Kromhout $1987^{1 \mathrm{LS}}$ & 63 & carotcnoid intake & n.s. & 0.68 & $+\$$. Zulphen. NL \\
\hline Paganini-Hill $1987^{111}$ & 56 & carotenoid intake & n.s. & $0.72 ; 0.67$ & o: 9 , Leisure World, LA \\
\hline Knekl $1991^{1 \text { मI }}$ & 108 & carotenoid intake & $\downarrow$ & $0.40 ; 0.93$ & $d$, Finland (non-; smokers) \\
\hline Fraser $1991^{1+1}$ & 61 & fruit + grcen salad & $\downarrow$ & $0.26 ; 0.65$ & White ${ }^{\prime}$, California Adven. \\
\hline Willett $1984^{142}$ & 17 & plasma total carotene & n.s. & - & $o^{x}+9$. USA. hypert. follow-up \\
\hline Connett $1989^{1+3}$ & 66 & plasma $\beta$-carotene & $\downarrow$ & 0.43 & o, USA, MRFIT Study \\
\hline Nomura $1985^{14-}$ & 74 & plasma $\beta$-carotene & $\downarrow$ & 0.29 & $\sigma^{*}$ Jap. Ancestry, Hawaii \\
\hline Wald $1988^{145}$ & 50 & plasma $\beta$-carotene & $\downarrow$ & 0.41 & o, UK, BUPA Study \\
\hline Stähelin $1991^{1+6}$ & 64 & plasma total carotene & $\downarrow$ & 0.56 & $d^{2}+q$, Basel Study \\
\hline Knekt $1990^{1 \mathrm{~s}}$ & 108 & plasma $\beta$-carotene & n.s. & 1.00 & $d+q$, Finland \\
\hline Comstock $1991^{1+1 / 4}$ & 99 & plasma $\beta$-carotene & $\downarrow$ & 0.45 & $\sigma+q$, Washington County \\
\hline Orentreich $1991^{149}$ & 123 & plasma $\beta$-carotene & $\downarrow$ & 0.33 & $\sigma^{*}+7$, USA \\
\hline \multicolumn{6}{|l|}{ Stomach } \\
\hline Hirayama $1986^{177}$ & 5247 & green \& yellow veg. & $\downarrow$ & $0.66: 0.66$ & $\sigma^{7} \%$, Japan \\
\hline Nomura $1985^{144}$ & 70 & plasma $\beta$-carotene & n.s. & - & on, Jap. Ancestry, Hawaii \\
\hline Wald $1988^{145}$ & 13 & plasma $\beta$-carotene & n.s. & - & $\sigma^{*}$, UK, BUPA Study \\
\hline Knekt $1990^{147}$ & 32 & plasma $\beta$-carotene & n.s. & 0.8 & $\sigma^{2}+q$, Finland \\
\hline Stähelin $1991^{146}$ & 16 & plasma total carotene & $\downarrow$ & 0.34 & $\sigma^{x}+q$, Basel Study \\
\hline \multicolumn{6}{|l|}{ Pancreas } \\
\hline Knekt $1990^{147}$ & 10 & plasma $\beta$-carotene & n.s. & 0.60 & $\sigma^{2}+q$, Finland \\
\hline Mills $1988^{|x|}$ & 40 & green veg. \& salad & n.s. & - & $\sigma^{2}+$, California Adventists \\
\hline Comstock 199$]^{1+8}$ & 22 & plasma $\beta$-carotene & n.s. & 0.83 & $o+q$, Washington County \\
\hline
\end{tabular}


Table 2, continued

\begin{tabular}{|c|c|c|c|c|c|}
\hline First author & $\begin{array}{l}\text { no of } \\
\text { cases }\end{array}$ & Exposure measure & $\begin{array}{l}\text { Ass } \\
\text { ocia } \\
\text { tion }\end{array}$ & $\begin{array}{l}\text { Relative risk } \\
\text { high vs } \\
\text { lowest }\end{array}$ & Population \\
\hline \multicolumn{6}{|l|}{ Colon, Rectum } \\
\hline Heilbrun $1989^{151}$ & 162 & dietary $\beta$-carotene & n.s. & 0.72 & - \\
\hline Paganini-Hill $1987^{130}$ & 110 & dietary carotenoids & n.s. & $0.90 ; 1.17$ & $\sigma^{x} ;$, Leisure World LA \\
\hline Shekelle $1981^{135}$ & 49 & dietary carotenoids & n.s. & - & $\sigma^{*}$, Western Electric Study \\
\hline Comstock $1991^{1+8}$ & 106 & plasma $\beta$-carotene & n.s. & $0.83 ; 1.25$ & $\sigma^{2}+q$, Washington,(colon;rectum) \\
\hline Connetl $1989^{143}$ & 14 & plasma $\beta$-carotene & n.s. & - & $\sigma^{x}$, USA, MRFIT Study \\
\hline Nomura $1985^{144}$ & 113 & plasma $\beta$-carotene & n.s. & - & o', Jap. Ancestry, Hawaii \\
\hline Schober $1987^{152}$ & 72 & plasma $\beta$-carotene & n.s. & 0.83 & White $\sigma^{2}+q$, Washington \\
\hline Wald $1988^{145}$ & 30 & plasma $\beta$-carotene & n.s. & - & o, UK, BUPA Study \\
\hline Knekt $1990^{1.97}$ & 13 & plasma $\beta$-carotene & n.s. & 0.30 & $d^{x}+q$, Finland \\
\hline Stähelin $1991^{146}$ & 32 & plasma total carotene & n.s. & 0.76 & $\sigma^{x}+q$. Basel Study \\
\hline \multicolumn{6}{|l|}{ Bladder } \\
\hline Knekt $1990^{147}$ & 18 & plasma $\beta$-carotene & n.s. & 3.30 & $o^{2}+q$, Finland \\
\hline Paganini-Hill $1987^{139}$ & 59 & dietary carotenoids & $\downarrow$ & $0.62 ; 0.15$ & o": 9 , Leisure World LA \\
\hline Shekelle $1981^{135}$ & 19 & diatary carotenoids & n.s. & - & o. Western Electric Study \\
\hline Nomura $1985^{1+4}$ & 27 & plasma $\beta$-carotene & n.s. & - & d. Jap. Ancestry, Hawaii \\
\hline Wald $1988^{145}$ & 15 & plasma $\beta$-carotene & n.s. & - & $\sigma$, UK, BUPA Study \\
\hline Comstock $1991^{1 \text { th }}$ & 35 & plasma $\beta$-carotene & n.s. & 0.63 & $\sigma^{\prime \prime}+q$, Washington County \\
\hline \multicolumn{6}{|l|}{ Breast } \\
\hline Hirayama $1979^{15.4}$ & 142 & green \& yellow veg. & n.s. & - & ף. Japan \\
\hline Paganini-Hill $1987^{199}$ & 123 & dietary carotenoids & n.s. & 0.83 & $d^{x}+q$. Leisure World LA \\
\hline Comslock $1991^{1.1 k}$ & 30 & plasma $\beta$-carolene & n.s. & 0.9 & \%. pustmenop. Washington \\
\hline Wald $1984^{1.45}$ & 39 & plasma $\beta$-carotene & n.s. & 0.35 & §. Guernsey. UK \\
\hline Willell $1984^{1.42}$ & 14 & plasma total carotenc & n.s. & - & , USA. hypert. follow-up \\
\hline \multicolumn{6}{|l|}{ Prostate } \\
\hline Hirayama $1986^{1.77}$ & 183 & green \& yellow veg. & n.s. & 1.23 & o. Japan \\
\hline Mills $1988^{154}$ & 180 & fruits \& salads & $\downarrow$ & $0.70 ; 0.68$ & o., Calif.Adv. (fruits;salads) \\
\hline Snowdown $1984^{1.5}$ & 247 & fruits \& vegetables & n.s. & - & $\sigma$, Seventh-day Adventists \\
\hline Paganini-Hill $1987^{1.9}$ & 93 & dietary carotenoids & n.s. & 0.98 & o, Leisure World LA \\
\hline Shekelle $1981^{135}$ & 29 & dietary carotenoids & n.s. & - & o, Western Electric Study \\
\hline Comstock $1991^{1+k}$ & 103 & plasma $\beta$-carotene & n.s. & 0.91 & $\sigma$, Washington Counly \\
\hline Willet1 $1984^{1 \cdot 12}$ & 11 & plasma total carotene & n.s. & - & $\sigma^{\prime}$, USA, hypert. follow-up \\
\hline Knekt $1990^{1.17}$ & 32 & plasma $\beta$-carotene & $\downarrow$ & 0.20 & $\sigma$, Finland \\
\hline \multicolumn{6}{|l|}{ Skin } \\
\hline Shekelle $1981^{1.35}$ & 36 & dietary carotenoids & n.s. & - & ๙. USA, W.Electric Study \\
\hline Wald $1988^{1+5}$ & 56 & plasma $\beta$-carolene & n.s. & - & $\sigma^{*}$, UK, BUPA Study \\
\hline Knekl $1991^{1.17}$ & 38 & plasma $\beta$-carolene & n.s. & 3.1 & $\sigma^{\pi}+9$, Finland \\
\hline
\end{tabular}

n.s. = not statistically significant. $+=$ women; $\sigma^{x}=$ men. 


\section{Current concepts of carcinogenesis}

The traditional two-stage view of carcinogenesis, initiation followed by promotion, is derived primarily from animal models on chemical carcinogenesis. Tumor initiation involves exposure of normai cells to chemical, physical or microbial carcinogens that cause a genetic change. The altered genotype of the initiated cell is considered irreversible, but the initiated phenotype is not fully expressed except in the presence of a promotor. Promotors both enhance the expression of the initiated cell phenotype and provide a selective growth stimulus to cells expressing this phenotype, allowing clonal expansion of the initiated cells. This second stage of carcinogenesis, tumor promotion, does not involve a genetic change and is considered reversible. ${ }^{3}$

The classical view of two-stage carcinogenesis involving a mutation (initiation) and an epigenetic change (promotion) has been conceptually important but is also considered to be simplistic in that the number of independent genetic and epigenetic changes may be six or more in certain types of cancer. ${ }^{4}$ Carcinogenesis is thus considered as a multistage process; subsequent genetic and epigenetic changes allow susceptible cells to gain a growth advantage and undergo clonal expansions. ${ }^{4}$ This probably involves activation of protooncogenes and/or inactivation of tumor suppressor genes (for a review, see reference 5).

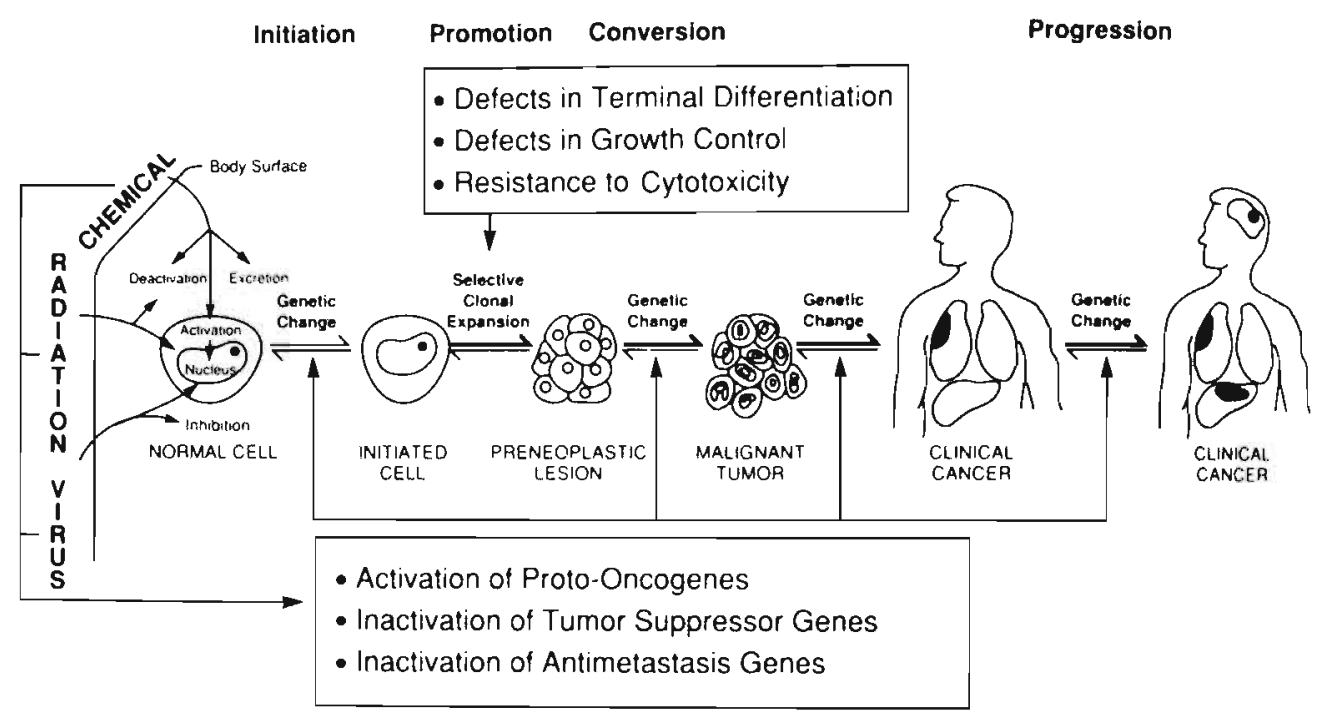

Figure 1. A multi stage model for carcinogenesis involving multiple genetic and epigenetic events (source; ref 4 ).

A simplified scheme of current concepts of carcinogenesis is given in figure 1. Genetic changes are considered to result from interactions between carcinogen and DNA. Many chemical carcinogens require metabolic activation, generally into high energy electrophiles, 
to exert their carcinogenic effect, which is often considered to be mediated through carcinogen-DNA adduct formation. ${ }^{4}$ Metabolic activities and genetic damage is assumed to occur within a few hours of exposure. ${ }^{6}$ If repair of the damage does not occur within a period of days or weeks, the damage is converted to a stable biological lesion during DNA replication. ${ }^{6}$ Tumor promotion enhances the probability of accumulative additional genetic damage including endogenous mutations by allowing expansion of the population of initiated cells. The probability of converting to malignancy may be substantially increased by further exposure to DNA-damaging agents. ${ }^{4}$ The conversion of an initiated cel to a premalignant or fully malignant cell is a lengthy process and may take well over 10 years.

\section{Possible cancer preventive activities of carotenoids}

Almost 600 carotenoids from natural sources have been characterized. Green leafy vegetables and many colored fruits are rich in carotenoids. Dietary carotenoids in humans are absorbed from the intestine and appear in the blood. Human serum contains $\beta$-carotene, $\alpha$-carotene, cryptoxanthin, lycopene and lutein as major components ${ }^{7}$ (figure 2).
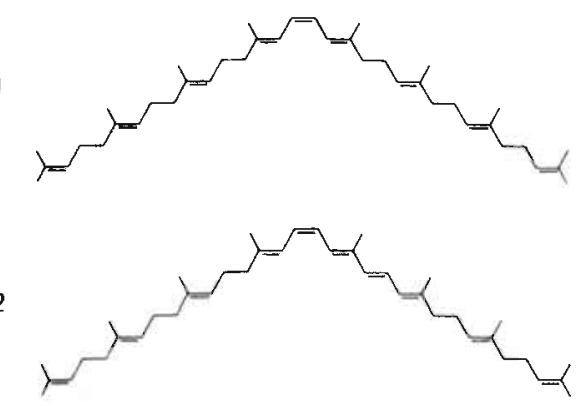

3

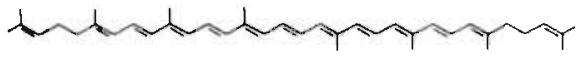

4

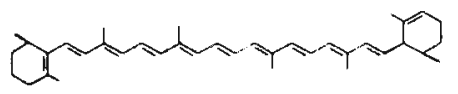

5

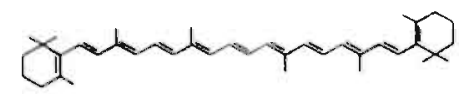

6<smiles>CC(C)=CC=CC(C)=CC=CC(C)=CC=CC(C)=CC=CC1CCCCC1C</smiles>

7

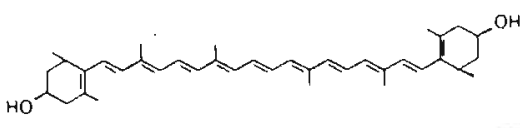

8<smiles>C/C=C/C=C/C=C(C)/C=C/C=C(C)/C=C/C=C/C=C(C)/C=C/C1C(C)=CC(O)CC1C</smiles>

9<smiles>CC(C=CC=CC(C)=CC1=C(C)C(O)CCC1C)=CC=CC(C)=CC=CC(C)=CC=CC1=C(C)C(O)CCC1C</smiles>

10

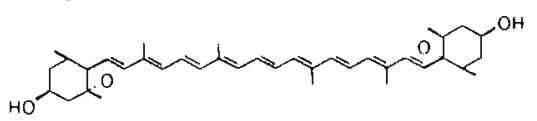

11

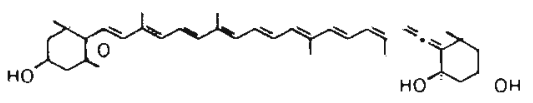

12<smiles>CC(/C=C/C=C(C)/C=C/C(C)=C/C=C/C1CC(C)(C)CC(O)C1O)=C\C=C\C(C)=C\C=C\C1C(C)C(O)C(O)CC1(C)C</smiles>

Figure 2. Polyenes and carotenoids in foods that may also be found in animal tissues. 1, phytoene; 2 , phytofluene: 3, lycopene; 4, $\alpha$-carotene; $5, \beta$-carotene; $6, \beta$-cryptoxanthin; 7 , zeaxanthin; 8, Iutein; 9 . canthaxanthin; 10, violaxanthin; 11, neoxanthin; 12, astaxanthin. (source; ref 57). 
Carotenoids are present in varying concentrations in adipose tissue, liver, muscle and other tissues, associated mainly with the lipid portions and membranes. A number of biological activities of carotenoids have been described that may pertain to their putative cancer preventive potential:

\section{Conversion 10 vitamin $A$}

Less than $10 \%$ of all carotenoids serve as precursor for vitamin $A$. In humans, $\beta$-carotene, $\alpha$-carotene and cryptoxanthin are converted to vitamin $A$, whereas lutein and lycopene are not. The major pathway of conversion is by central cleavage catalyzed by the enzyme $15,15^{\prime}$ - $\beta$-carotenoid dioxygenase. In addition, random cleavage pathways have been demonstrated in micro-organisms, and fish and birds can also form vitamin A from astaxanthin, canthaxanthin and isozeoxanthin. The enzymatic conversion of carotenoids to retinal is considered to occur almost solely in the intestine and the liver. ${ }^{\circ}$ Blood levels of carotenoids reflect dietary intake, whereas blood levels of retinol are under homeostatic control. Almost all epidemiologic studies that observed reduced cancer risk with increasing $\beta$-carotene intake did not observe similar associations with preformed vitamin A intake. ${ }^{y}$ The protective action of $\beta$-carotene has therefore been considered not to be connected with its conversion to retinol. However, De Vet ${ }^{10}$ has argued that epidemiologic studies indicating protection through $\beta$-carotene are most consistent for sites involving mainly epidermoid cancers, which is in line with the effects of vitamin $A$ on epithelial differentiation and proliferation. De Vet" has therefore hypothesized that $\beta$-carotene may exert an influence through local conversion into retinol, i.e. after reaching post-hepatic tissues. This possibility is supported by experiments in rats that showed conversion to retinol of intravenously administered $\beta$-carotene after removal of the liver, intestine and several other organs. ${ }^{1 \cdot 13}$ Also, recent work by Wang et al. ${ }^{14}$ gives evidence for conversion of $\beta$-carotene in adipose-, kidneyand lung tissue. The hypothesis of post-hepatic conversion also seems to be supported by recent experiments performed by Edes. ${ }^{15}$ He observed that administration of the carcinogen benzo[a]pyrene induced lower tissue levels of retinol in rats. This reduction of retinol could be prevented by administration of $\beta$-carotene, but not by retinol administration. If confirmed, these experiments could indicate that $\beta$-carotene is capable of rapidly compensating localized vitamin $A$ deficiencies induced by carcinogens.

The mechanisms through which retinoids may influence carcinogenesis have been well documented. ${ }^{\mid 6,1]}$ These mechanisms have been hypothesized to include an action on the cell nucleus, involving the expression of genetic information controlling cell differentiation. Specific binding proteins for retinol and retinoic acid are believed to be responsible for the transport of retinol and retinoic acid within the cell and across the nucleus membrane, suggesting a hormone like control of cell differentiation. In addition, retinol has a variety of effects on the cell membrane, involving altered glycoprotein synthesis and changes in membrane receptors for various hormones, including those mediated by c-AMP. The action on these receptors may influence cell-cell interactions, cell adhesion, and cell membrane permeability. Finally, animal studies have shown that retinol increases both the humoral and 
cell-mediated immune response and could thus enhance immune surveillance in tumorigenesis. ${ }^{18}$ With regard to the previously discussed model for multi stage carcinogenesis, retinoids thus seem to influence only epigenetic changes, implying an influence primarily in the promotional stages of carcinogenesis. In accordance, an antagonistic effect of retinoids on tumor promotors has been frequently reported in animal studies. ${ }^{17}$

\section{Antioxidant functions}

The antioxidant functions of carotenoids are attributed to their molecular structure. This structure would enable them to confer photoprotection by quenching (inactivating) light-energized or excited states of molecules, such as singlet oxygen. Moreover, their structure would enable them to neutralize free radicals, intermediates of metabolism that are highly reactive since they contain a non-paired electron. ${ }^{19}$ The photoprotective actions of carotenoids involve a mechanism, in which light energy is transferred from a sensitized or 'excited' molecule to a carotenoid molecule. This reaction yields a non-excited, original sensitizer molecule and a high energy, so called triplet state of the carotenoid. Subsequently, the carotenoid can return to its ground state with the liberation of a small amount of heat. This heat liberation is attributed to rotational and vibrational interactions with the solvent, facilitated by the conjugated polyene nature of the carotenoid. ${ }^{20}$ Th is protective action of carotenoids may be especially important since sensitized molecules can react with biomolecules to generate radical species. Singlet oxygen in particular is an extremely reactive species capable of initiating lipid peroxidation by reactions with polyunsaturated fatty acids, inactivating proteins and enzyme by reactions with amino acids, and damaging RNA and DNA by reactions with guanine.

Carotenoids can not only quench excited species of molecules, but can also react with free radical species. Free radical species can result from photochemical reactions and from oxidant stress e.g. induced by cigarette smoking, but free radicals are also a result of normal cell metabolism. ${ }^{21}$ Free radicals from normal cell metabolism include superoxide $\left(\mathrm{O}_{2}\right)$ as well as the hydroxyl radical $(\cdot \mathrm{OH})$, derived from hydrogen peroxide, and lipid peroxides, e.g. from arachidonic acid metabolism. If the cell is insufficiently protected by enzymatic and non-enzymatic antioxidants, free radicals can react with biomolecules and thus damage cellular structures. This is exemplified by the chain reaction of lipid peroxidation:

$\begin{array}{lll}\text { Initiation: } & \mathrm{LH}+\mathrm{OH} & \rightarrow \mathrm{L}+\mathrm{H}_{2} \mathrm{O} \\ \text { Propagation: } & \mathrm{L} \cdot+\mathrm{O}_{2} & \rightarrow \mathrm{LOO} \cdot \\ & \mathrm{LOO}+\mathrm{LH} & \rightarrow \mathrm{LOOH}+\mathrm{L} \cdot \\ \text { Termination: } & \mathrm{LOO}+\mathrm{LOO} \cdot & \rightarrow \mathrm{LOH}+\mathrm{L}=\mathrm{O}+\mathrm{O}_{2}\end{array}$

Enzymatic antioxidants include catalase, superoxide dismutase and the selenium dependent glutathione peroxidase. Non-enzymatic antioxidants include vitamins $C$ and $E$ and 
carotenoids. $^{21}$ Burton and Ingold ${ }^{22}$ have postulated that $\beta$-carotene may exert its anti-oxidant function through its ability to interact with a radical (e.g. peroxyl radical) yielding a carbon centered radical species. Since the conjugated bond system of $\beta$-carotene would provide considerable resonance stability, this latter radical species would be more stable and have less tendency to react with biomolecules such as lipids (figure 3 ). However, very little is as yet known about the chemistry of reactions of carotenoids with radicals. $\beta$-carotene functions as an antioxidant in many, but not all in vitro systems. ${ }^{2.3}$ In this respect, the evidence that $\beta$-carotene is a good radical trapping anti-oxidant only at low oxygen partial pressures ${ }^{22}$ is of interest, since low oxygen pressures are found in most tissues under physiological conditions.

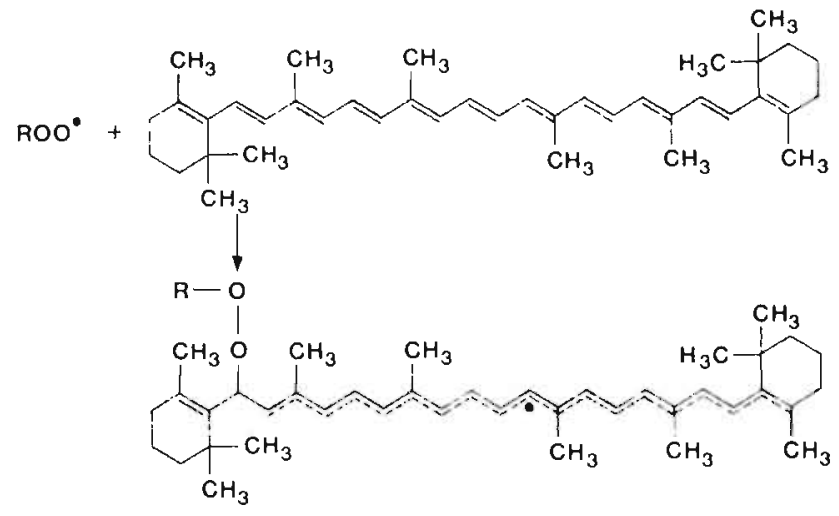

Figure 3. A proposed interaction between $\beta$-carotene and a peroxyl radical to produce a resonance-stabilized carbon-centercd radical (source; ref 22).

With respect to carcinogenesis, antioxidants have been implied in both the initiation and promotion phases in animal studies. ${ }^{17}$ Antioxidants may prevent genetic changes by preventing DNA damage directly induced by free radicals ${ }^{24}$ or can hypothetically interfere with the metabolic activation of chemical carcinogens. ${ }^{25.26}$ Hypotheses on the role of free radicals and antioxidants in tumor promotion ${ }^{24.27 .24}$ have been mostly derived from studies using synthetic antioxidants such as BHT or BHA. ${ }^{17}$ A number of recent studies have also used carotenoids. ${ }^{18}$ Though the molecular mechanisms are not clear, the proposed involvement of antioxidants in tumor promotion stems from observations in animal studies that 1) free radical generating compounds are tumor promotors, 2) well known promotors such as phorbol acetate have been shown to stimulate oxygen radical production, 3) promotors can modulate antioxidant defense mechanisms and 4) antioxidants are antipromotors. 


\section{Immunomodulatory effects}

Several animal studies have shown that carotenoids may exert immunomodulatory functions. For example, $T$ and $B$ lymphocytes in the spleens of rats showed enhanced proliferative responses after supplementation with eiter $\beta$-carotene or cathaxanthin, ${ }^{30}$ whereas hamsters with chemically induced tumors showed increased numbers of cytotoxic T cells. ${ }^{31}$ The postulated immunomodulatory effects of carotenoids have summarized by Bendich. ${ }^{3 t}$ The mechanisms by which carotenoids may influence immune response are not yet clear. Immuno-enhancing mechanisms have been postulated to involve the quenching of free radicals, which could lower the level of immunosuppressing lipid peroxides, alter arachidonic acid metabolism, stabilize lysozome membranes, or protect nuclear structures. Alternatively, retinol mediated mechanisms could be involved, since retinol has several influences on the immune system. ${ }^{18}$

A possible immunomodulatory effect of carotenoids would imply an action in the promotion phase of carcinogenesis. However, the concept of immunoregulation of carcinogenesis may only apply to certain forms of human cancer, since a substantial number of human cancers does not exhibit any immunogenic properties. ${ }^{32}$

\section{Other mechanisms}

In addition to the above mentioned mechanisms other effects of carotenoids have been described. Edes et al. ${ }^{3.3}$ observed modulation of the cytochrome P450 dependent Aryl Hydrocarbon Hydroxylase (AHH) in rat liver by $\beta$-carotene, whereas Tan and $\mathrm{Chu}^{3.4}$ performed in vitro experiments that showed modulation of $\mathrm{P} 450$ mediated benzo[a]pyrene metabolism by carotenoids. These observations suggest that carotenoids could modify the enzymatic activation of (pro)carcinogens. Another mechanism of action has recently been suggested by Zhang et al. ${ }^{35}$ They observed enhancement of gap-junc communication by several carotenoids in in vitro experiments. Enhanced cell to cell communication would restrict clonal expansion of initiated cells and has been described to be brought on by retinoids. ${ }^{36}$ In the mentioned experiments however, the effect of carotenoids was not dependent on their pro-vitamin A activity.

\section{Human intervention studies}

The possible mechanisms of action for carotenoids given above have mainly been derived from in vitro experiments. The interest in carotenoids and cancer has also prompted a number of animal studies, which have recently been reviewed by Krinsky. ${ }^{23}$ Many, though certainly not all studies indicate that carotenoids can prevent the appearance of skin tumors induced by ultraviolet light with or without chemical carcinogens. In addition, carotenoids may also prevent internal tumors induced by carcinogens. The results of these studies are not always consistent, and many workers have used systems unique to their own laboratory. Moreover, the metabolism of carotenoids in most laboratory animals differs noteably from that in humans. Intervention studies in humans are therefore necessary to substantiate the evidence from observational epidemiology, in vitro experiments and animal studies. 
Table 3. Ongoing human intervention trials using $\beta$-carotene*

\begin{tabular}{|c|c|c|c|c|}
\hline $\begin{array}{l}\text { Target } \\
\text { site/organ }\end{array}$ & $\begin{array}{l}\text { Target } / \text { high risk } \\
\text { group }\end{array}$ & Inhibitory Agents & Investigator & Location \\
\hline All sites & physicians & $\beta$-carotene & Hennekens & Bosion, MA, USA \\
\hline Colon & colon polyps & $\beta$-carotene & Bowen & Illinois, $\mathrm{CH}$, USA \\
\hline Colon & colon polyps & $\beta$-carotene, vit $C \& E$ & Greenberg & Hannover, NH, USA \\
\hline Colon & colon polyps & $\begin{array}{l}\beta \text {-carotene, fiber, } \\
\text { low fat }\end{array}$ & Maclennan & Brisbane, Australia \\
\hline Lung & asbestosis & $\beta$-carotene, retinol & Omenn & Seattle, WA, USA \\
\hline Lung & smokers & $\beta$-carotene, vit $E$ & $\begin{array}{l}\text { Huttunen/ } \\
\text { Albanes }\end{array}$ & $\begin{array}{l}\text { Helsinki, Finland } \\
\text { Bethesda, MD, USA }\end{array}$ \\
\hline Lung & tin miners in China & $\begin{array}{l}\beta \text {-carotene, retinol, } \\
\text { vit } E, \mathrm{Se}\end{array}$ & Schatzkin & Bethesda, MD, USA \\
\hline Lung & $\begin{array}{l}\text { DNA damage, } \\
\text { smokers }\end{array}$ & $\beta$-carotene & Van Poppel & Zeist, Netherlands \\
\hline Lung & asbestos workers & $\beta$-carotene, retinol & Musk & Perth, Australia \\
\hline Skin & albinos & $\beta$-carotene & Luande & Dar es Salaam, Tanzania \\
\hline Skin & basal cell carcinoma & $\beta$-carotene, vit $C \& E$ & Safai & New York, USA \\
\hline Skin & basal carcinoma & $\beta$-carotene & Siu & Calgary, Canada \\
\hline Esophagus & $\begin{array}{l}\text { dysplastic patients + } \\
\text { high risk group }\end{array}$ & $\begin{array}{l}\text { multiple vitamin }+ \\
\beta \text {-carotene }\end{array}$ & Taylor & $\begin{array}{l}\text { Bethesda, MD, USA } \\
\text { Beijing, China }\end{array}$ \\
\hline $\begin{array}{l}\text { Mouth, } \\
\text { esophagus }\end{array}$ & $\begin{array}{l}\text { oral leukoplakia + } \\
\text { oesophagitis }\end{array}$ & $\begin{array}{l}\beta \text {-carotene, retinol } \\
\text { riboflavin }\end{array}$ & Zaridze & Uzbckistan, USSR \\
\hline Mouth & oral leukoplakia & $\beta$-carotene & Garewal & Tuscon, AZ, USA \\
\hline Cervix & corvical dysplasia & $\begin{array}{l}\text { B-carotenc, vil } C \text {. } \\
\text { folic acid }\end{array}$ & Romncy & New York, USA \\
\hline
\end{tabular}

* Adapted from:

Cullen JW: The National Cancer Institutes Intervention Trials. Cancer 62, 1851-1864, 1988.

Coleman M, Wahrendorf J (cds). Direclory of on-going rescarch in cancer epidemiology 1991.

IARC Scicntific Publication no. 110. Lyon Internationa! Agency for Research on Cancer 199!.

Human intervention studies use either cancer incidence or mortality as an endpoint, or they focus on intermediate endpoints or early biomarkers for cancer risk. ${ }^{37}$ These biomarkers are parameters for (alterations in) functions or cellular structures that are thought to bear relevance to carcinogenesis. Such biomarkers include measurements for DNA damage, e.g. micronuclei, measurements of immune system cells or immunological response, or potentially pre-malignant lesion e.g. leukoplakia or dysplasia. For most of these biomarkers, the predictive value for ultimate cancer development has not been unambiguously established. Studies on biomarkers do however have the merit of yielding information on mechanisms of action in humans, whereas they do not imply the long time span necessary for studies on cancer incidence. Moreover, biomarker studies allow for a considerable smaller study size and can 
therefore often be better controlled. Biomarker studies can thus yield important information that can be used for both evaluation of cancer preventive potential as well as for optimizing the design of large-scale intervention studies on cancer incidence. Human intervention studies on biomarkers or cancer incidence that are in progress are listed in table 3 . Studies that have already published results are discussed below.

Studies on the effect of carotenoids and retinol on micronuclei in buccal mucosa of tobacco chewers have been performed by Stich and co-workers. Micronuclei are DNA fragments in exfoliated cells that occur after carcinogenic exposure. Several lines of evidence indicate that they may provide a marker for early stage carcinogenesis, but their predictive value has not been established. Strong reductions in micronucleated cells were observed after Indian and Fillipino villagers had been supplemented with $\beta$-carotene (180 $\mathrm{mg} /$ week), $\beta$-carotene combined with retinol (100.000 IU/week), or retinol alone. ${ }^{.8-4)}$ Since these villagers were considered to have marginal vitamin $A$ status, these results may be attributable an enhanced vitamin $A$ intake, and not to a specific carotenoid effect; in accordance, canthaxanthin was not effective. ${ }^{39}$ However, it is not clear whether cathaxanthin does reach the buccal mucosa, whereas this has indeed been shown for $\beta$-carotene. ${ }^{41.42}$ A specific carotenoid effect therefore cannot be ruled out, even more so because a subsequent study showed $\beta$-carotene to be effective in Inuit snuff users from a population having normal plasma retinol levels. ${ }^{43}$ The latter study, however, did not monitor individual plasma retinol or antioxidant levels during the trial.

Immunological studies in humans on the effect of $\beta$-carotene so far have focused on assessment of lymphocyte subpopulations in peripheral blood. These studies must be cautiously interpreted, since the relevance of peripheral lymphocyte subpopulations for functional immune response in target tissue in not certain. So far, the studies have yielded inconsistent results. Alexander et al..$^{\text {th }}$ reported an increase in the number of lymphocytes expressing CD4+ (indicating $T$ helper function) after two weeks of $\beta$-carotene $(180 \mathrm{mg} /$ day) in normal human volunteers. This study, however. was not placebo controlled, and plasma retinol levels were not monitored. Another study in patients with precancerous lesions ${ }^{45}$ used $30 \mathrm{mg} /$ day for three months and reported an increase in percentage of lymphocytes expressing Leu-1lb (indicating natural killer cell function) and interleukin 2 receptors, whereas the percentage of cells expressing CD4+ was not affected. This study, again, was not placebo controlled and did not monitor retinol levels. Watson et al. ${ }^{4 h}$ performed a study in 20 healthy subjects aged 50-65 years using $\beta$-carotene doses of $0,15,30,45$, and $60 \mathrm{mg} /$ day and report increases in the percentage of lymphoid cells expressing CD4+ and interleukin 2 receptor, as well as an increase in cells expressing CD16+ (indicating natural killer cell function). Watsons study did not observe concomitant changes in plasma retinol, but his study has been methodologically criticized. ${ }^{47}$ In contrast to Watsons study, Ringer et al. ${ }^{\text {th }}$ did not observe any effects on lymphocyte subpopulations in a placebo controlled study in 50 healthy males and females, using doses up to $300 \mathrm{mg} /$ day.

The effect of 6 months $\beta$-carotene, with or without retinol, was studied in Indian tobacco chewers showing oral leukoplakia. Oral leukoplakia is a potentially pre-malignant lesion in 
oral carcinogenesis, ${ }^{40}$ but the predictive value has not been established. As compared with a placebo group, the combination of $\beta$-carotene $(180 \mathrm{mg} /$ week) and vitamin $\mathrm{A}(100.000$ IU/week) resulted in more frequent regression of established leukoplakias, and less frequent appearance of new leukoplakias. $\beta$-carotene alone showed some effects, but these were not significant. Here again, the participants may have been vitamin A deficient, and plasma retinol levels of the participants were not monitored. Results by Garewal ${ }^{49}$ indicate (partial) regression of oral leukoplakias in 17 of 24 patients after 3-6 months $\beta$-carotene (30 mg/day). However, this pilot study was not placebo-controlled, results may be partly explained by regression to the mean, and plasma retinol levels were not monitored. A randomized, placebo controlled, 18 month study on oral leukoplakia is now being conducted by the same group. ${ }^{50}$

De Vet et al. ${ }^{51}$ studied the effect of $\beta$-carotene ( $10 \mathrm{mg} /$ day for 3 months) on regression or progression of cervical dysplasia, a putative precursor lesion of cervical carcinoma. Their carefully designed placebo controlled study showed no effect of $\beta$-carotene. Possibly, their dose of $\beta$-carotene may have been to low to demonstrate short-term effects. Also, the recently available evidence from observational case-control studies does not indicate a consistent inverse relation between cervical cancer and dietary intake of carotenoids (table 1). Finally, $\beta$-carotene may not affect the late (promotional) stages of carcinogenesis that are reflected by cervical dysplasia.

So far, only one $\beta$-carotene intervention study on cancer incidence has been reported. ${ }^{52}$ This 5 year placebo controlled trial showed no effect of $\beta$-carotene $(50 \mathrm{mg} /$ day $)$ on the occurrence of new skin cancers in persons with previous nonmelanoma skin cancers. It has been argued, however, that an effect of $\beta$-carotene in this study on cancer recurrence could only be expected if $\beta$-carotene were effective in very late stages of carcinogenesis. $\$$ Moreover, the only three observational epidemiologic studies performed so far did not show an inverse relation between carotenoids and human skin cancer (table 2).

\section{Conclusions and implications}

A number of human intervention studies on cancer or biomarkers related to cancer risk have been performed so far. These studies have all focused on $\beta$-carotene because this carotenoid has both pro-vitamin $\mathrm{A}$ and anti-oxidant capacity, and has been proven non-toxic. ${ }^{54}$ Studies on buccal micronuclei and oral leukoplakia support a cancer preventive role for $\beta$-carotene, whereas studies on peripheral immune cells show conflicting results. A study on skin cancer recurrence and a study on cervical dysplasia were negative. Some results thus suggest that $\beta$-carotene can affect human carcinogenesis, whereas other results indicate that this will not occur at all stages of carcinogenesis, or at all cancer sites.

It seems advisable to aim future human intervention studies at cancer sites that have been most consistently associated with carotenoid protection in observational studies. Such studies should be methodologically sound, i.e. randomized and placebo-controlled. Moreover, they should monitor the status of retinol. Since several antioxidants may act in a synergistic manner, it also seems warranted to monitor the status of several anti-oxidants in intervention trials. Also, in 
studies using biomarkers, application of a relevant set of biomarkers may yield more insight in the mechanisms of action and possible site specificity of carotenoids.

More insight into the putative cancer preventive potential of $\beta$-carotene can be expected from two large ongoing randomized trials. The US-Finland lung cancer prevention trial is evaluating the effect of $\beta$-carotene ( $20 \mathrm{mg} /$ day) on lung cancer incidence in 19.500 male smokers. ${ }^{55}$ However, the proposed follow up of 6 years may be insufficient if $\beta$-carotene is primarily effective in earlier stages of carcinogenesis. A randomized trial in 22.000 US Physicians is evaluating the effect of $\beta$-carotene ( $50 \mathrm{mg}$ on alternate days) on cancer at all sites. ${ }^{56}$ This trial has recently been extended to 12.5 years follow up. ${ }^{53}$ However, lung cancer incidence may not be very large among predominantly non-smoking physicians.

This overview has shown that a high intake of carotenoid-rich fruits and vegetables is associated with a decreased risk of cancer at a number of common sites in epidemiological studies. For several other sites, however, the evidence is not consistent. This association may indeed be due to carotenoids, and not to associated food factors, since a number of plausible cancer preventive mechanisms for carotenoids have been suggested. It is envisaged that a number of human intervention studies, that are currently being conducted, will provide more answers regarding the proposed cancer preventive properties of particularly $\beta$-carotene.

\section{References}

I. Peto R, Doll R, Buckley JD, Sporn MB. Can dietary $\beta$-carotene materially reduce human cancer rates? Naturc 1981:290:201-208.

2. Willett WC. Vitamin A and lung cancer. Nutr Rev 1990:48:201-211.

3. Murray AW, Edwards EM, Hii CST. Tumour promotion; biology and molecular mechanisms. In CS Cooper and PL Grover (eds); Chemical carcinogenesis and mutagenesis II. Springer Verlag. Berlin 1990. pages 135-149.

4. Harris CC. Chemical and physical carcinogenesis: advances and perspectives for the 1990s. Cancer Res 1991;5I supll:5023S-5044S.

5. Weinberg RA. Oncogenes, antioncogenes, and the molecular bases of multistep carcinogenesis. Cancer Res 1989;49:3713-3721

6. Bertram JS, Kolonel LN, Meyskens FL. Rationale and stratcgies for chemoprevention of cancer in humans. Cancer Res 1987:47:3012-3031.

7. Parker RS. Carotenoids in human blood and tissues. J Nutr 1989:119:101-104.

8. Olson JA. Provitamin A function of carotenoids: the conversion of $\beta$-carotenc into vitamin A. J Nutr 1989:119:105-108.

9. Ziegler RG. A review of epidemiologic evidence that carotenoids reduce the risk of cancer. J Nutr 1989:119:116-122.

10. De Vet HCW. The puzzling role of vitamin $A$ in cancer prevention (review). Anlicancer Res 1989:9:145-152.

11. Worker NA. The elfect of complete hepatectomy on the utilization by rats and rabbits of intravenously administered aqueous dispersions of carotene. Br J Nutr 1956;10:169-175.

12. Worker NA. Site of conversion of carotene into vitamin $A$ in the rat: further studies on aqueous dispersions administered intravenously. Br J Nut 1957:11:44-47.

13. McGillivray WA. Thompson SY, Worker NA. Further studies on the metabolism by rats of intravenously administered aqueous dispersions of carotenoids pigments. Br J Nutr 1956:10:126-134.

14. Wang XD. Tang GW, Fox JG. el al. Enzymatic conversion of $\beta$-carolene into $\beta$-apo-carotenals and retinoids by human, monkey, ferrel, and rat tissues. Arch Biochem Bioph 1991;285:8-16.

15. Edes TE, Gysbers DG, Buckley CS, Thomton WH. Exposure to the carcinogen benzopyrene depletes tissuc vitamin A: $\beta$-carolene prevents depletion. Nutr Cancer 1991;15:159-166. 
16. Sporn MB, Roberts AB. Role of retinoids in differentiation and carcinogenesis. Cancer Res 1983:43:3034-3040.

17. DiGiovanni J. Inhibition of chemical carcinogenesis. In: CS Cooper and PL Grover (eds), Chemical carcinogenesis and mutagenisis II. Springer Verlag, Berlin 1990, pages 159-202.

18. Tomkins A, Hussey G. Vitamin A, immunity and infection. Nutr Res Rev 1989;2:17-28.

19. Krinsky N1. Carotenoids as chemopreventive agents. Prev Med 1989;18:592-602.

20. Krinsky NI. Antioxidant functions of carotenoids. Free Radical Biol Med 1989;7:617-635.

21. Halliwell B, Gutleridge JMC. Free radicals in biology and medicine. Oxford University Press, New York, 1985.

22. Burton GW, Ingold KU. Beta-carotene: An unusual type of lipid antioxidant. Science 1984;224:569-573.

23. Krinsky NI. Effects of carotenoids in cellular and animal systems. Am J Clin Nutr 1991;53:238S-246S.

24. Sun Y. Free radicals, antioxidant enzymes, and carcinogenesis. Free Radical Biol Med 1990;8:583-599.

25. Cavalieri EL, Rogan EG. Radical cations in aromatic hydrocarbon carcinogenesis. Free Rad Res Comms 1990;11:77-87.

26. Bryla $\mathrm{P}$, Weyand $\mathrm{EH}$. Role of activated oxygen species in benzo[a]pyrene:DNA adducl formation in vitro. Free Radical Biology and Medicine 1991;11:17-24.

27. Cerulti PA. Prooxidant states and tumor promotions. Science 1985;227:375-381.

28. Goldstein BD, Czerniecki B, Witz G. The role of free radicals in tumor promotion. Environmental Health Perspeclives 1989;81:55-57.

29. Burdon RH, Gill V, Rice-Evans C. Oxidative stress and tumour cell proliferation. Free Rad Res Comms 1990;11:65-76.

30. Bendich A, Shapiro SS. Effect of $\beta$-carotene and canthaxanthin on the immune responses of the rat. J Nutr 1986:116:2254-2262.

31. Bendich A. Carotenoids and the immune response. J Nutr 1989:119:112-115.

32. Kripke ML. Immunoregulation of carcinogenesis: past, present, and future. J Natl Cancer 1988;80:722-727.

33. Edes TE, Thornton W, Shah J. Beta-carotene and Aryl Hydrocarbon Hydroxylase in the rat: an effect of $\beta$-carotene independent of vitamin A activily. J Nutr 1989;1 19:796-799.

34. Tan B, Chu FL. Effects of palm carotenoids in rat hepatic cytochrome P450-mediated benzo[a]pyrene metabolism. Am J Clin Nutr 1991:53:1071S-1075S.

35. Zhang LX, Cooney RV, Bertram JS. Carotenoids enhance gap junctional communication and inhibit lipid peroxidation in $\mathrm{C}^{3} \mathrm{H}_{\prime}^{\prime} 10 \mathrm{Tl} / 2$ cells: relationship to their cancer chemopreventive action. Carcinogenesis 1991:12:2109-2114.

36. Rutten AAJJL, Jongen WFM, Haan LHJ de, et al. Effects of retinol and cigareute smoke condensate on dye-coupled intercellular communication between hamster tracheal epithelial cells. Carcinogenesis 1988;9:31.5-320.

37. Schatzkin A. Freedman LS, Schiffman MH. Dawsey SM. Validation of intermediate end points in cancer research. J Natl Cancer Inst 1990:82:1746-1752.

38. Stich HF, Rosin MP, Vallejcra MO. Reduction with vitamin $A$ and $\beta$-carotene administration of proportion of micronucleated buccal mucosal cells in Asian betel nut and tobacco chewers. Lancet 1984:i:1204-1206.

39. Stich HF, Stich W. Rusin MP, Vallejera MO. Use of the micronucleus test to monitor the cffect of vitamin A. $\beta$-carotene and canthaxanthin on the buccal mucosa of betel nut/tobacco chewers. Int J Cancer 1984:34:745-750.

40. Stich HF, Rosin MP, Hornby AP. at al. Remission of oral leukoplakias and micronuclei in tobacco/betcl quid chewers treated with $\beta$-carotenc and with $\beta$-carotene plus vitamin A. Int J Cancer 1988;42:195-199.

41. Cameron LM, Rosin MP. Stich HF. Use of exfoliated cells to study tissue- specific levels of $\beta$-carotene in humans. Cancer Lett 1989;45:203-207.

42. Gilbert AM. Stich HF, Rosin MP, Davison AJ. Variations in the uptake of $\beta$-carotene in the oral mucosa of individuals after 3 days of supplementation. Int J Cancer 1990;45:855-859.

43. Stich HF, Hornby AP, Dunn BP. A pilot $\beta$-carotene intervention trial with inuits using smokeless tobacco. Int J Cancer 1985;36:321-327.

44. Alexander M, Newmark H, Miler RG. Oral $\beta$-carotene can increase the number of OKT4 ${ }^{*}$ cells in human blood. Immunol Letters 1985;9:221-224.

45. Prabhala RH, Garewa! HS, Hicks MJ, et al. The effects of 13-cis-retinoic acid and $\beta$-carotene on cellular immunity in humans. Cancer 1991;67:1556-1560.

46. Watson RR, Prabhala RH, Plezia PM, Alberts DS. Effect of $\beta$-carotene on lymphocyte subpopulations in elderly humans: evidence for a dose-response relationship. Am J Clin Nutr 1991;53:90-94. 
47. Bryant DG, Prasad C. Re: Effect of $\beta$-carotene on lymphocyte subpopulations in elderly humans. Am J Clin Nutr 1991;54:432-433.

48. Ringer TV, De Loof MJ, Winterrowd GE, et al. $\beta$-carotene's effect on serum lipoproteins and immunologic indices in humans. Am J Clin Nutr 1991;53:688-694.

49. Garewal HS, Meyskens FL, Killen D, et al. Response of oral leukoplakia to ß-carotene. J Clin Oncol 1990;8:1715-1720.

50. Garewal H. Oral Leukoplakia. Presented at the symposium "Vitamins and cancer prevention" Baton Rouge, Louisiana, Oct 30 - Nov 1, 1991.

51. De Vet HCW, Knipschild PG, Willcbrand D, et al. The effect of $\beta$-carotene on the regression and progression of cervical dysplasia: a clinical experiment. J Clin Epidemiol 1991;44:273-283.

52. Greenberg ER, Baron JA, Stukel TA, et al. A clinical trial of $\beta$-carotene to prevent basal-cell and squamous-cell cancers of the skin. N Engl J Med 1990;323:789-795.

53. Manson JE, Hunter DJ, Burning JE, Hennekens $\mathrm{CH}$. $\beta$-carotene to prevent skin cancer. $N$ Engl J Med $1991 ; 324: 924$.

54. Bendich A. The safety of $\beta$-carotene. Nutr Cancer 1988;11:207-214.

55. Albanes D, Virtamo J, Rautalahti M, et al. Pilot study: The US-Finland lung cancer prevention trial. J Nut $r$ Growth and Cancer 1986:3:207-214.

56. Hennekens $\mathrm{CH}$, Eberlein K. A randomized trial of aspirin and $\beta$-carotene among US physicians. Prev Med I985; 14:165-168.

57. Bendich A, Olson JA. Biological actions of carotenoids. FASEB J 1989;3:1927-1932.

58. Maclennan R, DaCosta J, Day NE. et al. Risk factors for lung cancer in Singapore Chinese, a population with high female incidence rates. Int J Cancer 1977;20:854-860.

59. Kolonel LN, Nomura AMY, Hinds MW, et al. Role of diel in cancer incidence in Hawaii. Cancer Res 1983;43:2397S-2402S.

60. Hinds MW, Kolonel LN, Hankin JH, Lee J. Dietary vitamin A, carolene, vitamin C and risk of lung cancer in Hawaii. Am J Epidemiol 1984;119:227-237

61. Wu AH, Henderson BE, Pike MC. Yu M. Smoking and other risk factors for lung cancer in women. J Natl Cancer Inst 1985;74:747-751.

62. Samet JN, Skipper BJ, Humble CG, Pathak D. Lung cancer risk and vitamin A consumption in New Mcxico. Am Rev Respir Dis 1985:131:198-202.

63. Ziegler RG, Mason TJ, Stemhagen A, et al. Carotenoid intake vegetables and the risk of lung cancer among white men in New Jersey. Am J Epidemiol 1986;123:1080-1093.

64. Pisani P, Berrino F, Macaluso M, el al. Carrots, green vegetables and lung cancer: A case-control study. Int J Epidemiol 1986;15:463-468.

65. Bond GB, Thompson FE, Cook RR. Dietary vitamin A and lung cancer: results of a case-control study among chemical workers. Nutr Cancer 1987;9:109-121.

66. Bycrs T, Graham S, Haughey BP, Marshall JR, et al. Diet and lung cancer risk: findings from the Western New York Diel Sludy. Am J Epidemiol 1987;127:351-363.

67. Pastorino U, Pisani P, Berrino F, et al. Vitamin A and female lung cancer: a case-control study on plasma and diel. Nutr Cancer 1987:10:171-179.

68. Koo LC. Dielary habits and lung cancer risk among Chinese females in Hong Kong who never smoked. Nutr Cancer 1988;11:155-172.

69. Fontham ETH, Williams Pickle L, Haenszel W, et al. Dietary vilamins $A$ and $C$ and lung cancer risk in Louisiana. Cancer 1988;62:2267-2273.

70. Le Marchand L, Yoshizawa CN, Kolonel LN, et al. Vegetable consumption and lung cancer risk: a population based casc-control study in Hawaii. J Natl Cancer Insı 1989;81:1158-1164.

71. Jain M. Burch JD. Howe GR, Risch HA, Miller AB. Dietary factors and risk of lung cancer: results from a case-control study, Toronto, 1981-1985. Int J Cancer 1990;45:287-293.

72. Dartigues JF, Dabis F, Gros N, cl al. Dielary vitamin A, $\beta$-carotene and risk of epidermoid lung cancer in south-wcstern France. Eur J Epidemiol 1990;6:261-265.

73. Harris RWC, Key TJA, Silcocks PB, Bull D, Wald NJ. A case-control study of dietary carotene in men with lung cancer and in men with olher epithelial cancers. Nutr Cancer 1991;15:63-68.

74. Wu-Williams AH, Dai XD, Blot W, et al. Lung cancer among women in north-cast China. Br J Cancer 1990:62:982-987.

75. Ziegler RG, Morris LE, Blot WJ, et al. Esophageal cancer among black men in Washington, D.C. II. Role of nutrition. J Natl Cancer Inst 1981;67:1199-1206. 
76. Tuyns AJ, Riboli E, Doornbos G, Péquinot G. Diet and esophageal cancer in Calvados (France). Nuur Cancer 1987;9:81-92.

77. Decarli A, Liati P. Negri E, et al. Vitamin A and other dietary factors in the etiology of esophageal cancer. Nutr Cancer 1987;10:29-37.

78. Brown LM, Blot WJ, Schuman SH, et al. Environmental factors and high risk of esophagal cancer among men is coastal South Carolina. J Nati Cancer Inst 1988;80:1620.

79. Graham S, Marshal] J, Haughey B, et al. Nutritional epidemiology of cancer of the esophagus. Am J Epidemiol 1990;131:454-467.

80. Winn DM, Ziegler RG. Pickle LW, et al. Diet in the etiology of oral and pharyngeal cancer among women from the Southern United States. Cancer Res 1984;44:1216-I222.

81. McLaughlin JK, Gridley G, Block G, et al. Dietary Cactors in oral and pharyngeal cancer. J Natl Cancer Ins1 1988;80:1237-1243.

82. Rossing MA, Vaughan TL, McKnight B. Diet and pharyngeal cancer. Int J Cancer 1989;44:593-597.

83. Ning JP, Yu MC, Wang QS, Henderson BE. Consumption of salted fish and other risk factors for nasopharyngeal carcinoma (NPC) in Tianjin, a low-risk region for NPC in the People's Republic of China. J Natl Cancer Insi 1990;82:291-296.

84. Correa P, Fontham E, Williams Pickle L, et al. Dietary determinants of gastric cancer in South Louisiana inhabitants. J Natl Cancer Inst 1985;75:645-654.

85. Risch HA, Jain M, Choi NW, et at. Dietary factors and the incidence of cancer of the stomach. Am J Epidemiol 1985;122:947-959.

86. Jedrychowski W, Wahrendorf J, Popiela T, Rachtan J. A case-control study of dietary factors and stomach cancer risk in Poland. Int J Cancer 1986;37:837-842.

87. La Vecchia C, Negri E, Decarli A, et al. A case-control study of diet and gastric cancer in northern Italy. Int J Cancer 1987;40:484-489.

88. You WC, Blot WJ, Chang YS, et al. Diet and high risk of stomach cancer in Shandong, China. Cancer Res 1988;48:3518-3523.

89. Gold EB, Gordis L, Denier MD, et al. Diet and other risk factors for cancer of the pancreas. Cancer $1985 ; 55: 460-467$.

90. Norell SE, Ahlbom A, Erwald R, et al. Diet and pancreatic cancer: a case-control study. Am J Epidemiol 1986;124:894-902.

91. Falk RT, Williams Pickle L, Fontham ET, et al. Life-style risk factors for pancreatic cancer in Louisiana: a case-control study. Am J Epidemiol 1988;128:324-336.

92. Olsen GW, Mandel JS, Gibson RW, et al. A case-control study of pancreatic cancer and cigarcttes, alcohol, coffee and diet. Am J Public Health 1989;79:1016-1019.

93. Macquart-Moulin G, Riboli E, Cornée J, et al. Case-control study on colorectal cancer and dict in Marseilles. Int J Cancer 1986;38:183-191.

94. Polter JD. McMichael AJ. Diet and cancer of colon and rcclum: a case control study. J Natl Cancer Inst $1986 ; 76: 557-569$.

95. Kune S, Kune GA, Watson LF. Case-control study of dietary etiological factors: the Melbourne colorcctal cancer study. Nutr Cancer 1987;9:21-42.

96. Graham S, Marshall J. Haughey B. et al. Dietary epidemiology of cancer of the colon in Western New York. Am J Epidemiol 1988;128:490-503.

97. La Vecchia C. Negri E, Decarli A, et al. A case-control study of diet and colo-rectal cancer in northern Italy. Int J Cancer 1988;41:492-498.

98. West DW. Slattery ML, Robison LM, et al. Dietary intake and colon cancer: sex- and anatomic site-specific associations. Am J Epidemiol 1989;130:883-894.

99. Freudenheim JL, Graham S, Marshall JR, et al. A case-control study of diet and rectal cancer in western New York. Am J Epidemiol 1990;131:612-624.

100. Peters RK, Garabant DH, Yu MC, Mack TM. A case control study of occupational and dictary factors in colorectal cancer in young men by subsite. Cancer Res 1989;49:5459-5468.

101. Young TB, Wolf DA. Case-control study of proximal and distal colon cancer and diet in Wisconsin. Int J Cancer 1988;42:167-175.

102. Slattery ML. Sorenson AW, Mahoney AW, et al. Diet and colon cancer: assessment of risk by fiber type and food source. I Natl Cancer Inst 1988;80:1474-1480.

103. Bidoli E, Franceshi S, Talamini R, et al. Food consumption and cancer of the colon and rectum in North-eastern Italy. Int J Cancer 1992;50:223-229. 
104. Dunham LJ, Rabson AS, Stewart HL, et al. Rates, interview, and pathology study of cancer of the urinary bladder in New Orleans, Louisiana. J Natl Cancer Inst 1968;41:683-709.

105. Mettlin C. Graham S. Dietary risk factors in human bladder cancer. Am J Epidemiol 1979:1 10:255-263.

106. La Vecchia C. Negri E, Decarli A, ct al. Dietary factors in the risk of bladder cancer. Nutr Cancer 1989;12:93-101.

107. Risch HA, Burch JD, Miller AB, et al. Dietary factors and the incidence of cancer of the urinary bladder. Am J Epidemiol 1988:127:1179-1191

108. Claude J, Kunze E. Frentzel-Beyme R, et al. Life-style and occupational risk factors in cancer of the lower urinary tract. Am J Epidemiol 1986;124:578-589.

109. Marshall JR, Graham S, Byers T, et al. Diel and smoking in the epidemiology of cancer of the cervix. J Natl Cancer lnst 1983;70:847-851.

110. Brock KE, Berry G, Mock PA, et al. Nutrients in diet and plasma and risk of in situ cervical cancer. J Natl Cancer Inst 1988;80:580-585.

111. La Vecchia C, Decarli A, Fasoli M, el al. Dietary vitamin A and the risk of intraepithelial and invasive cervical neoplasia. Gynecologic Oncology 1988;30:187-195.

112. Verreault R, Chu J. Mandelson M, Shy K. A case-control study of diet and invasive cervical cancer. Int J Cancer 1989:43:1050-1054.

113. Ziegler RG, Brinton LA. Hamman RF, et al. Diet and the risk of invasive cervical cancer among white women in the United States. Am J Epidemiol 1990;132:432-445.

114. Van Eenwyk J, Davis FG, Bowen PE. Dietary and serum carotenoids and cervical intraepithelial neoplasia. Int J Cancer 1991;48:34-38.

115. La Vecchia C. Decarli A, Franceschi S, et al. Dietary factors and the risk of breast cancer. Nutr Cancer 1987:10:205-214.

116. Iscovich JM, Iscovich RB, Howe G, et al. A case-control study of diet and breast cancer in Argentina. Int J Cancer 1989:44:770-776.

117. Katsouyanni K, Willett W. Trichopoulos D. el al. Risk of breası cancer among Greek women in relation to nutrient intake. Cancer 1988;61:181-185.

118. Rohan TE, McMichael AJ, Baghurst PA. A population-based case-control study of diet and breast cancer in Australia. Am J Epidemiol 1988;128:478-489.

119. Marubini E. Decarli A, Costa A, et al. The relationship of dietary intake and serum levels of retinol and P-carotenc with breast cancer. Cancer 1988;61:173-180.

120. Toniolo P, Riboli E. Prolta F, el al. Calorie-providing nutrients and risk of breası cancer. J Nati Cancer Inst 1989;81:278-286.

121. Veer $P$ van 1. Kolb CH, Verhoef $P$, el al. Dietary fiber, $\beta$-carotene and breast cancer: results from a case-control study. Int J cancer 1990:45:825-828.

122. Potischman N. McCultoch CE. Byers T, et al. Breast cancer and dietary and plasma concentrations of carotenoids and vitamin A. Am J Clin Nutr 1990:52:909-915.

123. Richardson $\mathrm{S}$. Gerber $\mathrm{M}$, Cence $\mathrm{S}$. The role of fat, animal protein and some vitamin consumption in breast cancer: a case control study in Southern France. Int J Cancer 1991;48:1-9.

124. Slattery ML. Schuman KL. West DW. et al. Nutrient intake and ovarian cancer. Am J Epidemiol 1989:1.30:497.502.

125. Byers T, Marshall J. Graham S. et al. A casc-control study of dietary and nondietary factors in ovarian cancer. J Nall Cancer Inst 1983;71:681-686.

126. La Vecchia C, Decarli A, Negri E, et al. Dietary factors and the risk of epithelial ovarian cancer. J Natl Cancer Insı 1987:79:663-669.

127. Shu XO, Gao YT, Yuan JM. et al. Dietary factors and epithelial ovarian cancer. Br J Cancer 1989:59:92-96.

128. Ohno Y, Yoshida O. Oisi K, et al. Dielary $\beta$-carolene and cancer of the prostate: a case control sludy in Kyoto, Japan. Cancer Res 1988:48:1331-1336.

129. Ross RK, Shimizu H, Paganini-Hill A, et al. Case-control studies of prostate cancer in blacks and whites in Southern Californiá. J Natl Cancer Inst 1987:78:869-874.

130. Mishina T. Watanabe H. Araki H, Nakao M. Epidemiological study of prostatic cancer by matched-pair analysis. The Prostate 1985;6:423-436.

131. Talamini R, La Vecchia C, Decarli A, et al. Nutrition, social factors and prostatic cancer in a Northern Italian population. Br J Cancer 1986;53:817-821

132. Metllin C. Selenskas S. Natarajan N. Huben R. Beta-carotene and animal fats and their relationship to prostate cancer risk. A case-control study. Cancer 1989:64:605-612. 
133. Oishi K, Okada K, Yoshida O, et al. A case-control study of prostatic cancer with reference to dietary habits. The Prostate 1988:12:179-190.

134. Le Marchand L. Hankin JH, Kolonel LN, Wilkens LR. Vegetable and fruit consumption in relation to prospate cancer risk in Hawaii: a reevaluation of the effect of dietary $\beta$-carotene. Am J Epidemiol 1991;133:215-219.

135. Shekelle RB, Lepper M, Liu S, et al. Dietary vitamin A and risk of cancer in the Western Electric Study. Lancel 1981;ii:1185-1190.

136. Lung-de W. Hammond EC. Lung cancer, fruit, green salad and vitamin pills. Chinese Medical Journal 1985:98:206-210.

137. Hirayama T. A large scale cohort study on cancer risk by diet-with special reference to the risk reducing cffects of green-yellow vegetable consumption. Diel. Vutrition and Cancer (ed.) Y. Hayashi et a!. (eds.). Japan Sci.Soc.Press. Tokyo, pp 41-53, 1986.

138. Kromhout D. Essential micronutrients in relation to carcinogenesis. Am J Clin Nutr 1987:45:1361-1367.

139. Paganini-Hill A, Chao A, Ross RK. Henderson BE. Vitamin A, $\beta$-carolene, and the risk of cancer: a prospective sludy. J Natl Cancer Inst 1987;79:443-448.

140. Knekı P. Järvinen R, Scppänen R. et al. Dietary antioxidants and the risk of lung cancer. Am J Epidemiol $1991 ; 134: 471-479$.

141. Fraser GE, Beeson WL, Phillips RL. Diel and lung cancer in California Seventh-day Adventists. Am J Epidemiol 1991:133:683-693.

142. Willell WC, Polk BF, Underwood BA. et al. Retation of serum vitamins $A$ and $E$ and carotenoids to the risk of cancer. N Engl J Med 1984;310:430-434.

143. Connett JE, Kuller LH, Kjelsberg MO. et al. Relationship between carotenoids and cancer. The multiple risk factor intervention trial (MRFIT) study. Cancer 1989;64:126-134.

144. Nomura AMY. Stemmermann GN, Heilbrun LK, el al. Serum vitamin levels and the risk of cancer of specific sites in men of Japanese ancestry in Hawaii. Cancer Res 1985:45:2369-2372.

145. Wald NJ, Thompson SG. Densem JW, et al. Serum $\beta$-carotene and subsequent risk of cancer: results from the BUPA sludy. Br J Cancer 1988;57:428-433.

146. Stähclin HB, Gey KF, Eichholzer M. et al. Plasma antioxidant vitamins and subsequent cancer mortality in the 12-year follow-up of the prospective Basel Siudy. Am J Epidemiol 1991:133:766-775.

147. Knekt P. Aromaa A, Maatela J. el al. Serum vitamin A and subsequent risk of cancer: cancer incidence follow-up of the Finnish mobilc clinic health examination survey. Am J Epidemiol 1990;132:857-870.

148. Comstock GW. Helzsouer KJ. Bush TL. Prediagnostic serum levels of carotenoids and vitamin $E$ as related to subsequent cancer in Washington County, Maryland. Am J Clin Nutr 1991;53:260S-264S.

149. Orentreich N. Matias JR. Vogelman JH. Salkeld RM. The predictive value of serum $\beta$-carotenc for subsequent development of lung cancer. Nutr Cancer 1991:15:167-168.

150. Mills PK. Beeson WL. Abbey DE. cl al. Diclary habits and pasi medical history as related to falal pancreas cancer risk among Adventists. Cancer 1988;61:2578-2585.

151. Heilbrun LK, Nomura A. Hankin JH. Stemmermann GN. Dict and colorectal cancer with special reference to fiber intake. Int J Cancer 1989:44:1-6

152. Schober SE. Comstock GW. Helsing KJ, et al. Serologic precursors of cancer. 1. Prediagnostic serum nutrients and colon cancer risk. Am J Epidemiol 1987:126:1033-1041.

153. Hirayama T. Diet and cancer. Vutr Cancer 1979:1:67-81.

154. Mills PK. Becson WL. Phillip RL. Fraser GE. Cohort study of diet, lifestyle, and prostate cancer in Adventisı men. Cancer 1989;64:598-604

155. Snowdon DA. Phillips RL. Chor W. Diel, uhesity, and risk of fatal prostate cancer. Am J Epidemiol $1984 ; 120: 244-250$ 



\section{Markers for cytogenetic damage in smokers: associations with plasma antioxidants and glutathione S-transferase $\mu$}

Geert van Poppel, Hans Verhagen, Pieter van 't Veer, Peter J. van Bladeren

\section{Abstract}

Biomarkers for increased cytogenetic damage in smokers include sister chromatid exchanges (SCE) in peripheral lymphocytes and micronuclei in sputum cells. These markers may reflect increased cancer risk. Increased cancer risk has also been associated with lower blood levels of the antioxidants $\beta$-carotene and vitamin $C$ and with genetic deficiency of the detoxification enzyme glutathione S-transferase $\mu$ (GST- $\mu$ ). We therefore evaluated the associations of plasma antioxidants, GST- $\mu$ phenotype and indices for tobacco exposure with SCEs and micronuclei in a group of 156 male cigarette smokers and 38 non-smokers.

As expected, smokers as compared with non-smokers had higher SCE levels (5.08 vs. 4.71 SCE per lymphocyte) and lower levels of plasma $\beta$-carotene $(0.31$ vs. $0.48 \mu \mathrm{mol} / \mathrm{l})$ and blood vitamin $\mathrm{C}$ (36.6 vs. $54.8 \mu \mathrm{mol} / \mathrm{l})$. In smokers, SCEs were weakly correlated with plasma cotinine $(R=0.186$ ) but not with plasma antioxidants (all $R<0.04$ ). Micronuclei in smokers were not correlated with either cotinine or antioxidants (all $R<0.14$ ). As reported previously, SCEs were higher (5.24 vs. 4.97 SCE per lymphocyte) in GST- $\mu$ deficient smokers than in nondeficient smokers. Micronuclei, however, were similar in both GST- $\mu$ phenotypes ( 4.3 vs. 4.9 micronuclei/3000 cells). No correlation was observed between micronuclei and SCEs $(R=-\mathbf{0 . 0 2 5})$.

Large random variations in both SCEs and micronuclei make it difficult to interpret the absence of relations unambiguously. The results indicate that SCEs and micronuclei have only limited sensitivity to variations in cigarette smoke exposure. The association between GST $-\mu$ and cancer risk may be mediated through increases in certain forms of smoking induced DNA damage in GST- $\mu$ deficiency.

\section{Introduction}

Biomarkers are increasingly used in cancer epidemiology to estimate exposure to carcinogens or putative anticarcinogens, preclinical biological effects, as well as genetic factors that may determine individual susceptibility.' Markers for DNA damage are of special interest since DNA damage is a crucial step in carcinogenesis. ${ }^{2}$ Markers for DNA damage such as $\mathrm{SCE}^{3}$ and micronuclei ${ }^{4}$ are increased in smokers, who have a known increased risk of cancer. ${ }^{5}$ 
Despite a large risk, a majority of smokers do not develop cancer. Smokers may be partially protected by dietary anti-oxidants such as $\beta$-carotene and vitamin $\mathrm{C}^{6.7} \mathrm{Also}$, genetical differences in detoxification of tobacco constituents may determine individual cancer risk. ${ }^{8.10}$ The possible protection against cancer of antioxidants has been hypothesized to involve decreased DNA damage." Likewise, a more efficient detoxification of tobacco smoke could offer protection by limiting DNA damage. ${ }^{x-10}$ It can therefore be hypothesized that increased antioxidant status and more successful detoxification will correspond with less DNA damage in smokers.

We have previously used the SCE measure to demonstrate an association between deficiency in the detoxification enzyme GST- $\mu$ and increased cytogenetic damage in smokers. ${ }^{12}$ We now have new data on blood levels of antioxidants and micronuclei in expectorated sputum from the same cross sectional study. This allowed us to evaluate whether the two biomarkers for cytogenetic damage are inversely related with markers for antioxidant status, and positively associated with markers for cigarette smoke exposure. Also, the association of GST $-\mu$ phenotype with micronuclei was studied, and we evaluated whether SCE and micronuclei are associated.

\section{Subjects and methods}

\section{Subjects}

We studied healthy male volunteers, employed at the AMEV Insurance Company, the Taxation Office and the Power Company at Utrecht. The study was approved by an external Medical Ethical Comity and all participants gave their informed consent. Smokers were studied if they reported consumption of more than 15 cigarettes per day over more than two years. Nonsmokers were included in this study if they reported never to have smoked and, in addition, did not work or live together with smokers. None of the participants used vitamin preparations containing retinol or carotenoids, or medications known to influence SCE levels. Moreover, they reported not to be exposed to chemicals during working or leisure time. Initially, 163 smokers and 38 non-smokers volunteered and were eligible for the study. The smokers were studied as part of an intervention trial. ${ }^{13.14}$ The present analysis is limited to the 156 smokers and 38 non-smokers for whom SCE data are available. The GST $\mu$ assay was ambiguous for one smoker and missing for another smoker. Sputum samples were only collected by smokers since non-smokers do not spontaneously produce sputum. In the smokers group, 29 participants failed to produce sputum samples whereas insufficient sputum cells could be evaluated in another 7 smokers.

\section{Blood parameters}

Non-fasting blood samples were collected between 8.00 am and 12.00 am. Directly after venipuncture blood samples were stored in the dark at 0 to $4^{\circ} \mathrm{C}$. After 20 to 23 hours overnight dark storage at $4^{\circ} \mathrm{C}$, a separate evacuated tube containing heparin as anticoagulant was opened to determine the sum of ascorbic acid + dehydro-ascorbic acid (vitamin $\mathrm{C}$ ) in 
whole blood by HPLC with fluorometric detection. ${ }^{15}$ All-trans retinol, $\alpha$-tocopherol, $\beta$-carotene and total carotenoids were assayed in EDTA plasma (stored at $-80^{\circ} \mathrm{C}$ ) by $\mathrm{HPLC}$ with colorimetric detection. ${ }^{16}$ For these assays, coefficients of variation for samples from a plasma pool were $4.3,4.1,7.0$, and $5.7 \%$ respectively. Plasma cotinine levels were determined by gas chromatography. ${ }^{17}$ Analysis of blind split samples for both a smoker (17 duplicate samples) and a non smoker ( 7 duplicate samples) revealed a variation coefficient of $3 \%$ for the cotinine assay. Presence or absence of GST- $\mu$ was established in heparinized whole blond using an enzyme-linked immunosorbent assay (MUKIT, Medlabs, Dublin, Ireland).

\section{Sister chromatid exchanges}

Blood cultures for determination of SCEs in lymphocytes ${ }^{18}$ were set up within 2 to 6 hours after venipuncture, after the blood had reached room temperature for 30 minutes. For the total study group, blood cultures were set up on 18 separate days; non smokers were studied on 10 of these 18 days. Heparinized whole blood $(0.5 \mathrm{ml})$ was added to $4.4 \mathrm{ml}$ pre-warmed RPMI 1640 medium (Flow) containing $20 \%$ foetal calf serum (inactivated for 30 minutes at $56^{\circ} \mathrm{C}$ ), $2.5 \%$ phytohaemaglutinin (HA-15 Welcome), $100 \mathrm{lU} / \mathrm{ml}$ penicillin, $100 \mu \mathrm{g} / \mathrm{ml}$ streptomycin, $2 \mathrm{mM} \mathrm{L}$-glutamine and $10 \mu \mathrm{g} / \mathrm{ml} 5$-bromo,2-deoxyuridine. The blood was cultured in the dark at $37^{\circ} \mathrm{C}$ in $\mathrm{T}-25$ culture flasks (Costar) in $5 \% \mathrm{CO}_{2}$ for $68 \pm 1$ hour. Colcemid was added to a final concentration of $0.2 \mu \mathrm{g} / \mathrm{ml}$ for the last two hours of incubation. The cells were collected by centrifugation, treated with hypotonic $\mathrm{KCl}(0.075 \mathrm{M})$ for 8 minutes to spread the chromosomes and to haemolyse the $\mathrm{RBC}$, and fixed three times with methanol-acetic acid (3:1). After overnight storage in the dark at $4^{\circ} \mathrm{C}$, cells were transferred to microscopic slides and air-dried. Preparations aged for 3 days and were stained by the Fluorescence plus Giemsa Technique $^{18}$ to obtain harlequin chromosomes. For each subject SCEs in 50 second-division metaphases were scored as colour changes in the longitudinal direction of the chromatid, excluding the centromere. Only metaphases with 46 chromosomes were scored. Individual data are the mean counts of 50 metaphases. SCEs were scored by a single observer in the nonsmokers group, whereas an additional observer assisted in scoring SCEs in the smokers group.

\section{Micronuclei in sputum}

Sputum was collected and processed as described in detail by Saccomano et al. ${ }^{19}$ Each participant received a careful individual instruction on how to produce a specimen from "deep in the lungs". Sputum was collected at home on three consecutive mornings, directly after rising and after carefully rinsing the mouth. The three, or minimally two samples collected in preservative $(50 \mathrm{ml} 50 \%$ ethanol with $2 \%$ polyethylene glycol (Carbowax 1540, Merck) were mixed, homogenized, centrifuged and smeared onto slides. Sputum was collected on the days following the venipuncture. The slides were stained with Feulgen and fast green, which is specific for DNA and strongly highlights micronuclei. ${ }^{20}$ For each subject, 3000 cells were examined and evaluated on the basis of the following criteria: shape and size typical of epithelial cells, a well defined nucleus and a clearly defined cytoplasm. The criteria in defining a micronucleus were: chromatin structure and colour intensity similar to those of the main 
nucleus; on focusing, the micronucleus must be on the same level as the nucleus, must be roundish and clearly included in the cytoplasm. The dimensions should be less than $1 / 5$ of that of the main nucleus, and it should not be connected to it. Slides were screened at $400 \mathrm{x}$ magnification and micronucleuted cells were examined at $1000 \mathrm{x}$ magnification. Slides were read coded/blinded by a single observer. Repeated blinded scoring of 9 samples yielded a good correlation (Pearson $R=0.86$ ), with 2 of the 9 samples showing a difference of more than 1 micronucleus upon rescoring.

\section{Dala analysis}

Smoking and non-smoking groups, as well as GST- $\mu$ deficient and non-deficient groups were compared using the Student t-test and the chi-square test. Associations between variables were evaluated using simple and multiple linear regression. For micronuclei counts, square roots of observations were taken to stabilize variances before data analysis. In addition to the linear regression techniques, the untransformed micronuclei data were also analyzed using Poisson regression. Data analysis were performed using the BMDP package. ${ }^{21}$ For the Poisson regression, the GENSTAT program was used. ${ }^{22}$

\section{Results}

Table 1 shows the data for the smoking and non-smoking group. Plasma cotinine levels reflect the large contrast in cigarette consumption between both groups. Age, body mass index and

Table 1. Characteristics and blood parameters in smokers and non-smokers.

\begin{tabular}{lcc}
\hline & $\begin{array}{c}\text { Smokers } \\
(\mathrm{n}=156)\end{array}$ & $\begin{array}{c}\text { Non-smokers } \\
(\mathrm{n}=38)\end{array}$ \\
\hline Age & $39.0 \pm 9.6$ & $37.0 \pm 10.5$ \\
Body Mass Index $\left(\mathrm{kg} / \mathrm{m}^{2}\right)$ & $24.5 \pm 3.0$ & $23.6 \pm 2.4$ \\
Alcohol $(\mathrm{g} / \text { day })^{*}$ & $12.1 \pm 13.1$ & $2.8 \pm 4.2$ \\
Cigarettes/day & $21.1 \pm 6.5$ & 0 \\
Duration of smoking (yrs) & $20.9 \pm 10.0$ & 0 \\
Plasma cotinine* & $327.7 \pm 117.1$ & $0.6 \pm 0.5$ \\
Blood vitamin C* & $36.6 \pm 17.9$ & $54.8 \pm 11.5$ \\
Plasma retinol & $2.31 \pm 0.54$ & $2.16 \pm 0.38$ \\
Plasma $\alpha$-locopherol* & $30.9 \pm 6.5$ & $27.3 \pm 7.0$ \\
Plasma $\beta$-carotcne* & $0.31 \pm 0.18$ & $0.48 \pm 0.30$ \\
Plasma tolal carolenoids* & $1.56 \pm 0.59$ & $1.91 \pm 0.72$ \\
SCE per lymphocyte* & & $4.71 \pm 0.35$ \\
Micronuclei per 3000 sputum cells & $5.08 \pm 0.98$ & - \\
\hline
\end{tabular}

* Smokers different from non-smokers: $\mathrm{p}<0.01$.

\# data for 143 smokers and 3.5 non-smokers. 
plasma retinol are similar in both groups, though slightly higher in the smoking group. In the smoking group, there are more alcohol users ( $78 \mathrm{vs.} 63 \%$ ) and the mean alcohol consumption is substantially higher. All plasma antioxidants are higher in non-smokers than in smokers, except for plasma $\alpha$-tocopherol which is slightly though significantly higher in smokers. The SCE measure is about $10 \%$ increased in smokers. Adjustment for alcohol consumption did not alter this difference ( $\mathrm{SCE}=0.37$ before adjustment, 0.33 after adjustment). The distribution of SCEs is given in figure 1, whereas the distribution of micronuclei counts is given in figure 2.

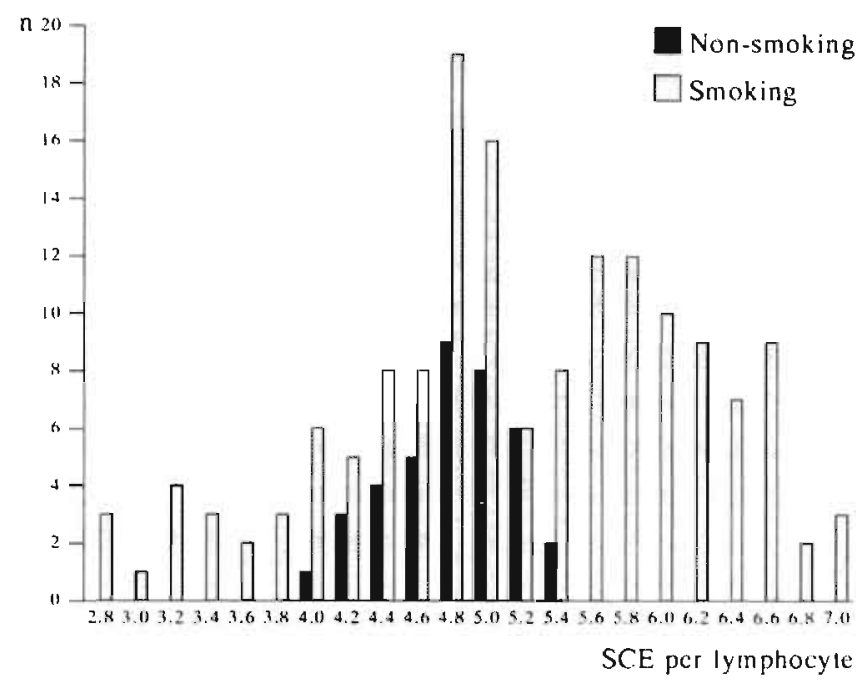

Figure 1. Distribution of sister chromatid exchanges in smokers $(n=156)$ and non-smokers $(n=38)$. Numbers on abscissa, upper boundaires of categories for SCEs

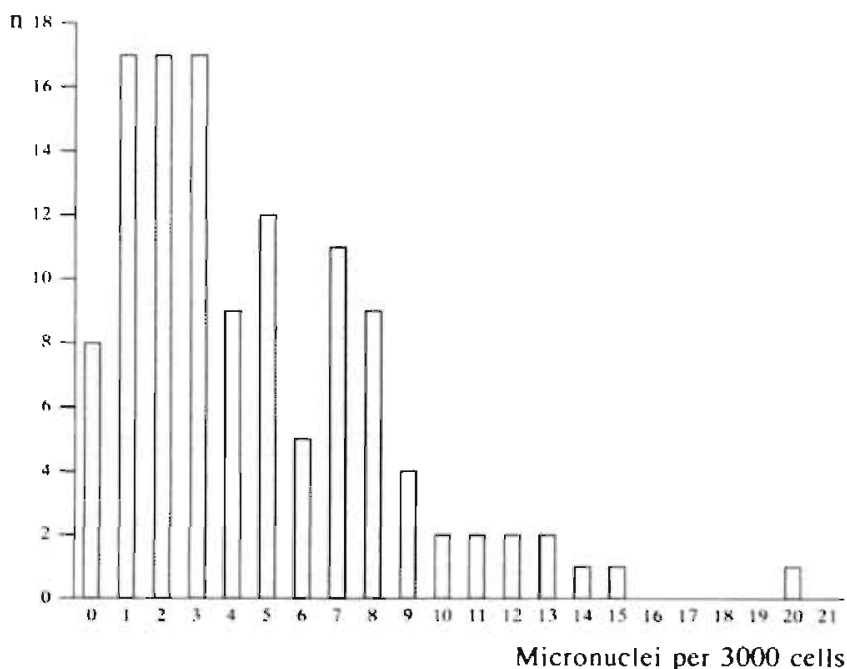

Figure 2. Distribution of spulum micronuclei counts in smokers $(n=143)$. 
The correlations for SCEs, micronuclei, and plasma cotinine for the smokers group are given in table 2. Plasma cotinine is clearly positively associated with the reported cigarette consumption and weakly though significantly with age, smoking years, and, unexpectedly, plasma $\beta$-carotene. SCE levels show a weak significant association with both plasma cotinine and reported cigarette consumption, but no association whatsoever with plasma antioxidants or alcohol consumption. No association was observed between SCEs and micronuclei in the smokers group ( $R=-0.025$; figure 3 ). For the non-smokers group, there were no significant associations of SCEs with any of the parameters in table 2 (all $R<0.14$ ). Micronuclei counts were not associated with any of the indices for tobacco consumption or antioxidant status. Poisson regression models for the micronuclei counts yielded results similar to those in table 2: none of the associations with the listed parameters was significant.

Table 2. Correlation (Pearson cocfficients) of several characteristics and blood parameters with SCE. micronuclei and plasma cotinine in male cigarette smokers $(n=156)$.

\begin{tabular}{|c|c|c|c|}
\hline & Plasma cotinine & SCE & Micronuclei $(n=120)$ \\
\hline Age & $0.193^{*}$ & 0.152 & 0.054 \\
\hline Body Mass Index $\left(\mathrm{kg} / \mathrm{m}^{2}\right)$ & $-0.163^{*}$ & 0.08 .3 & 0.006 \\
\hline Alcohol (g/day) & -0.085 & 0.0 .52 & -0.057 \\
\hline Cigarclles/day & $0.368^{*}$ & $0.248^{*}$ & -0.006 \\
\hline Duration of smoking (yrs) & $0.239^{*}$ & 0.109 & 0.006 \\
\hline Plasma colinine & 1.000 & $0.186^{*}$ & -0.013 \\
\hline Blood vitamin $C$ & 0.042 & 0.0 .39 & $-0.11 . \overline{7}$ \\
\hline Plasma rulinol & 0.058 & 0.010 .3 & $0.0(19$ \\
\hline Plasma a-locopherol & 0.0 .59 & -0.022 & 0.0017 \\
\hline Plisnnal p-carotenc & $0.177^{*}$ & -0.0 .38 & 0.100 \\
\hline Plasma lotal carolenoids & -0.090 & -0.021 & 0.136 \\
\hline
\end{tabular}

$* p<0.05$.

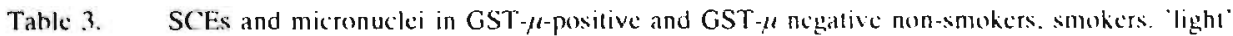
smokers (plasma cotinine $<31.5 \mathrm{ng} / \mathrm{ml}$ ) and heavy' smokers (plasma cotininc > $31.5 \mathrm{ng} / \mathrm{ml}$ ).

\begin{tabular}{|c|c|c|c|}
\hline & & 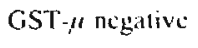 & GST- $-\mu$ pesitive \\
\hline \multirow[t]{2}{*}{ Non-smokers } & SCE: & $4.69 \pm 0.35$ & $4.74 \pm 10.35$ \\
\hline & Micronuclci & - & - \\
\hline \multirow[t]{2}{*}{ Smokers } & SCEN\# & $5.24 \pm 0.95$ & $4.97 \pm(1.98$ \\
\hline & Micronuclei & $4.3^{3} \pm 4.3$ & $4.9 \pm 2.9$ \\
\hline \multirow[t]{2}{*}{ light sinokers } & SCEs & $4.95 \pm 0 .(x)$ & $4.97 \pm 1.01$ \\
\hline & Micronucli & $4.1 \pm 3.0$ & $4.9 \pm .3 .(1$ \\
\hline \multirow[t]{2}{*}{ Heavy smokers } & SCEs* & $5.50 \pm 0.84$ & $4.97 \pm(1.97$ \\
\hline & Micrunuclei & $4.5 \pm 5.11$ & $5.0 \pm 2.9$ \\
\hline
\end{tabular}

* dilfirent $\mu-$ from $\mu+, \mathrm{p}=0.0) 1$.

\# p valuc lor comparision $\mu-v i . \mu t=0 .(\%)$. 
Of all subjects, $45 \%$ were deficient in GST $-\mu$. We observed no association between GST- $\mu$ and any of the blood parameters or characteristics given in table 2 . The association of GST- $\mu$ deficiency with SCEs and micronuclei is given in table 3. In non-smokers, there is no relation between GST- $\mu$ deficiency and SCE levels. In GST- $\mu$ deficient smokers, SCE levels are higher than in non-deficient smokers. This $\mu$-related difference is more pronounced in 'heavy' smokers (plasma cotinine above the median), whereas it is absent in 'light' smokers. In the heavy smokers, the $\mu$-related difference was similar in multiple regression analysis controlling for age, body mass index, duration and quantity of smoking, and cotinine levels (5.47 vs. 4.99; $\mathrm{p}=0.02$ ). In the light smokers, the multivariate adjustment also yielded similar results (4.94 vs. $4.98 ; p=0.87)$. Similar analyses for micronuclei in smokers did not reveal any associations with GST- $\mu$ phenotype, either in light or heavy smokers (table 3 ).

For the SCE count in smokers, we observed an effect of culturing day variation (multiple partial $R=0.53, p<0.001$ ) and variation between observers (partial $R=0.51, p<0.001$ ) in a model that included 18 runs and 2 observers (multiple $R=0.71$ for the total model). Adjustment for culturing day and observer variation did not materially alter the SCE data and correlations for SCEs given in the tables 1-3. Only the difference in SCEs between smokers and non-smokers was more pronounced after this adjustment (4.85 vs. 5.66 SCE per lymphocyte; $p<0.001)$. For the determination of micronuclei, we did not observe a significant effect of the 18 different runs on the micronuclei counts (multiple $R=0.42, p=0.20$ in linear regression, $\mathrm{p}=0.20$ in multiple Poisson regression).

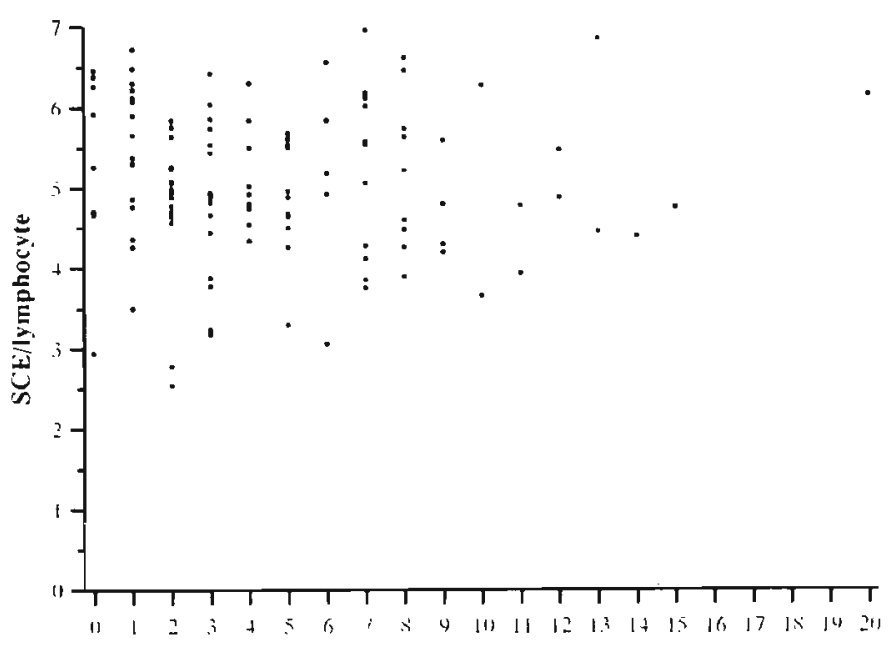

Micronuclei counts (per 3000) (ells)

Figure 3. Relationship between sputum micronuclei counts and lymphocyte SCE in smokers $(n=14.3)$. 


\section{Discussion}

The decreased blood levels of carotenoids and vitamin $\mathrm{C}$ that we observe in smokers are in line with previous studies. ${ }^{23,24}$ These differences may reflect a decreased dietary intake of vitamin $\mathrm{C}$ and carotenoids in smokers or a metabolic consequence of cigarette smoking. ${ }^{23,24}$ A metabolic effect is biologically plausible, since cigarette smoke is a major source of free radicals and oxidant stress. ${ }^{25}$ Our study did not measure dietary intake, but a metabolic effect of smoking is not clearly supported by the low correlations that we observe between plasma levels of cotinine, vitamin $C$, and carotenoids. For plasma cotinine and plasma $\beta$-carotene, we even observe an unexpected weak positive association. The antioxidant vitamin $\mathrm{E}$ is slightly, although significantly, higher in smokers than in non-smokers, but this may be explained by higher plasma lipid levels, which are common in smokers. ${ }^{26}$ We had no lipid measurements to standardize the vitamin E levels. ${ }^{27}$

An increase in SCE levels in smokers is also a well known phenomenon, with levels being $10-88 \%$ higher than in non-smokers. ${ }^{5}$ It should be noted that SCE levels observed in several studies cannot readily be compared, since laboratory protocols are not standardized. ${ }^{18}$ The sensitivity of the SCE determination to laboratory variations is illustrated by the significant variation over the 18 culturing days, which we observe despite adherence to a strict protocol. Non-laboratory-related differences between the culturing days may also have attributed to this variation. In the analyses within the group of smokers (tables $2 \& 3$, figure 3 ) the scorer- and run-variations did not bias our results, since the smokers were randomly divided over the scoring runs, and the observers were equally represented in every scoring run. The analyses adjusted for run- and observer-variation therefore yielded results similar to the unadjusted analyses. The potential for hias, however, is illustrated by the contrast between non-smokers and smokers. This contrast increased after adjustment for run- and scorervariation, reflecting the unequal distribution of non-smokers over the runs and scorers. This is also exemplified by figure I, showing that the overall variation in SCE counts is far less in the non-smoker group than in the smoker group.

The correlations within the group of smokers between reported cigarette consumption or plasma cotinine are rather small. Reported cigarette consumption may not be a good measure of genotoxic exposure due to differences in brands and smoking and inhaling practices. ${ }^{2 *}$ Also, the relation between nicotine content and content of genotoxic agents in cigarettes is uncertain. However, since we also observe an only 10-20\% increase in smokers as compared with non-smokers, the conclusion that the SCE measure in lymphocytes is not very sensitive to variations in tobacco smoke exposure seems warranted. In this respect, it is noteworthy that lymphocytes also do not seem to be very sensitive to other types of genetic damage. DNA adducts or HPRT mutant frequency are also only moderately elevated in heavy smokers. ${ }^{24.30}$

Micronuclei in sputum ${ }^{31}$ or bronchial brushings ${ }^{32}$ have been reported to be 3 -fold higher in smokers than non-smokers. Micronuclei in exfoliated epithelial cells reflect the extent of chromosome breakage due to mutagenic exposure, when the cells were dividing a few days 
or weeks earlier, in the basal layer of the epithelium of the tracheobronchial tree. ${ }^{33}$ The mean micronuclei counts in our study in healthy volunteers are lower than in studies using hospitalized patients. ${ }^{31.32}$ Benner et al. ${ }^{34}$ also observed lower micronuclei counts in healthy smokers undergoing bronchoscopy than in patients. The previous studies ${ }^{31,32}$ also did not describe their scoring criteria, and counts for 'high certainty micronuclei' may be much lower than counts including 'medium certainty micronuclei'. ${ }^{35}$ Within our group of smokers, the micronuclei parameter is not associated with smoking intensity, as was reported previously using counts in only 500 sputum cells in patients. ${ }^{31}$ The lack of sensitivity for micronuclei in sputum in our study may be attributed to a large random sampling site variation, since expectorated cells may originate from all locations in the tracheobronchial tree. Studies using buccal micronuclei $i^{33,35}$ and bronchial brushings ${ }^{34}$ have indeed demonstrated major sampling site variations.

Both micronuclei and SCEs reflect DNA damage, but the exact molecular mechanisms are not known. Micronuclei are considered to reflect chromosome breakage, ${ }^{3.3}$ whereas SCEs are considered to be due to perturbations in the DNA that persist through DNA replication. ${ }^{36}$ In vitro studies indicate that the mechanisms may be mediated by free radicals and oxidants but can also involve other pathways. ${ }^{37.40}$ The absence of associations of the vitamins $\mathrm{C}$ and $\mathrm{E}$ or carotenoids with SCEs and micronuclei does not support an involvement of free radicals and oxidants in vivo. However, there are numerous other non-enzymatic and enzymatic antioxidants that we did nol measure," blood levels may not reflect long-term antioxidant levels in lymphocytes or lung tissue. and the range of antioxidant levels in our study may not have been sufficiently large to demonstrate associations. Also, large random variations both in micronuclei and SCE counts may introduce bias towards the null and thus obscure a possible weak association.

The results for the GST- $\mu$ phenotype indicate that a part of the variation in SCE counts in smokers is genetically determined, since the GST- $\mu$ isozyme is inherited in an autosomal dominant fashion. ${ }^{42}$ Glutathione S-transferases detoxify reactive electrophiles, in particular epoxides, ${ }^{43}$ and GST- $\mu$ deficiency may imply a more limited capacity for detoxification and more carcinogen-mediated DNA damage. Our results for the SCE measure support this hypothesis and suggest that increased DNA damage in GST- $\mu$ deficient heavy smokers may be involved the association between GST- $\mu$ and lung cancer that is observed in case-control studies, ${ }^{x, 44.46}$ as we have previously discussed in more detail. ${ }^{12}$ One of the studies showed a clear inverse relation between GST- $\mu$ deficiency and lung cancer in heavy smokers but not in light smokers, ${ }^{1 \times}$ which seems to correspond with our data. Another study ${ }^{\text {th }}$ was more equivocal but also observed an inverse relation (although not statistically significant) only in heavy smokers. Zhong ${ }^{45}$ observed an inverse relation for squamous carcinoma but not for adenocarcinoma of the lung. The results for the micronuclei counts do not support this hypothesis since micronuclei counts were even somewhat lower in GST- $\mu$-deficient subjects. The different results for the GST- $\mu$ analysis suggest that micronuclei and SCE may be different biological phenomena; although epoxides may contribute to in vivo SCE induction, this may not be the case for micronuclei. 
The concept that SCEs and micronuclei reflect different biological phenomena is also supported by the lack of an association between micronuclei and SCEs, as depicted in figure 3. Both micronuclei and SCEs are sensitive to carcinogens in experimental in vivo and in vitro models, ${ }^{36,47,48}$ but there is little information on correlations between SCEs and micronuclei in these models to compare with our epidemiological observations. Here again, caution in interpretation of our data is required since unexplained random variation in both parameters may have obscured a weak association. Also, differences in tissues and time frame that the two cytogenetic parameters reflect may have contributed to the absence of a relation.

This study has evaluated the application of a number of biomarkers in a cross-sectional study in smokers and non-smokers. SCEs and micronuclei have been successfully used in previous studies to demonstrate differences in DNA damage between smokers and nonsmokers. For the SCE measure, our study confirms these previous studies. In addition, the SCE measure in our study could be used to demonstrate differences in cytogenetic damage between smokers with or without a genetically determined detoxification enzyme. Our results do, however, demonstrate that both SCE and micronuclei have only limited or no sensitivity to variations in cigarette smoke exposure within a group of smokers. This limited sensitivity may be partly attributed to large variations of as yet unknown origin that we observe between persons in both SCE and micronuclei. This presumably random variation makes it difficult to unambiguously interpret the absence of relations (e.g. between antioxidants and cytogenetic damage) that we observe in this study. More information on biological, laboratory, and design factors that determine variations is necessary to be conclusive about the absence of associations.

\section{References}

1. Hulka BS, Wilcosky TC, Gril 「ith JD (cds). Biological Markers in Epidemiology. Oxford University Press. New York Oxlord 1990.

2. Weinstcin IB. The origins of human cancer: molecular mechanisms of carcinogenesis and their implications for cancer prevention and treatment. Cancer Res 1988:48:4135-4143.

3. Wilcosky IC. Rynard SM. Sister Chromatid Exchange. In: Hulka BS, Wilcosky TC, Griffith JD (eds). Biological Markers in Epidemiology. Oxford University Press. New York Oxlord 1990.

4. Vinc MF. Micronuclei. In: Hulka BS. Wilcosky TC. Griffith ID (eds): Biological Markers in Epidemiolugy. Oxford University Press. New York Oxford 1990.

5. IARC Monograph on the evaluation of the carcinogenic risk of chemicals to humans, vol 38: Tobacco Smoking. WHO/Intcrnational Agcncy for Resuarch on Cancer, Lyon. 1986.

6. Byers T. Perry G. Dietary carolenes, vitamin $C$. and vitamin $E$ as protective antioxidants in human cancers. Annu Rev Nutr 19)2:12:139-159.

7. Steinmetr KA. Poltcr JD. Vegctubles. Fruits and cancer II. Mechanisms. Cancer Causes \& Control $1991: 2: 427-442$.

8. Seidegård J, Pero RW, Miller DG, Beattie EJ, A glutathione transferasc in human leukocytes as a marker for the susceptibility to lung cancer. Carcinogenesis 1986;7:751-753.

9. Gelboin HV. Carcinogens, drugs. and cylochromes P.450. N Engl J Med 1983;309:105-107.

10. Cough AC. Miles JS, Spurr NK, et al. Identification of the primary gene defect at the cytochrome P450 CYP2D locus. Nature 1990:347:77,3-776.

11. Sun Y. Frec radicals, antioxidant en/ymes. and carcinogenesis. Free Radical Biol Med 1990:8:583-599.

12. Van Poppel G. De Vogel N, Van Bladeren P. Kok FJ. Increased cytogenelic damage in smokers deficient in glutathione S-transferase isozyme $\mu$. Carcinogenesis 1992;13:303-305. 
13. Van Poppel G, Kok FJ, Duijzings P, De Vogel $N$. No influence of $\beta$-carotene on smoking induced DNA damage as reflected by sister chromatid exchanges. Int J Cancer 1992;51:355-358.

14. Van Poppel G, Kok FJ. Hermus RJJ. B-Carotene supplementation in smokers reduces the frequency of micronuclei in sputum. Br J Cancer 1992;66:1164-1168.

15. Speek AJ, Schrijver J, Schreurs WHP. Fluorimetric determination of total vitamin $C$ in whole blood by high performance liquid chromatography with pre-column derivatization. J Chromatogr 1984;305:53-60.

16. Van Vliet T. Van Schaik F. Van Schoonhoven J, Schrijver J. Determination of several retinoids. carotenoids, and E vitamers by HPLC. Application 10 plasma and lissues of rats fed a diet rich in either B-carotene or canthaxanthin. J Chromatography 1991:553:179-186.

17. Feyerabend C. Bryant A, Jarvis MJ, Russell MAH. Determination of cotinine in biological Cluids of nonsmokers by packed column gas-liquid chromatography. J Pharm Pharmacol 1984:38:1075-1078.

18. Perry PE, Thomson EJ. The methodology of sister chromatid exchanges. In: BJ Kilbey, M Legator, W Nichols, C Ramel (eds); Handbook of mulagenicity test procedures, 2nd cdition. Elseviers Sciences Publishers, Amsterdam, 1984.

19. Saccomanno G. Diagnostic pulmonary cytology. ISBN 0-89189-050-5. American Society of Clinical Pathologists, Chicago, 1978.

20. Bruck HC. Histologische Technik. Leidfaden für de Herstellung microskopischer Präparate in Unterrichı und Praxis. ISBN 3-13314304-2. Georg Thieme Verlag, Stuttgart - New York, 1981.

21. Dixon WJ (ed). BMDP Statistical Software Manual, University of California Press, Berkeley, 1988.

22. GENSTAT 5 Committee. GENSTAT 5 Reference Manual. Oxford University Press. Oxford. 1987.

23. Schectman G. Byrd JC, Gruchow HW. The influence of smoking on vitamin C status in adults. Am J Public Health 1989;79:158-162.

24. Gerster H. $\beta$-Carotene and smoking. J Nutr Growth Cancer 1987:4:45-49

25. Pryor WA, Hales BJ. Premovic PI, Church DF. The radicals in cigarette tar: their nature and suggested physiological complications. Science 1983;220:425-427.

26. Craig WY, Palomaki GE. Haddon JE. Cigaret smoking and serum lipid and lipoprotcin concentrations: an analysis of published data. Br Med J 1989:298:784-788.

27. Hunter D. Biochemical indicators of dietary intake. In: Willelt W.C. Nutritional Lipidemiology. Monographs in Epidemiology and biostatistics vol. 15. Oxford University Press. New York 1990.

28. Pojer R. Whitficld JB. Poulos V. ct al. Carboxyhemoglobin. cotinine and thiocyanate assay compared for distinguishing smokers from non-smokers. Clin Chem 1984;30:1377-1380.

29. Perera FP, Santella RM, Brenner D. et al. DNA adducts, protein adducts, and sister chromatid exchange in cigarelle smokers and non-smokers. J Nat! Cancer Inst 1987:79:449-456.

30. Vrieling H. Thijsscn JCP. Rossi A.M. el al. Enhanced hprt mutant frequency but no significant difference in mutation spectrum between a smoking and a non-smoking human population. Carcinogenesis 1992;13:1625-1631.

31. Fontham E, Correa P. Rodrigucz. E, Lin Y. Validation of smoking history with the micronuclei Itst. In: Hoffmann D. Harris CC (eds): Mechanisms in tobacco carcinogenesis. Banbury Repurt 23, 113-118. Cold Spring Harbor Laboratory. New York 1986.

32. Lippmann SM, Pcters EJ, Wargovich MJ. ct al. Bronchial micronuclei as a marker of an carly stagc of carcinogenesis in the human tracheobronchial epithelium. Int $J$ Cancer 1990;45:811-815.

33. Stich HF, Rosin MP. Micronuclei in exfoliated human cells as a lool for studies in cancer risk and cancer intervention. Cancer Lett 1984:22:241-253.

34. Benner SE. Lippman SM. Wargovich MJ, el al. Micronuclei in bronchial biopsy specimens from heavy smokers: characterization of an intermediate marker of lung carcinugenesis. In J Cancer 1992:52:44-47.

35. Tolbert PE. Shy CM. Allen WJ. Micronuclei and other nuclear anomalies in buccal smears: a field lest in snuff users. Am J Epidemiol 1991:134:840-850

36. Wolff $S$. Sister chromatid exchange: the mosi sensitive mammalian system for determining the effect of mutagenic carcinogens. In: $\mathrm{K}$ Berg (ed). Genetic damage in man caused by environmental agents $p p$ 229-246 New York. Academic Press, 1979.

37. Lee CK, Brown BG, Rice WY, Doolittle DJ. Role of oxygen free radicals in the induction of sister chromatid exchanges by cigarette smoke. Environ Molecul Mutagen 1989; 13:54-59.

38. Weitberg AB, Weitzman SA. Clarck EP. Stossel TP. Effects of antioxidants on oxidant induced sister chromatid exchange formation. J Clin Invest 1985:75:1835-1841.

39. Lasne C, Gu ZW, Venegas W. Chouroulinkov 1. The in vilro micronucleus assay for deteclion of cylogenetic effects induced by mutagen-carcinogens: comparison with the in vitro sister-chromatid exchange assay. Mutat Res 1984;130:273-282. 
40. Vanparys $P$, Vermeiren F, Sysmans M. Temmerman R. The micronucleus assay as a test for the detection of aneugenic activity. Mutat Res 1990;244:95-103.

41. Halliwell B, Gutteridge JMC. Frce radicals in biology and medicine. Oxford University Press, New York 1985.

42. Seidegård J. Pero PW. The heriditary uransmission of high glutathione transferase activity towards transstilbene oxide in human mononuclear leukocytes. Hum Genet 1985;69:66-68.

43. Mannervik B, Danielson UH. Glutathione-transferases - structure and catalytic activity. CRC Critical Reviews in Biochemistry 1988:23:283-337.

44. Seidegărd J. Pero RW, Markowitz MM, et al. Isoenzyme(s) of glutathione transferase (class Mu) as a marker for the susceptibility to lung cancer; a foltow up study. Carcinogenesis 1990;1 1:33-36.

45. Zhong S, Howie AF, Ketlerer B, et al. Glutathione S-transferase $\mu$ locus: use of genotyping and phenotyping assays to assess association with lung cancer susceptibility. Carcinogenesis $1991 ; 12: 1533-$ 1537.

46. Hecbert SR, Weiss NS, Hornung SK, et al. Glutathione S-transferase and epoxide hydrolase activity in human leukocytes in relation to risk of lung cancer and other smoking-related cancers. J Natl Cancer Inst 1992;84:414-422.

47. Jcnsen D, Ramel C. The micronuclei test as part of short term mutagenicity test program for the prediction of carcinogenety evaluated by 143 agents tested. Mutation Res 1980;75;179-191.

48. Stich HF, Stich W, Parida BB. Elevated frequency of micronucleated cells in the buccal mucosa of individuals at high risk for oral cancer: betel quid chewers. Cancer Lett 1982;17:125-134. 


\title{
Increased cytogenetic damage in smokers deficient in glutathione $S$-transferase isozyme $\mu$
}

Geert van Poppel, Nico de Vogel, Peter J. van Bladeren, Frans J. Kok

\begin{abstract}
Reduced expression of the $\mu$-isozyme of glutathione S-transferase (GST; EC 2.5.1.18) has been associated with increased lung cancer risk. We studied the association between GST- $\mu$ expression and DNA damage as measured by sister chromatid exchanges (SCE) in healthy male smokers. SCE levels were higher in the 71 GST- $\mu$-deficient smokers compared to the 83 non-deficient smokers (5.24 vs. 4.97 SCE per lymphocyte; $p=0.09$ ). In smokers having high plasma cotinine levels ( $>$ median of $315 \mathrm{ng} / \mathrm{ml}$ ), this $\mu$-related difference was more pronounced ( 5.50 vs. $4.97 ; p=0.01$ ), whereas it was absent in smokers having low cotinine levels (4.95 vs. $4.97 ; p=0.92$ ). Increased cytogenetic damage in GST- $\mu$ deficient heavy smokers may thus explain the association between GST $\mu$ expression and lung cancer.
\end{abstract}

\section{Introduction}

Although cigarette smoking causes almost all cases of bronchial carcinoma, many smokers do not develop lung cancer.' Individual susceptibility to lung cancer may be influenced by the enzymes that detoxify carcinogens in cigarette smoke.' Glutathione S-transferases (GST; EC 2.5.1.18) detoxify reactive electrophiles and may thus inhibit binding of carcinogens to DNA. ${ }^{2}$ The three main types of glutathione S-transferase in humans are classes of isozymes designated $\alpha, \mu$ and $\pi .^{2}$ The GST- $\mu$ isozyme is inherited in an autosomal dominant fashion, ${ }^{3}$ and in about $50 \%$ of the human population, GST- $\mu$ activity is virtually absent. ${ }^{3}$ There is evidence that expression of GST- $\mu$ is reduced in lung cancer patients. ${ }^{4.5}$ This reduction in enzyme activity may be a result of the disease process, but it is hypothesized that increased smoking-induced cytogenetic damage in GST- $\mu$ deficient subjects explains the association between GST- $\mu$ deficiency and lung cancer. ${ }^{6}$ To evaluate this hypothesis, we studied the association between GST- $\mu$ expression and cytogenetic damage in healthy males. Sister Chromatid Exchanges (SCE) in peripheral blood lymphocytes were measured as an endpoint of cytogenetic damage. 


\section{Subject and methods}

We studied healthy male volunteers, employed at the AMEV Insurance Company, the Taxation Office and the Power Company at Utrecht. The study was approved by an external Medical Ethical Committy and all participants gave their informed consent. Blood samples were taken by venapuncture into sterile heparinized Vacutainer tubes, and immediately stored at $4^{\circ} \mathrm{C}$. Smokers $(n=155)$ reported consumption of $>15$ cigarettes/day over $>2$ years, whereas non-smokers $(n=66)$ reported never to have smoked. Plasma cotinine levels were determined by gas chromatography. ${ }^{7}$ As cotinine is a good marker of smoking behaviour,' smokers were divided into either 'heavy' or 'light' smokers at the median of plasma cotinine levels. Presence or absence of GST- $\mu$ was established in heparinized whole blood using an enzyme-linked immunosorbent assay (MUKIT, Medlabs, Dublin, Ireland). One smoker was excluded from the analyses because the GST assay was ambiguous. None of the subjects reported exposure to chemicals or medications that could influence SCE levels.

Blood cultures for determination of Sister Chromatid Exchange in lymphocytes ${ }^{8}$ were set up within 2-6 hours after venapunction, after the blood was allowed to reach room temperature for 30 minutes Heparinized whole blood $(0.5 \mathrm{ml})$ was added to $4.4 \mathrm{ml}$ prewarmed RPMI 1640 medium (Flow) containing 20\% fetal calf serum (inactivated for 30 minutes at $56^{\circ} \mathrm{C}$ ), $2.5 \%$ phytohaemagglutinin (HA-15 Welcome), $100 \mathrm{IU} / \mathrm{ml}$ penicillin, 100 $\mu \mathrm{g} / \mathrm{ml}$ streptomycin and $2 \mathrm{mM} \mathrm{L-glutamine.} \mathrm{5-Bromo-2-deoxyuridine} \mathrm{was} \mathrm{added} \mathrm{to} \mathrm{a} \mathrm{final}$ concentration of $10 \mu \mathrm{g} / \mathrm{ml}$. The blood was cultured in the dark at $37^{\circ} \mathrm{C}$ in $\mathrm{T}-25$ culture flasks (Costar) in $5 \% \mathrm{CO}_{2}$ for $68 \pm 1$ hour. Colcemid was added at a final concentration of $0.2 \mu \mathrm{g} / \mathrm{ml}$ for the last 2 hours of incubation. The cells were collected by centrifugation, treated with hypotonic $\mathrm{KCl}(0.075 \mathrm{M})$ for 8 minutes to spread the chromosomes and to haemolyse the red blood cells, and fixed three times with methanol/acetic acid (3:1). After overnight storage in the dark at $4^{\circ} \mathrm{C}$, cells were transferred to microscopic slides and air-dried. Preparations aged for 3 days and were stained by the fluorescence plus Giemsa technique ${ }^{x}$ to obtain harlequin chromosomes. For each subject SCE in 50 second-division metaphases were scored as colour changes in the longitudinal direction of the chromatid, excluding the centromere. Only nuclei with 46 chromosomes were scored. Individual data are the mean counts of 50 metaphases. Differences between GST- $\mu$-deficient and non-deficient subjects were evaluated using a two-tailed unpaired t-test and multivariate regression analysis.

\section{Results and discussion}

As we expected, smokers had a higher number of SCE per lymphocyte than non-smokers ( 5.08 vs. $4.66, p<0.001$, see also figure 1$)$. An approximately $10 \%$ increase in SCE levels in smokers is in accordance with some, but not all studies. ${ }^{1}$ In 24 out of 27 studies, SCE were increased in smokers, levels being $10-88 \%$ higher that in non-smokers. 'It should be 
noted that SCE levels observed in several studies cannot readily be compared, as laboratory protocols are not standardized. ${ }^{8}$ The non-smokers were younger than the smokers and had a lower body mass index. However, multivariate regression analysis did not reveal significant associations between age or body mass index and SCE levels, and the significant difference in SCE level between smokers and non-smokers persisted after controlling for age and body mass index.

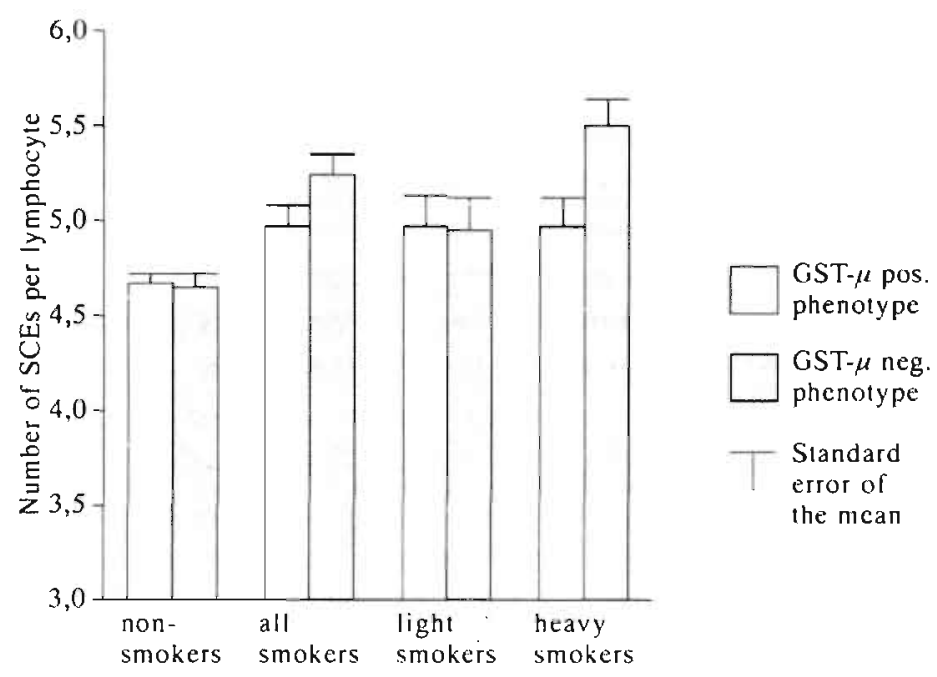

Figure 1. Levels of SCE in cultured lymphocytes of GST- $\mu$-positive and -negative smokers and non-smokers. Characteristics of non-smokers, smokers, light smokers and hcavy smokers have been given in the text.

Forty-five per cent of all subjects were deficient in GST- $\mu$, which agrees well with previous estimates. ${ }^{3}$ Age, body mass index, cigarette consumption and cotinine levels were almost similar for $\mu$-positive or $\mu$-negative subjects (table 1 and table 2 ). In the 'heavy' smokers, reported cigarette consumption was only $14 \%$ higher $(19.8$ vs. $22.5, p<0.01)$ than in the 'light' smokers, indicating that self-reported cigarette consumption yields only a rough estimate of actual exposure. Figure 1 shows levels of SCE in the smoking and nonsmoking groups. In non-smokers no differences between GST- $\mu$ phenotypes were observed (4.67 vs. $4.65, p=0.79$ ). In the smokers, however, the GST- $\mu$ negative phenotype was associated with higher SCE levels (5.24 vs. 4.97, $\mathrm{p}=0.09$ ). This $\mu$-related difference in SCE was more pronounced in heavy smokers $(5.50$ vs. $4.97, p=0.01)$, whereas it was absent in light smokers (4.95 vs. $4.97, \mathrm{p}=0.92)$. In the heavy smokers, the $\mu$-related difference in SCE was similar in multiple regression analysis adjusting for age, body mass index, duration and quantity of smoking, and cotinine levels (5.47 vs. 4.99, p = 0.02). In the light smokers, the multivariate adjustment also yielded similar results (4.94 vs. 4.98 , $\mathrm{p}=0.87$ ). 
Table 1. Characteristics of GST- $\mu$-positive and -negative smokers and non-smokers (mean \pm SD).

\begin{tabular}{lcccc}
\hline & $\begin{array}{c}\text { GST- } \mu \text {-positive } \\
\text { non-smokers } \\
(\mathrm{n}=39)\end{array}$ & $\begin{array}{c}\text { GST- } \mu \text {-negative } \\
\text { non-smokers } \\
(\mathrm{n}=27)\end{array}$ & $\begin{array}{c}\text { GST- } \mu \text {-positive } \\
\text { smokers } \\
(\mathrm{n}=81)\end{array}$ & $\begin{array}{c}\text { GST- } \mu \text {-negative } \\
\text { smokers } \\
(\mathrm{n}=73)\end{array}$ \\
\hline Age (years $)$ & $33.5 \pm 8.5$ & $37.2 \pm 10.8$ & $39.5 \pm 9.0$ & $38.6 \pm 10.5$ \\
Body Mass Index $\left(\mathrm{kg} / \mathrm{m}^{2}\right)$ & $23.7 \pm 2.3$ & $24.1 \pm 2.6$ & $24.4 \pm 3.2$ & $24.7 \pm 2.9$ \\
Plasma Cotinine $(\mu \mathrm{g} / \mathrm{ml})$ & $1.0 \pm 1.0$ & $0.9 \pm 0.6$ & $323.1 \pm 120.0$ & $334.9 \pm 114.8$ \\
Cigaretles/day & 0 & 0 & $20.8 \pm 5.7$ & $21.5 \pm 7.3$ \\
Packycars' & 0 & 0 & $22.3 \pm 12.1$ & $22.3 \pm 12.7$ \\
\hline
\end{tabular}

1 Reported number of packs smoked per day $x$ number of years smoked.

Table 2. Characteristics of GST- $\mu$-positive and -negative light smokers (plasma cotinine $<315 \mu \mathrm{g} / \mathrm{ml}$ ) and heavy smokers (plasma cotinine $>315 \mu \mathrm{g} / \mathrm{ml}$ ) (mean $\pm \mathrm{SD}$ ).

\begin{tabular}{lcccc}
\hline & $\begin{array}{c}\text { GST }-\mu \text { positive } \\
\text { light smoker } \\
(\mathrm{n}=41)\end{array}$ & $\begin{array}{c}\text { GST }-\mu \text { negative } \\
\text { light smoker } \\
(\mathrm{n}=35)\end{array}$ & $\begin{array}{c}\text { GST- } \mu \text { positive } \\
\text { heavy smoker } \\
(\mathrm{n}=40)\end{array}$ & $\begin{array}{c}\text { GST- } \mu \text { negative } \\
\text { heavy smoker } \\
(\mathrm{n}=38)\end{array}$ \\
\hline Age (years) & $38.5 \pm 9.5$ & $37.2 \pm 10.8$ & $40.5 \pm 8.4$ & $39.5 \pm 10.7$ \\
Body Mass Index $\left(\mathrm{kg} / \mathrm{m}^{2}\right)$ & $25.0 \pm 3.6$ & $24.8 \pm 2.6$ & $23.7 \pm 2.7$ & $24.7 \pm 3.1$ \\
Plasma Cotinine $(\mu \mathrm{g} / \mathrm{ml})$ & $230.6 \pm 64.4$ & $236.2 \pm 58.3$ & $415.9 \pm 86.4$ & $425.9 \pm 69.4$ \\
Cigaretles/day & $20.2 \pm 4.8$ & $19.0 \pm 4.7$ & $21.4 \pm 6.5$ & $23.7 \pm 8.5$ \\
Packyears' & $20.8 \pm 12.2$ & $18.3 \pm 9.9$ & $23.9 \pm 11.9$ & $25.9 \pm 14.0$ \\
\hline
\end{tabular}

' Reported number of packs smoked per day $\mathrm{x}$ number of years smoked.

The $10 \%$ increase in SCE levels, that we observed in GST- $\mu$-deficient heavy smokers, is of the same order of magnitude as the difference we observed between smokers and nonsmokers. These results thus show for the first time that a genetic deficiency in detoxication of xenobiotics is associated with substantially increased cytogenetic damage in a human population exposed to carcinogens. Biotransformation of xenobiotics involves both the oxidative phase I metabolism, usually catalysed by cytochrome P450 isoenzymes, and phase Il conjugation reactions. Reactive intermediates are often produced through phase I metabolism and subsequently detoxicated by phase II enzymes." The phase II glutathione S-transferases in particular detoxify epoxides by conjugating them to glutathione., . $^{20}$ Cigarette smoke is a complex mixture of many compounds.' Substrates for GST- $\mu$ derived from cigarette smoke conscituents include styrene oxide ${ }^{10}$ and the mutagenic benzo[a]pyrene (BP) metabolites BP 4,5-oxide, ${ }^{11}$ and anti-BP-7, 8-diol-9, 10-oxide, ${ }^{11}$ of which the latter has been shown to activate $\mathrm{C}-\mathrm{Ha}$-ras-1 protooncogene in vitro. ${ }^{12}$ Also, GST- $\mu$ shows a particularly high specificity for trans-stilbene oxide, ${ }^{2}$ which, however, is 
not known to occur in cigarette smoke. Nevertheless, a recent in vitro stuáy showed SCE induction by trans-stilbene oxide to be inversely associated with GST- $\mu^{6}{ }^{6}$ which is in accordance with our findings.

DNA damage is considered crucial in carcinogenesis, ${ }^{13}$ and SCE are highly sensitive to the mutagenic activity of a great number of carcinogens. ${ }^{14}$ Numerous studies have shown that SCE in lymphocytes are increased in smokers as compared to non-smokers. ${ }^{1.13}$ Also, SCE levels were reported to be increased in lung cancer patients as compared with controls matched for smoking habits. ${ }^{15}$ These observations are suggestive, but there have not been any follow-up studies to provide direct evidence for a predictive value of SCE in the development of lung cancer. Moreover, the GST- $\mu$ assay in this study was performed in peripheral blood. GST- $\mu$ deficiency in peripheral blood cells is assumed to correspond with GST- $\mu$ deficiency in other tissues. For human liver tissue, this has indeed been shown, ${ }^{16}$ but similar data on lung tissue are lacking. Our results do, however, show a striking similarity with a study in lung cancer patients, ${ }^{4}$ which reported GST- $\mu$ deficiency (assessed in peripheral blood) to be associated with lung cancer in heavy smokers, but not in light smokers. This seeming relevance of GST $-\mu$ only at high exposures may be explained by other forms of GST isozymes. This may be exemplified by the fact that both $\mu$ and $\pi$ class isozymes are efficient at conjugating benzo[a]pyrene diol epoxide, whereas the $\alpha$ class transferase shows only weak activity. The $\mu$ and $\pi$ isozymes display comparable $K_{M}$ and $V_{\max }$ values with ( \pm )-anti-BDPE as substrate. "For the isozyme $\pi$ no deficiencies have been described and the organism is thus, even in the absence of the $\mu$ isozyme, able to detoxify the epoxide, but with a more limited capacity. ${ }^{17}$

We conclude that increased DNA damage in GST- $\mu$-deficient heavy smokers may be the aetiological explanation of the epidemiological association berween GST- $\mu$ phenotype and lung cancer. Clearly, GST- $\mu$ phenotype cannot explain all of the variation in cytogenetic damage and lung cancer risk among smokers. Interestingly, two genetically controlled phase I enzymes, aryl hydrocarbon hydroxylase (cytochrome P450lA1) and debrisoquine hydroxylase (cytochrome P450IID6), have also been reported to be correlated with susceptibility to lung cancer in smokers, though the results have not been unambiguous. ${ }^{18.19}$ The genetically determined balance between phase I and phase II enzymes may therefore be important with regard to susceptibility to lung cancer and deserves further study.

\section{References}

1. IARC. IARC Monograph on the evaluation of the carcinogenic risk of chemicals to humans, vol 38: Tobacco Smoking. WHO/International Agency for Research on Cancer, Lyon, 1986.

2. Mannervik B, Danielson UH. Glutathione-transferases - structure and catalytic activity. CRC Critical Reviews in Biochemistry 1988;23:283-337.

3. Seidegård J, Pero PW. The heriditary transmission of high glutathione transferase activity towards trans-stilbene oxide in human mononuclear leukocytes. Hum Genet 1985;69:66-68.

4. Seidegård J, Pero RW, Miller DG, Beattie EJ. A glutathione transferase in human leukocytes as a marker for the susceptibility to lung cancer. Carcinogenesis 1986;7:751-753.

5. Seidegård J, Pero RW, Markowitz MM, et al. Isoenzyme(s) of glutathione transferase (class $\mathrm{Mu}$ ) as a 
marker for the susceptibility to lung cancer; a follow up study. Carcinogenesis 1990;11:33-36.

6. Wienckc JK, Kelsey KT, Lamela RA, Toscano WA. Human glutathione-S-transferase deficiency as a marker of susceptibility to epoxide-induced cytogenetic damage. Cancer Res 1990;50:1585-1590.

7. Feyerabend C, Bryant A, Jarvis MJ, Russell MAH. Determination of cotinine in biological fluids of non-smokers by packed column gas-liquid chromatography. J Pharm Pharmacol 1984;38:1075-1078.

8. Perry PE, Thomson EJ. The methodology of sister chromatid exchanges. In: BJ Kilbey, M Legator, W Nichols. C Ramel (eds); Handbook of mutagenicity lest procedures. 2nd edition. Elseviers Sciences Publishers, Amsterdam, 1984.

9. Mulder GJ (ed). Conjugation Reactions in Drug Metabolism; an integrated approach. Taylor \& Francis. London, 1990.

10. Warholm M, Guthenberg C, Mannervik B. Molecular and catalytic properties of glutathione transferase $\mu$ from human liver; an enzyme efficiently conjugating epoxides. Biochemistry 1983:22:3610-3617.

11. Robertson IGC, Guthenberg C, Mannervik B, Jernström B. Differences in stereoselectivity and catalytic efficiency of three human glutathione transferases in the conjugation of glutathione with $7 \beta$.

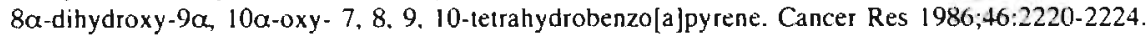

12. Marshall $\mathrm{CJ}$, Vousden $\mathrm{KH}$, Phillips $\mathrm{DH}$. Activation of $\mathrm{c}-\mathrm{Ha}$-ras-l proto-oncogene by in ritro modification with a chemical carcinogen, benzo[a|pyrene diol-epoxide. Nature 1984;310:586-589.

13. Weinstein IB. The origins of human cancer; molecular mechanisms of carcinogenesis and their implications for cancer prevention and treatment. Cancer Res 1988;48:4135-4143.

14. Wolff $S$. Sister chromatid exchange: the most sensitive mammalian system for determining the effect of mulagenic carcinogens. In: K. Berg (ed). Genetic damage in man caused by environmental agents. pp 229-246. New York, Academic Press, 1979.

15. Hopkin JM. Evans JH. Cigarette smoke-induced DNA damage and lung cancer risk. Nature [980;283:388-390.

16. Seidegård J. Vorachck WR. Pern RW. Pearson WR. Hereditary differences in the expression of the human glulathione transferase active on trans-stilbene oxide are due to a gene deletion. Proc Natl Acad Sci USA 1988:85:7293-7297.

17. Vos RME. Van Welic RTH. Peiters WHM. el al. Genetic deficiciency of human class mu glutathion S-transferase isocnzymes in relation to the urinary excretion of the mercapturic acids of $Z$ - and $E$ 1.3-dichloropropene. Arch Toxicol 1991:65:95-9).

18. Gelboin HV. Carcinogens. drugs, and cylochromes P-450. N Engl J Med 1983:3119:105-107.

19. Cough AC. Mikes JS, Spurr NK, et al. Identification of the primary gene defect at the eytochrome Ptso CYP2D locus. Niture 1\%90,347,773,776. 


\section{No influence of beta-carotene on smoking induced DNA damage as reflected by sister chromatid exchanges}

Geert van Poppel, Frans J. Kok, Paul Duijzings, Nico de Vogel

\section{Abstract}

The putative cancer preventive potential of $\beta$-carotene may be explained by its antioxidant capacity to prevent free radical-induced DNA damage. To evaluate this hypothesis, we studied the effect of 14-weeks of $\beta$-carotene supplementation on the frequency of sister chromatid exchanges (SCE) in lymphocytes in 143 heavy smokers in a randomized, double-blind, placebo-controlled intervention trial. Age, smoking habits and pre-treatment blood levels of cotinine, $\beta$-carotene, retinol, and vitamins $\mathrm{C}$ and $E$ were similar in the placebo group $(n=73)$ and the treatment group $(n=70)$. Plasma $\beta$-carotene levels increased 13-fold in the treatment group during intervention, whereas the other parameters remained stable in both groups. Initial SCE levels were similar in the treatment and placebo groups $(5.10 \pm 0.98$ vs. $5.00 \pm 0.99 \mathrm{SCE}$ per lymphocyte). During the intervention, both groups showed an almost identical decrease, and at the end of the intervention period there was no difference in SCE levels between the treatment and the placebo groups $(4.37 \pm 0.38$ vs. $4.24 \pm 0.37 \mathrm{SCE}$ per lymphocyte).

This study shows no protective effect of $\beta$-carotene on DNA damage as reflected by sister chromatid exchanges in lymphocytes. Our results thus do not yield support for a cancer preventive mechanism of $\beta$-carotene involving this form of DNA damage. It cannot be excluded, however, that $\beta$-carotene prevents other forms of smoking induced DNA damage, affects other tissues, or is preventive in later stages of carcinogenesis.

\section{Introduction}

The adverse effects of smoking on the development of lung cancer have been well documented.' However, a majority of smokers do not develop lung cancer. Smokers may be partially protected by components in the diet, and several studies suggest that $\beta$-carotene might reduce the risk of lung cancer. ${ }^{2}$

$\beta$-carotene, an antioxidant, is hypothesized to he effective through its ability to quench free radicals. ${ }^{3.4}$ Components of cigarette smoke may induce (in vivo) formation of free radicals which may damage DNA. ${ }^{5}$ DNA damage is regarded as a crucial step in chemical carcinogenesis." Increased cytogenetic damage in vive, as measured by sister 
chromatid exchanges (SCEs) in lymphocytes, may thus reflect increased cancer risk. Thus, SCE levels have been reported to be increased in smokers and in lung cancer patients. ${ }^{1.7}$

To test the hypothesis that $\beta$-carotene protects against smoking induced DNA damage, we performed a randomized double-blind placebo-controlled intervention trial. We evaluated the effect of $\beta$-carotene suppletion on DNA damage in smokers measured by the sister chromatide exchange measure.

\section{Subjects and methods}

\section{Study design}

Healthy male employees of the AMEV Insurance Company, the Taxation Office and the Power Company, all based at Utrecht were asked to volunteer for the intervention trial. All participants had smoked at least 15 cigarettes/day for over 2 years, did not use vitamin preparations containing retinol or carotenoids, or medications known to influence SCE levels. Moreover, they reported that they were not exposed to chemicals during working or leisure time. The volunteers were prestratified on age, duration and quantity of smoking and randomly assigned to either $\beta$-carotene $(20 \mathrm{mg}$ capsules, Hoffmann-La Roche, Mijdrecht, The Netherlands) or placebo treatment.

Blood samples were collected before and after the 14-weeks treatment. The participants were instructed to take capsules daily with dinner; 2 capsules/day during the first 2-weeks, followed by 1 capsule/day for the next 12-weeks. Every 4-weeks, the participants were sent their next strip of 28 capsules, and were asked to return the used strips with the remaining capsules to monitor compliance. In addition, $\beta$-carotene was determined in a blood sample taken after 7 -weeks of treatment.

Initially, 163 smokers volunteered to participate; 83 were assigned to the placebo treatment, 80 to the $\beta$-carotene treatment. During the trial, 13 smokers (6 placebo, $7 \beta$-carotene) terminated participation because of stopping smoking $(n=4)$, illness or accident $(n=3)$, private circumstances $(n=1)$, forgetting to take capsules $(n=2)$, or without giving a reason $(n=3)$. Of the 150 smokers who completed the trial, another 7 (4 placebo, $3 \beta$-carotene) dropped out because microscopic preparations were inadequate, leaving 143 subjects ( 73 placebo, $70 \beta$-carotene) for data analysis.

\section{Sister chromatid exchanges}

Blood cultures for determination of SCEs in lymphocytes ${ }^{8}$ were set up within 2 to 6 hours after venipuncture, after the blood had reached room temperature for 30 minutes. Heparinized whole blood $(0.5 \mathrm{ml})$ was added to $4.4 \mathrm{ml}$ prewarmed RPMI 1640 medium (Flow, Irvine, UK) containing $20 \% \mathrm{FCS}$ (inactivated for 30 minutes at $56^{\circ} \mathrm{C}$ ), $2.5 \%$ phytohaemagglutinin (HA-15 Welcome, Weesp, The Netherlands), $100 \mathrm{IU} / \mathrm{ml}$ penicillin, $100 \mu \mathrm{g} / \mathrm{ml}$ streptomycin and $2 \mathrm{mM}$ L-glutamine. 5-bromo, 2-deoxyuridine was added to a final concentration of $10 \mu \mathrm{g} / \mathrm{ml}$. The blood was cultured in the dark at $37^{\circ} \mathrm{C}$ in $\mathrm{T}-25$ culture flasks (Costar, Cambridge, MA) in $5 \% \mathrm{CO}_{z}$ for $68 \pm 1$ hour. Colcemid was added to a final 
concentration of $0.2 \mu \mathrm{g} / \mathrm{ml}$ for the last 2 hours of incubation. The cells were collected by centrifugation, treated with hypotonic $\mathrm{KCl}(0.075 \mathrm{M})$ for 8 minutes to spread the chromosomes and to heamolyse the $\mathrm{RBC}$, and fixed 3 times with methanol-acetic acid (3:1). After overnight storage in the dark at $4^{\circ} \mathrm{C}$, cells were transferred to microscopic slides and air-dried. Preparations aged for 3 days and were stained by the fluorescence plus Giemsa technique ${ }^{x}$ to obtain harlequin chromosomes. For each subject, SCEs in 50 seconddivision metaphases were scored as colour changes in the longitudinal direction of the chromatid, excluding the centromere. Only nuclei with 46 chromosomes were scored. Individual data are the mean counts of 50 metaphases.

\section{Blood parameters}

Directly after venipuncture, blood samples were stored in the dark at 0 to $4^{\circ} \mathrm{C}$. Lymphocyte counts were obtained in Na-EDTA blood samples, after 3 to 5 hours storage, with the use of an Sysmex K-1000 Haematology Analyzer (Toa, Tokyo, Japan). After 20 to 23 hours overnight dark storage at $4^{\circ} \mathrm{C}$, a separate evacuated tube was opened to determine the sum of ascorbic acid + dehydro-ascorbic acid (vitamin $\mathrm{C}$ ) in whole blood by HPLC with fluorometric detection." All-trans retinol, $\alpha$-tocopherol, retinol, $\beta$-carotene and total carotenoids were assayed in EDTA plasma (stored at $-80^{\circ} \mathrm{C}$ ) by HPLC with colorimetric detection. " Plasma cotinine levels were determined by gas chromatography."

\section{Data analysis}

Initial values for all variables and changes in these variables during the intervention period were compared between the $\beta$-carotene and placebo groups using the unpaired Student's t-test. Associations between variables were evaluated by univariate linear regression analysis: correlation coefficients are Pearson coefficients. Multiple regression analysis was used to correct for residual confounding in the comparison between the $\beta$-carotene and placebo groups. Data analysis was performed with the use of the BMDP statistical software package. ${ }^{12}$

\section{Results}

The placebo and $\beta$-carotene groups had comparable age $(39.1 \pm 10.1$ vs. $39.2 \pm 9.5$ years $)$ and smoking habits $(20.8 \pm 6.9$ vs. $21.4 \pm 5.8$ cigarettes/day). Table 1 shows that the placebo and $\beta$-carotene groups are comparable for all other characteristics and that, except for plasma $\beta$-carotene, only minor changes occurred during the intervention. In accordance with the stable cotinine levels, only one smoker (placebo group) reported having changed his smoking habits during the trial. His plasma cotinine levels, however, hardly changed (349 vs. $313 \mu \mathrm{mol} / /$ respectively). The mean body mass index was similar in the placebo group $\left(24.5 \pm 3.0 \mathrm{~kg} / \mathrm{m}^{2}\right)$ and the $\beta$-carotene group $\left(24.6 \pm 3.1 \mathrm{~kg} / \mathrm{m}^{2}\right)$, and all participants but one reported stable weights during the trial (one placebo participant: BMI from 24.9 to $22.2 \mathrm{~kg} / \mathrm{m}^{2}$ ). After 7-weeks, the mean plasma $\beta$-carotene level had increased 13 -fold to 
$4.44 \pm 2.12 \mu \mathrm{mol} / 1$ in the supplemented group $(0.28 \pm 0.18$ in the placebo group), and remained stable until the end of the trial (table 1). Plasma $\beta$-carotene levels increased in all supplemented subjects but one. For this subject, pill counts to evaluate compliance were not available. For all other supplemented volunteers, the minimum increase in plasma $\beta$-carotene after supplementation was 1.7 -fold (from 0.44 to $0.74 \mu \mathrm{mol} / \mathrm{l}$ ), and all but 5 supplemented subjects had after-treatment plasma levels above $1.0 \mu \mathrm{mol} / \mathrm{l}$. Twenty participants (19 $\beta$-carotene and, surprisingly, one placebo) reported having observed skin yellowing during the trial. Pill counts showed that $91 \%$ of all capsules were taken on average (data for 129 subjects); all but 10 participants took more than $75 \%$ of their capsules.

Table 1. Initial and final values (mean \pm s.d.) of blood parameters during a 14-weeks intervention trial in male smokers, assigned to either $\beta$-carotene or placebo treatment.

\begin{tabular}{|c|c|c|c|c|}
\hline & \multicolumn{2}{|c|}{ Placebo group $(n=73)$} & \multicolumn{2}{|c|}{$\beta$-carotene group $(n=70)$} \\
\hline & $\begin{array}{l}\text { initial } \\
\text { values }\end{array}$ & $\begin{array}{c}\text { final } \\
\text { values }\end{array}$ & $\begin{array}{l}\text { initial } \\
\text { values }\end{array}$ & $\begin{array}{l}\text { final } \\
\text { values }\end{array}$ \\
\hline Lymphocyte count $\left(10^{9} \mathrm{ce} / \mathrm{ls} / \mathrm{I}\right)^{1}$ & $2.29 \pm 0.63$ & $2.21 \pm 0.56$ & $2.24 \pm 0.58$ & $2.15 \pm 0.48$ \\
\hline Blood vitamin $\mathrm{C}(\mu \mathrm{mol} / \mathrm{l})^{2}$ & $35.2 \pm 17.6$ & $36.1 \pm 17.9$ & $37.3 \pm 17.2$ & $35.2 \pm 16.2$ \\
\hline Plasma retinol $(\mu \mathrm{mol} / \mathrm{l})$ & $2.31 \pm 0.60$ & $2.25 \pm 0.46$ & $2.33 \pm 0.48$ & $2.36 \pm 0.57$ \\
\hline Plasma $\alpha$-locophcrol $(\mu \mathrm{mol} / \mathrm{l})$ & $30.2 \pm 6.6$ & $31.7 \pm 6.8$ & $31.4 \pm 6.0$ & $31.8 \pm 6.1$ \\
\hline Plasma $\beta$-carotene $(\mu \mathrm{mol} / \mathrm{l})$ & $0.30 \pm 0.20$ & $0.28 \pm 0.19$ & $0.33 \pm 0.16$ & $4.36 \pm 2.32^{*}$ \\
\hline Plasma tolal carotenoids $(\mu \mathrm{mol} / \mathrm{l})$ & $1.57 \pm 0.57$ & $1.63 \pm 0.62$ & $1.59 \pm 0.62$ & $5.36 \pm 2.44^{*}$ \\
\hline Plasma cotinine $(\mu \mathrm{g} / \mathrm{l})$ & $318.7 \pm 126.4$ & $309.0 \pm 130.6$ & $335.6 \pm 106.9$ & $322.8 \pm 105.3$ \\
\hline
\end{tabular}

* $\beta$-carotene group significantly different from placebo group, $p<0.0001$.

- nine missing values. - 2 five missing values.

In the baseline measurement, significant correlations with SCE levels were observed for plasma cotinine $(R=0.19, p=0.02)$, cigarette consumption $(R=0.25, p=0.002)$ and age $(\dot{R}=0.15, p=0.06)$. No other baseline variables in table 1 showed associations with SCE levels ( $R<0.08, p>0.3$ for all of these). The changes in variables given in table 1 were not associated with changes in SCE levels during the intervention $(\mathrm{R}<0.07, \mathrm{p}>0.4$ for all variables). No association was detected between the individual SCE levels before and after the intervention trial ( $R=0.05, p=0.6)$, which indicates a very large personal variation during the trial.

At baseline, the SCE levels in the $\beta$-carotene group and the placebo group were similar (table 2). During the intervention, these levels showed an almost identical decrease in both groups, and the SCE levels after treatment were also similar in both groups. This comparison yielded the same results when supplemented subjects with after-treatment $\beta$-carotene levels below the median $(4.11 \mu \mathrm{mol} / \mathrm{l})$ were excluded (initial SCE count per lymphocyte $5.16 \pm 1.0$; final SCE level $4.38 \pm 0.4$ ). Adjustment for age, cotinine level, 
lymphocyte count, and blood level of vitamins $A, C$ and $E$ did not influence the comparability in SCE levels between both groups before or after the intervention.

Tabie 2. Frequency of sister chromatid exchanges (mean \pm s.d. per lymphocyte) and changes in these frequencies during a 14 -weeks intervention trial in male smokers, assigned 10 either $\beta$-carotene or placebo treatment.

\begin{tabular}{|c|c|c|}
\hline & $\begin{array}{l}\text { Placebo group } \\
\qquad(n=73)\end{array}$ & $\begin{array}{c}\beta \text {-carotene group } \\
\quad(\mathrm{n}=70)\end{array}$ \\
\hline SCEs before intervention & $5.00 \pm 0.99$ & $5.10 \pm 0.98$ \\
\hline SCES after intervention & $4.24 \pm 0.37$ & $4.37 \pm 0.38$ \\
\hline Change in SCEs (after-before) & $-0.76 \pm 1.04$ & $-0.74 \pm 1.02$ \\
\hline
\end{tabular}

\section{Discussion}

This trial in heavy smokers shows no effect of $\beta$-carotene supplementation on the level of sister chromatid exchanges in lymphocytes. This indicates that $\beta$-carotene does not influence the DNA lesions reflected by sister chromatid exchanges in circulating lymphocytes.

The lack of an effect of $\beta$-carotene in this study can hardly be altributed to methodological shortcomings, since randomization was successful, withdrawals werc limited, and compliance, reflected both by pill counts and by blood parameters, was very good. Moreover, the $\beta$-carotene and placebo groups were always equally represented on measurement days, to minimize bias from between-run variations. It also seems unlikely that the dose of $\beta$-carotene was too low as $20 \mathrm{mg} /$ day is equivalent to 5 to 10 times the normal intake, and plasma levels in the $\beta$-carotene group increased dramatically. Moreover, we observed no tendency towards a favourable effect, even after exclusion of supplemented subjects with plasma $\beta$-carotene values below the median after treatment. Based on our results, there is only $5 \%$ chance of a more than $0.1 \%$ lower SCE value after treatment in the $\beta$-carotene group, as compared with the placebo group. For comparisons: we observed $10 \%$ lower SCE levels in 66 non-smokers as compared with the smokers during the baseline study. ${ }^{13}$ The SCE levels observed are in accordance with some studies, whereas other studies report higher levels in smokers.' SCE levels observed in different studies, however, cannot readily be compared, as laboratory protocols are not standardized."

The absence of an effect of $\beta$-carotene also can not be explained by the treatment time being insufficient to influence persistent lesions. If the lesions giving rise to SCEs did indeed persist unrepaired, then SCE levels in people would remain fairly constant over time. In contrast, we observed a decline in SCEs both in the placebo and the $\beta$-carotene groups, as well as large personal variations. Information on temporal fluctuations in SCE 
levels is scarce, ${ }^{14}$ but the decline in SCE levels may be explained by seasonal variations. Although we expended much effort on standardizing laboratory protocols, inevitable shifts in culturing conditions (e.g., ageing of the frozen batch of FCS), may also have contributed to the observed decline. The somewhat unexpected decline does not, however, influence the interpretation of the effect of $\beta$-carotene, as the trial was fully placebo-controlled, and both groups were always equally represented in all culturing, staining and scoring runs. By analogy, the large personal variations cannot have influenced the interpretation of $\beta$-carotene effects at a group level in this randomized, placebo-controlled trial. As we were not able to standardize the time of blood sampling in this epidemiological study setting, circadian rhythms in SCE levels ${ }^{14}$ may explain the large personal variations. Here again, placebo and $\beta$-carotene participants were randomly divided over sampling times during each sampling day.

It is tempting to interpret the lack of effect of $\beta$-carotene in this study as evidence for the absence of a cancer preventive potential of this provitamin. However, caution is called for when interpreting our data. In mouse mammary cell culture, $\beta$-carotene has been shown to reduce SCEs induced by chemical carcinogens. ${ }^{\text {Is }}$ In vitro studies have shown that SCEs are sensitive to the mutagenic activity of a great number of carcinogens. ${ }^{16}$ The precise molecular mechanism for in vivo SCE induction by inhaled cigarette smoke, however, has never been elucidated. ${ }^{14}$ This in vivo induction may be primarily caused by pathways not involving free radicals or oxidation reactions. This possibility is supported by in vitro experiments on SCE induction by cigarette smoke." If so, this would explain the absence of an effect of $\beta$-carotene without precluding the protective potential in other DNA damaging pathways. Indeed, we recently reported evidence that hydrocarbon epoxides may be important in in vivo SCE induction by cigarette smoke, ${ }^{13}$ whereas such epoxides are not believed to be formed or to damage DNA through mechanisms involving free radicals. ${ }^{18,14,21)}$

Though SCEs have been consistently reported to be higher in smokers than in nonsmokers, ${ }^{2}$ and even have been found to be elevated in lung cancer patients, ${ }^{7}$ the predictive value of SCEs in lung cancer development remains to be demonstrated. SCEs clearly reflect potentially deleterious effects of cigarette smoke, but the relevance of this measurement in lymphocytes to biological effects in lung tissue remains uncertain. This site specificity may be especially important with regard to $\beta$-carotene, as the observational evidence for the protective effect of this compound is remarkably consistent for lung cancer, and far more equivocal for other sites. ${ }^{2}$ The site specificity may be explained if $\beta$-carotene is primarily effective in cells directly exposed to tobacco components. Indeed, Stich et al. ${ }^{21}$ have shown that $\beta$-carotene reduces cytogenetic damage (micronuclei) in oral mucosal cells in tobacco chewers.

Our data in human volunteers exposed to cigarette smoke do not correspond with laboratory studies which indicate a role for $\beta$-carotene in antimutagenesis and prevention of malignant transformation." However, there are also indications that $\beta$-carotene may affect later stages of carcinogenesis. ${ }^{22}$ Studies in humans using other, more specific, biomarkers 
of DNA damage may further elucidate the role of $\beta$-carotene in DNA damage and earlystage carcinogenesis. In this respect, recent developments in the measurement of DNA adducts at a molecular level $l^{2.3}$ may offer exciting opportunities for future epidemiological research.

We conclude that our results using the SCE measurements in lymphocytes do not yield support for the cancer preventive potential of $\beta$-carotene. Our study shows that supplementary $\beta$-carotene is not able to prevent all forms of smoking-induced DNA damage. It cannot be excluded however, that $\beta$-carotene prevents other forms of smoking induced DNA damage, affects other tissues, or is preventive in later stages of carcinogenesis.

\section{References}

1. IARC Working Group on the evaluation of carcinogenic risks to humans. IARC Monographs on the evaluation of the carcinogenic risk of chemicals to humans. Tobacco Smoking 1986;38, Lyon.

2. Willett WC. Vitamin A and lung cancer. Nutr Rev 1990;48:201-211.

3. Krinsky NI. Antioxidant functions of carotenoids. Free Radical Biol Med 1989;7:617-635.

4. Krinsky N1. Carotenoids as chemopreventive agents. Prev Med 1989; 18:592-602.

5. Halliwell B, Gutteridge JMC. Free radicals in biology and medicine. Clarendon Press, Oxford University Press, New York, 1985.

6. Iversen $\mathrm{OH}$. Theories of Carcinogenesis. Hemisphere Publishing Corporation, Washington, 1988.

7. Hopkin JM, Evans JH. Cigarette smoke-induced DNA damage and lung cancer risks. Nature 1980;283:388-390.

8. Perry PE, Thomson EJ. The methodology of sister chromatid exchanges. In: Kilbey BJ, Legator M. Nichois W, Ramel C (eds). Handbook of mutagenicity tesı procedures, 2nd edition. Elsevicrs Sciences Publishers, Amsterdam, 1984.

9. Speek AJ, Schrijver J, Schreurs WHP. Fluorimetric determination of total vitamin $C$ in whole blood by high performance liquid chromalography with pre-column derivatization. J Chromatogr 1984;305:53-60.

10. Van Vliet T, Van Schaik F, Van Schoonhoven J, Schrijver J. Determination of several relinoids, carotenoids, and E vitamers by HPLC. Application to plasma and tissues of rats fed a diet rich in either $\beta$-carotene or canthaxanthin. J Chromatogr 1991;553:179-186.

11. Feyerabend C, Bryant A, Jarvis MJ, Russell MAH. Determination of cotinine in biological fluids of non-smokers by packed column gas-liquid chromatography. J Pharm Pharmacol 1984;38:1075-1078.

12: Dixon WJ. (ed). BMDP Statistical Software Manual. University of California Press, Berkcley 1988.

13. Van Poppel G, De Vogel N, Van Bladeren PJ, Kok FJ. Increased cylogenetic damage in smokers deficient in gluthathione S-Iransferase isozyme $\mu$. Carcinogenesis 1992:13:303-305.

14. Das BC. Factors that influence formation of sister chromatid exchanges in human lymphocytes. CRC Critical Reviews in Toxicology, 1988; 19:Issue 1.

15. Manoharan K, Banerjee MR. $\beta$ carotene reduces sister chromatid exchanges induced by chemical carcinogens in mouse mammary cells in organ culture. Cell Biol Intern Rep 1985;9:783-789.

16. Wolff S. Sister chromatid exchange: the most sensitive mammalian system for determining the effect of mutagenic carcinogens. In: K. Berg (ed). Genetic damage in man caused by environmental agents. pp 229-246, New York, Academic Press 1979.

17. Lee CK, Brown BG, Rice WY, Doolittle DJ. Role of oxygen free radicals in the induction of sister chromatid exchanges by cigarctle smoke. Environ Molecul Mutagen 1989;13:54-59.

18. Gelboin HV. Benzo[a]pyrene metabolism, activation and carcinogenesis: Role and regulation of mixcd function oxidases and related enzymes. Physiol Rev 1980;60:1107-1166.

19. Hernandez O, Bend JR. Metabolism of epoxides. In: Mannervik B (ed). Metabolic basis of detoxication, Academic Press, New York 1982. 
20. Pryor WA. Cigarette smoke and the involvement of free radical reactions in chemical carcinogenesis. Br J Cancer 1987;55 suppl VIII:19-23.

21. Stich HF, Rosin MP, Hornby AP, Mathew B, Sankaranarayanan R, Nair MK. Remission of oral leukoplakias and micronuclei in tobacco/betel quid chewers treated with $\beta$-carotene and with B-carotene plus vitamin A. Int J Cancer 1988;42:195-199.

22. Prabhala RH, Garewal HS, Hicks MJ, et al. The effects of 13-cis-retinoic acid and $\beta$-carotene on cellular immunity in humans. Cancer 1991;67:1556-1560.

23. Bartsch H, Hemminki K, O'Neill IK (eds). Methods for detecting DNA damaging agents in humans: applications in cancer epidemiology and prevention. IARC Scientific Publication No. 89. International Agency for Research on Cancer, Lyon 1988. 


\section{Appendix to chapter 5: Analysis stratified for GST- $\mu$.}

In chapters 3 and 4 , an association between glutathione S-transferase phenotype and sister chromatid exchanges in lymphocytes was demonstrated. The table therefore shows the results for the SCE measure before and after $\beta$-carotene intervention in the GST- $\mu$ negative and GST- $\mu$ positive groups. In both groups, there is no effect of $\beta$-carotene on sister chromatid exchanges.

\begin{tabular}{cccc}
\multicolumn{2}{c}{ GST $-\mu$ negative } & \multicolumn{2}{c}{ GST- $\mu$ positive } \\
Placebo & $\beta$-carotene & Placebo & $\beta$-carotene \\
$\mathrm{n}=33$ & $\mathrm{n}=37$ & $\mathrm{n}=39$ & $\mathrm{n}=33$
\end{tabular}

$\begin{array}{lrrrr}\text { SCE's before intervention } & 5.08 \pm 0.92 & 5.32 \pm 0.98 & 4.96 \pm 1.04 & 4.86 \pm 0.95 \\ \text { SCE's after intervention } & 4.34 \pm 0.37 & 4.42 \pm 0.33 & 4.17 \pm 0.37 & 4.30 \pm 0.43 \\ \text { Changes in SCE's } & -0.74 \pm 1.00 & -0.90 \pm 1.05 & -0.80 \pm 1.09 & -0.55 \pm 0.98\end{array}$





\title{
Beta-carotene supplementation in smokers reduces the frequency of micronuclei in sputum
}

\author{
Geert van Poppel, Frans J. Kok, Ruud J.J. Hermus
}

\begin{abstract}
$\beta$-carotene has been hypothesised to reduce lung cancer risk. We studied the effect of 14-weeks of $\beta$-carotene supplementation $(20 \mathrm{mg} /$ day) on the frequency of micronuclei in sputum in 114 heavy smokers in a double-blind trial. Micronuclei reflect DNA damage in exfoliated cells and may thus provide a marker of early-stage carcinogenesis.

Pre-treatment blood levels of cotinine, $\beta$-carotene, retinol and vitamins $\mathrm{C}$ and $\mathrm{E}$ were similar in the placebo group $(n=61)$ and the treatment group $(n=53)$. Plasma $\beta$-carotene levels increased 13 -fold in the treatment group during intervention. Initial micronuclei counts (per 3000 cells) were higher in the treatment group than in the placebo group (5.0 vs. 4.0, p < 0.05). During intervention, the treatment group showed a $47 \%$ decrease, whereas the placebo group showed a non-significant decrease $(16 \%)$. After adjustment for the initial levels, the treatment group had $27 \%$ lower micronuclei counts than the placebo group at the end of the trial (95\% Cl: $9-41 \%$ ). These results indicate that $\beta$-carotene may reduce lung cancer risk in man by preventing DNA damage in early-stage carcinogenesis.
\end{abstract}

\section{Introduction}

The scientific interest in the role of carotenoids and retinoids in the prevention of human cancer has culminated in recent years. ${ }^{1.2}$ Especially for lung cancer, epidemiological studies have consistently shown inverse associations between plasma or dietary $\beta$-carotene and cancer incidence. ${ }^{3,5}$ Since these studies cannot prove causal associations. two large randomized trials are currently conducted to evaluate the beneficial effect of $\beta$-carotene on human cancer development. ${ }^{0.7}$ These intervention studies, however, provide little information on biological mechanisms.

Damage to DNA is considered a crucial mechanism in cancer development. ${ }^{.}$Micronuclei, DNA fragments in exfoliated cells, may thus provide a marker of early-stage carcinogenesis in target tissues. ${ }^{9.10}$ In cigarette smokers, elevated micronuclei counts in expectorated sputum ${ }^{11}$ or bronchial brushings ${ }^{9}$ are thought to reflect increased lung cancer risk. 
So far, no studies have investigated the effect of $\beta$-carotene supplementation on sputum micronuclei, as a reflection of lung cancer risk. $\beta$-carotene has been shown to reduce micronucleated buccal mucosal cells in tobacco chewers ${ }^{10.12 .13}$ and may thus reduce risk for oral cancer. These trials, however, did not measure plasma levels of $\beta$-carotene and retinol. Moreover, other antioxidant vitamins may modify the effects of $\beta$-carotene. ${ }^{2}$ We now report on a 14-weeks, double-blind, randomized placebo-controlled trial of the effect of $\beta$-carotene on sputum micronuclei in 114 heavy smokers. We measured plasma cotinine as a marker for tobacco exposure and monitored blood levels of $\beta$-carotene, retinol and the antioxidant vitamins $\mathrm{C}$ and $\mathrm{E}$.

\section{Subjects and methods}

\section{Study design}

Healthy male employees of the AMEV Insurance Company, the Taxation Office and the Power Company at Utrecht, Netherlands, were asked to volunteer for the intervention trial, which was approved by an External Review Board for experiments with human volunteers. All participants had smoked at least 15 cigarettes/day for over 2 years, did not use preparations containing retinol or carotenoids, and did not report exposure to chemicals during working or leisure time. The volunteers were prestratified by age, duration and quantity of smoking and randomly assigned to either $\beta$-carotene (20 mg capsules, F. Hoffmann-La Roche) or placebo treatment.

Blood and sputum samples were collected before and after the 14-weeks treatment. The participants were instructed to take capsules daily with the evening meal, 2 capsules/day during the first 2-weeks, followed by one capsule/day over the next 12-weeks. Every 4weeks, the participants were sent their next strip of 28 capsules, and were asked to return the used strips with the capsules not taken to monitor compliance. In addition, $\beta$-carotene was determined in a blood sample taken after 7 -weeks of treatment.

Initially, 163 smokers volunteered to participate; 83 were assigned to placebo treatment, 80 to $\beta$-carotene treatment. During the trial, a total of 13 smokers ( 6 placebo, $7 \beta$-carotene) discontinued participation because of stopping smoking $(n=4)$, illness or an accident $(n=3)$, personal circumstances $(n=1)$, forgetting to take capsules $(n=2)$, or without giving a reason $(n=3)$. Of the 150 smokers who completed the trial, 29 (13 placebo, 16 $\beta$-carotene) failed to produce sputum samples. In addition, insufficient cells could be evaluated in 7 subjects ( 3 placebo, $4 \beta$-carotene), leaving 114 subjects (61 placebo, 53 $\beta$-carotene) for data analysis.

\section{Micronuclei in sputum}

Sputum was collected and processed as described in detail by Saccomano et al. (1978). ${ }^{14}$ Each participant received a careful individual instruction on how to produce a specimen from 'deep in the lungs'. Sputum was collected at home on three consecutive mornings, directly after rising and after carefully rinsing the mouth. The three, or minimally two 
samples collected in preservative $(50 \mathrm{ml} 50 \%$ ethanol with $2 \%$ polyethylene glycol (Carbowax 1540, Merck)) were mixed, homogenized, centrifuged and smeared onto slides. The slides were stained with Feulgen and fast green, which is specific for DNA and strongly highlights micronuclei. ${ }^{15}$

For each subject, 3000 cells were examined and evaluated on the basis of the following criteria: shape and size typical of epithelial cells, a well defined nucleus and a clearly defined cytoplasm. The criteria in defining a micronucleus were: chromatin structure and colour intensity similar to those of the main nucleus; on focusing, the micronucleus must be on the same level as the nucleus, must be roundish and clearly included in the cytoplasm. The dimensions should be less than $1 / 5$ of that of the main nucleus, and it should not be connected to it. Slides were screened at $400 \mathrm{x}$ magnification and micro-nucleated cells were examined at $1000 \mathrm{x}$ magnification. Slides were read coded/blinded by a single observer. Repeated blinded scoring of 9 samples yielded a good correlation (Pearson $\mathrm{R}=0.86$ ), with 2 of the 9 samples showing a difference of more than 1 micronucleus upon rescoring.

\section{Blood paramelers}

Directly after venapuncture, non-fasting blood samples containing $\mathrm{NaEDTA}$ as anti-coagulant were stored overnight in the dark at $4^{\circ} \mathrm{C}$ for $20-23$ hours. Directly after opening the evacuated tubes, the sum of L-ascorbic acid + dehydro-L-ascorbic acid (vitamin C) was assessed in wholeblood by HPLC with fluorometric detection." All-trans retinol, $\alpha$-tocopherol, $\beta$-carotene and total carotenoids were assayed in plasma (stored at $-80^{\circ} \mathrm{C}$ ) by HPLC with colorimetric detection. ${ }^{7}$ Plasma cotinine levels were determined by gas chromatography. ${ }^{\text {* }}$

\section{Data analysis}

Initial baseline values and changes in these values during the intervention period were compared hetween the placebo group and the $\beta$-carotene group using the unpaired Student's t-test. Univariate log-linear Poisson regression was used to compare micronuclei counts between hoth groups, and to evaluate associalions between micronuclei counls and other parameters. Percentual changes in micronuclei counts during the intervention trial were quantified by analyzing the final/initial micronuclei counts ratio in binomial regression. Multiple Poisson regression was used to quantify the difference in micronuclei between the placebo and B-carotenc group after correction for incomplele randomization. All data analysis were performed using the BMDP and GI:NSTAT packages. 14,21

\section{Results}

Table I shows that the placeho and $\beta$-carotene groups are comparable for all characteristics and that, except for plasma $\beta$-carotence, only minor changes occurred during the intervention trial. In accordanec with the stable cotinine levels. only one smoker (placelo) 
group) reported to have changed his smoking habits during the trial. His plasma cotinine levels, however, hardly changed ( 349 and $313 \mathrm{nmol} / \mathrm{ml}$ respectively). The mean body mass index (BMI) was similar in the placebo group $\left(24.3 \pm 3.0 \mathrm{~kg} / \mathrm{m}^{2}\right)$ and the $\beta$-carotene group $\left(24.7 \pm 3.3 \mathrm{~kg} / \mathrm{m}^{2}\right)$, and all participants but one reported stable weights during the trial (in one placebo participant BMI decreased from 24.9 to $22.2 \mathrm{~kg} / \mathrm{m}^{2}$ ). Reported alcohol consumption was also similar in the placebo $(13.4 \mathrm{~g} /$ day) and the $\beta$-carotene

Table 1. Baseline characleristics (mean $\pm \mathrm{SD}$ ) and changes in these characteristics during a 14-weeks intervention trial in male smokers, assigned to either $\beta$-carotene or placebo treatment.

\begin{tabular}{|c|c|c|c|c|}
\hline & \multicolumn{2}{|c|}{ Placebo group $(n=61)$} & \multicolumn{2}{|c|}{$\beta$-carotene group $(n=53)$} \\
\hline & $\begin{array}{l}\text { baseline } \\
\text { values }\end{array}$ & $\begin{array}{c}\text { change } \\
\text { (after-before) }\end{array}$ & $\begin{array}{l}\text { baseline } \\
\text { values }\end{array}$ & $\begin{array}{c}\text { change } \\
\text { (after-before) }\end{array}$ \\
\hline Age (yrs) & $40.0 \pm 10.1$ & n.a & $40.2 \pm 9.1$ & n.a \\
\hline Number of cigarettes/day & $20.8 \pm 6.7$ & n.a & $21.7 \pm 6.4$ & n.a \\
\hline Years of smoking & $21.9 \pm 10.5$ & ก.a & $22.0 \pm 9.1$ & n.a \\
\hline Blood vitamin C ( $\mu \mathrm{mol} / \mathrm{l})$ & $37.6 \pm 18.8$ & $-0.4 \pm 16.7$ & $38.2 \pm 17.2$ & $-1.1 \pm 16.0$ \\
\hline Plasma retinol $(\mu \mathrm{mol} / \mathrm{l})$ & $2.33 \pm 0.60$ & $-0.06 \pm 0.42$ & $2.38 \pm 0.55$ & $-0.01 \pm 0.41$ \\
\hline Plasma $\alpha$-tocopherol ( $\mu \mathrm{mol} / \mathrm{l})$ & $30.5 \pm 7.1$ & $1.4 \pm 4.3$ & $31.2 \pm 7.0$ & $0.5 \pm 3.2$ \\
\hline Plasma $\beta$-carolene $(\mu \mathrm{mol} / \mathrm{l})$ & $0.28 \pm 0.18$ & $-0.02 \pm 0.13$ & $0.32 \pm 0.16$ & $3.79 \pm 2.02^{*}$ \\
\hline Plasma tolal carolenoids $(\mu \mathrm{mol} / \mathrm{l})$ & $1.56 \pm 0.59$ & $0.09 \pm 0.43$ & $1.49 \pm 0.58$ & $3.66 \pm 1.93^{*}$ \\
\hline Plasma cotinine (ng/ml) & $323.1 \pm 122.6$ & $-8.4 \pm 72.8$ & $332.8 \pm 109.6$ & $-8.0 \pm 74.1$ \\
\hline
\end{tabular}

* $\beta$-carotene group significantly different from the placebo group. $p<0.0001$

n.a. $=$ not applicable.

group (12.6 g/day). After 7-weeks, mean plasma $\beta$-carotene had increased 13 -fold to $4.13 \pm 1.79 \mu \mathrm{mol} / /$ in the supplemented group $(0.26 \pm 0.15 \mu \mathrm{mol} / \mathrm{l}$ in the placebo group), and remained stable up to the end of the trial. The minimum increase in plasma $\beta$-carotene after supplementation was 1.7 -fold $(0.44 \rightarrow 0.74 \mu \mathrm{mol} / \mathrm{l})$, and all but 4 supplemented subjects had after treatment plasma levels above $1.0 \mu \mathrm{mol} / \mathrm{l}$. Thirteen participants (12 $\beta$-carotene and, surprisingly, one placebo) reported to have observed skin yellowing during the trial, whereas one of the investigators, unaware of intervention status, noted 19 cases of skin yellowing (all $\beta$-carotene subjects). Pill counts showed that $92 \%$ of all capsules were taken (data for 103 subjects); all but 4 participants took more than $75 \%$ of their capsules. At baseline, the micronuclei counts were significantly higher in the $\beta$-carotene group than in the placebo group (figure 1 and table 2). After the intervention, however, the micronuclei counts were significantly lower in the $\beta$-carotene group (table 2 ). The $\beta$-carotene group thus showed a strong decrease in micronuclei counts, whereas the placebo group showed a minor, non-significant decrease (figure 2 and table 2). In the treatment group the decrease in micronuclei was similar $(47 \%)$ in subjects with final $\beta$-carotene levels above and below the median of $4.1 \mu \mathrm{mol} / \mathrm{l}$. To obtain an unbiased estimate of the intervention effect, we calculated the difference between the placebo group and the $\beta$-carotene groups after 
intervention, allowing for the differences that existed between both groups before the intervention. After adjustment for initial micronuclei counts, the final micronuclei counts were estimated to be $27 \%$ lower in the $\beta$-carotene group than in the placebo group (95\% $\mathrm{Cl}: 9 \%-41 \%$ ). Adjustment for the baseline characteristics given in table 1 did not alter this estimate, since no associations were detected between micronuclei counts at baseline and any of the baseline characteristics listed in table 1, or alcohol consumption (All Pearson $\mathrm{R}<0.14$ ).

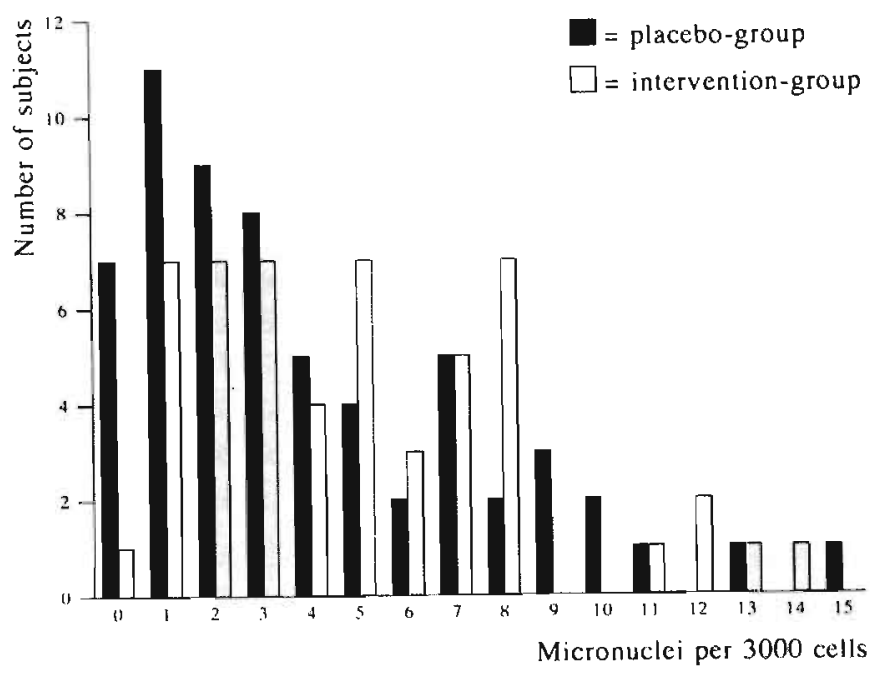

Figure 1. Distribution of micronuclei counts at baseline.

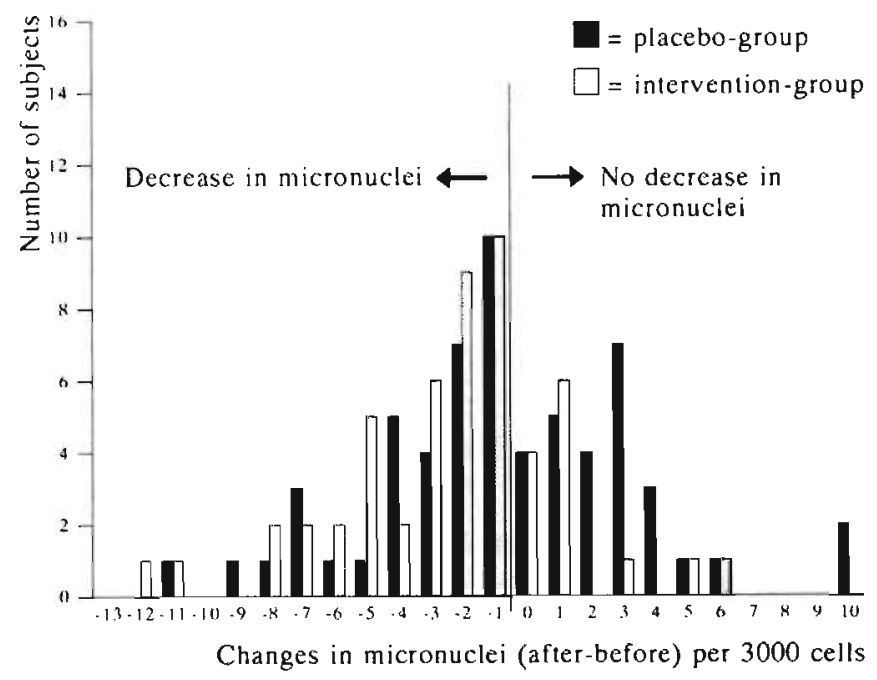

Figure 2. Changes in micronuclei counts. 
Tablc 2. Micronuclei counts (mean per 3000 cells \pm SD) and changes in micronuclei counts during a 14-weeks intervention trial in male smokers, assigned to either $\beta$-carotene or placebo treatment.

\begin{tabular}{lcc}
\hline & Placebo group $(\mathrm{n}=61)$ & $\beta$-carotene group $(\mathrm{n}=53)$ \\
\hline Micronuclei at baseline* $^{*}$ & $4.0 \pm 3.5$ & $5.0 \pm 3.4$ \\
Micronuclei after 14-weeks treatment* & $3.4 \pm 3.3$ & $2.6 \pm 2.8$ \\
Change in micronuclei (after-before) & $-0.6 \pm 4.0$ & $-2.3 \pm 3.4$ \\
$\%$ Change in micronuclei & -16 & -47 \\
$(95 \%$ confidence interval) & $(-31 \%-+1 \%)$ & $(-57 \%--35 \%$ \\
\hline
\end{tabular}

* $\beta$-carotene group significantly different from placebo group; $p<0.05$.

The micronuclei counts before and after the trial were clearly associated ( $p<0.001$ ), but we observed only a modest correlation in both the placebo group (Pearson $R=0.29$ ) and the $\beta$-carotene group (Pearson $R=0.40$ ). The micronuclei counts thus show a large within-person variation (see also figure 2 ).

\section{Discussion}

This trial in heavy smokers shows a reduction in frequency of micronucleated sputum cells after supplementation with $\beta$-carotene, suggesting that the inverse epidemiological association between $\beta$-carotene and lung cancer ${ }^{3.5}$ is indeed due to $\beta$-carotene, and not to associated food or life-style factors. These results thus support a protective role for $\beta$-carotene in the development of human cancer, as proposed by Peto et al. (1984). ${ }^{21}$ Moreover, the results indicate that $\beta$-carotene is protective in man by preventing DNA damage in target tissues, thus providing a plausible mechanism of action.

The approximately $30 \%$ reduction in micronuclei after $\beta$-carotene treatment is in accordance with the effect of $\beta$-carotene reported in buccal mucosa of betel nut chewers ${ }^{10}$ and tobacco chewers. ${ }^{12.13}$ Our findings extend these observations to cigarette smoke-induced tracheobronchial micronuclei, which may reflect lung cancer risk. ${ }^{22.23}$ Moreover, as plasma retinol levels were not changed, this study shows that the provitamin $\beta$-carotene does not exert its action after intestinal or hepatic conversion to retinol. It thus seems that $\beta$-carotene per se is effective at the cellular level. The protective action of $\beta$-carotene may be explained by its antioxidant capacity to quench highly reactive singlet oxygen and free radical species. ${ }^{24}$ Free radicals are abundant in cigarette smoke and $\operatorname{tar}^{25}$ and are believed to initiate cancer by damaging DNA. ${ }^{26}$ In addition, $\beta$-carotene has been hypothesized to be effective after conversion to retinol at a tissue or cellular level. ${ }^{27} \beta$-carotene could thus rapidly compensate for local deficiencies in retinol, which may be induced by carcinogens. ${ }^{2 k}$

Micronuclei in exfoliated epithelial cells reflect the extent of chromosome breakage due to carcinogenic exposure, when the cells were dividing a few days or weeks earlier, in the 
basal layer of the epithelium of the tracheobronchial tree. ${ }^{22}$ As DNA damage is considered crucial in carcinogenesis, ${ }^{8}$ the frequency of micronuclei may thus reflect cancer risk. In several experimental models, including the rat bronchial carcinoma model, ${ }^{22,23}$ high frequencies of micronuclei are observed after carcinogen exposure. In man, numbers of micronuclei in buccal mucosa cells have been found to increase after exposure to tobacco and alcohol, ${ }^{29}$ betel quid ${ }^{30}$ and $X$-radiation; $;^{31}$ all these exposures are known causes of oral cancer. Similarly, smokers have elevated frequencies of micronucleated cells in expectorated sputum ${ }^{\varsigma}$ and bronchial brushings. ${ }^{9}$ These observations strongly suggest that micronuclei indeed reflect early or intermediate stages of the carcinogenic process. Follow-up studies on the predictive value of micronuclei for cancer development, however, have not been published.

Surprisingly, our data show higher initial micronuclei counts in the $\beta$-carotene group, indicating unsuccessful randomization. The number of inevaluable volunteers, as well as the reasons for inevaluability were similar in the placebo and the $\beta$-carotene groups, and can therefore not explain this difference. During the trial, the $\beta$-carotene and placebo groups were equally represented in all staining and scoring runs, so that any systematic difference in staining or scoring procedures between the two groups seems improbable. Moreover, all slides were coded, and scored by a single technician, and all other baseline characteristics measured (table 1) were comparable between the two groups. Regression to the mean may have influenced the observed reduction in the $\beta$-carotene group, but cannot have influenced after-treatment micronuclei counts. Despite the higher initial count, the after treatment counts were significantly lower in the $\beta$-carotene group, even without adjustment for initial counts.

In the treatment group, we did not observe a dose-response relationship between plasma $\beta$-carotene and reduction in micronuclei count. However, we evaluated the effect of only one high dose of $\beta$-carotene, and almost all subjects showed dramatic increases in plasma levels. Furthermore, the limited number of subjects, the low frequency of micronuclei, as well as the considerable within-person variation in micronuclei counts make it difficult to evaluate a dose-response relationship. The low frequency of micronuclei in this study may be partly due to our stringent scoring criteria, aimed at identifying micronuclei reproducibly and with a high certainty. The large within-person variability may be explained by an inherent variability in sampling site, as expectorated cells may originate from all sites in the tracheobronchial tree. This large random sampling variation implies that the statistical power of studies using sputum is only sufficient to demonstrate large effects in study groups of considerable size. For future studies, repeated sampling and scoring can be used to diminish within-person variation. In addition, a run-in period prior to treatment could be used to assess eligibility with respect to sputum production and to stratify the treatment groups on micronuclei counts. Alternatively, studies using bronchial brushings, though more invasive, have the merit of being site-specific and may prove more useful to evaluate smaller effects, such as dose responses. Such studies may also be used to evaluate variations in counts between different sites. In addition, cellular levels of 
$\beta$-carotene could be studied in future studies, since plasma $\beta$-carotene levels may not wholly reflect tissue levels of $\beta$-carotene in the tracheobronchial tree.

Our data suggest that $\beta$-carotene is effective by preventing DNA damage and may thus affect early or intermediate stages of carcinogenesis. This is in line with laboratory studies that indicate a role for $\beta$-carotene in antimutagenesis and prevention of malignant transformation. ${ }^{24}$ However, there are also indications that $\beta$-carotene may affect later stages of carcinogenesis. ${ }^{32}$ The recently reported lack of effect of $\beta$-carotene in trials on cervical dysplasia $^{33}$ and second skin cancers ${ }^{34}$ may, apart from site specificity, be explained if $\beta$-carotene is primarily effective in earlier stages of carcinogenesis. To address this question, the ongoing intervention studies in cancer incidence will need a long follow-up. Indeed. the $\beta$-carotene trial in the Physicians Health Study has recently been extended to cover more than 10 years follow-up. ${ }^{35}$

This study yields evidence that the observed inverse association between $\beta$-carotene and lung cancer is due to $\beta$-carotene per se. Though the predictive value of micronuclei for cancer risk remains to be shown definitively, our results suggest that $\beta$-carotene may indeed reduce human cancer risk. It is clear that the health benefits of stopping smoking will far outweigh those of dietary changes. ${ }^{4}$ These results should therefore not be explained as a way to prevent lung cancer in people who continue to smoke.

\section{References}

1. Editorial. A carrot a day keeps cancer at bay? Lancet 1991:337:81-82.

2. Meyskens Fi.. Coming of age - the chemoprevention of cancer, N Engl J Med 1990;323:825-827.

3. Willctt WC. Macmahon B. Diet and cancer - an overview. N Engl J Med 1984;310:633-638.

4. Colditz GA, Stampfer MJ. Willett WC. Diet and luıg cancer -a review of the epidemiological evidence in humans. Arch Intern Med 1987;147:157-160.

5. Fontham ET. Protective dietary factors and lung cancer. Int J Epidemiol 1990;19 (supp| 1):S32-S42.

6. Hennekens $\mathrm{CH}$. Ebcrlein K. A randomized trial of aspirin and $\beta$-carotene among US physicians. Prev Med 1985:14:165-168.

7. Albanes D, Virtamo J, Rautalahti M, Pikkarainen J, Taylor PR. Greenwald P, Heinomen OP. Pilot study: The US-Finland lung cancer prevention trial. J Nutr Growth Cancer 1986;3:207-214.

8. Weinstein IB. The origins of human cancer: molecular mechanisms of carcinogenesis and their implications for cancer prevention and treatment. Cancer Res 1988:48:4135-4143.

9. Lippman SM, Peters EJ, Wargovich MJ, et al. Bronchial micronuclei as a marker of an early stage of carcinogenesis in the human tracheobronchial epithelium. Int J Cancer 1990;45:811-815.

10. Stich HF, Rosin MP, Vallejera MO. Reduction with vitamin $A$ and $\beta$-carotene administration of proportion of micronucleated buccal mucosal cells in Asian betel nut and tobacco chewers. Lancet $1984 ; \mathrm{i}: 1204-1206$.

11. Fontham ET, Correa P, Rodriguez E, Lin Y. Validation of smoking history with the micronuclei test. In: Hoffmann D, Harris CC (eds): Mechanisms in Tobacco Carcinogenesis, Banbury Report 23 , 1 13-118, Cold Spring Harbor Laboratory, New York, 1986.

12. Stich HF, Hornby P. Dunn BC. A pilot $\beta$-carotene intervention trial with lnuits using smokeless tobacco. Int J Cancer 1985;36:321-327.

13. Stich HF, Rosin MP, Hornby AP, et al. Remission of oral leukoplakias and micronuclei in tobacco/betel quid chewers treated with $\beta$-carotene and with $\beta$-carotene plus vitamin $A$. Int J Cancer 1988;42:195-199.

14. Saccomanno G. Diagnistic pulmonary cytology. ISBN 0-89189-050-5. American Society of Clinical Pathologists, Chicago, 1978. 
15. Bruck HC. Histologische Technik. Leitfaden für die Herstellung mikroskopischer Präparate in Unterricht und Praxis. ISBN 3-13314304-2. Georg Thieme Verlag, Stuttgart, New York, 1981.

16. Speek AJ, Schrijver J, Schreurs WHP. Fluorimetric determination of total vitamin C in whole blood by high performance liquid chromatography with pre-column derivatization. J Chromatogr 1984:305:53-60.

17. Van Vliet T, Van Schaik F. Van Schoonhoven J, Schrijver J. Determination of several retinoids, carotenoids, and E vitamers by HPLC. Application to plasma and lissues of rats fed a diet rich in either $\beta$-carotene or canthaxanthin. J Chromatogr 1991;553:179-186.

18. Feyerabend C. Bryant A, Jarvis MJ, Russcll MAH. Determination of cotinine in biological thuids of non-smokers by packed column gas-liquid chromatography. J Pharm Pharmacol 1984:38:1075-1078.

19. Dixon WJ (ed). BMDP Statistical Software Manual. University of California Press, Berkeley, 1988.

20. GENSTAT 5 Committee GENSTAT 5 Reference Manual. Oxford University Press, Oxford, 1987.

21. Peto R, Dolt R, Buckley JD, Sporn MB. Can dietary $\beta$-carotene materially reduce human cancer rates? Nature 1981:290:201-208.

22. Stich HF, Rosin MP. Micronuclei in exfoliated human cells as a tool for studies in cancer risk and cancer intervention. Cancer Lett 1984;22:241-253.

23. Lippman SM, Peters EJ, Wargovich MJ, el al. The evaluation of micronuclei as an intermediate endpoint of bronchial carcinogenesis. Advances in Cancer Control: Screening and Prevention Research, pp. 165-177. Wiley-Liss, New York, 1990.

24. Krinsky NI. Carotenoids as chemopreventive agents. Prev Med 1989;18:592-602.

25. Pryor WA. Hales BJ, Premovic PI, Church DF. The radicals in cigarette tar: their nature and suggested physiological complications. Science 1983;220:425-427.

26. Pryor WA. Cigarelte smoke and the involvement of free radical reactions in chemical carcinogenesis. Br J Cancer 1987;55 suppl VIII:19-23.

27. De Vet HCW. The puzzling sole of vitamin A in cancer prevention (review). Anticancer Res 1989:9:145-152.

28. Edes TE. Gysbers DG, Buckley CS. Thornton WH. Exposure to the carcinogen benzopyrene depletes tissue vitamin A: $\beta$-carotene prevents depletion. Nutr Cancer 1991:15:159-166

29. Stich HF, Rusin MP. Quantitating the synergistic effect of smoking and alcohol consumption with the micronucleus test on human buccal mucosal cells. Int J Cancer 1983;31:305-308.

30. Stich HF. Stich W. Parida BB. Elevated frequency of micronucleated cells in the buccal mucosa of individuals at high risk for oral cancer: betel quid chewers. Cancer Lelt 1982;17:125-134.

31. Stich HF. San RHC: Rosin MP. Adaptation of the DNA-rcpair and micronuclcus test on human cell suspensions and exfoliated cells. Ann NY Acad Sci 1983:407:93-105.

32. Prabhala RH, Garewal HS, Hicks MJ, Samplincr RE, Watson RR. The effects of 13-cis-retinoic acid and $\beta$-carotene on cellular immunity in humans. Cancer 1991:67:1556-1560.

33. De Vet HCW. Knipschild PG. Willebrand D, et al. The effect of $\beta$-carotene on the regression and progression of cervical Jysplasia: a clinical experiment. J Clin Epidemiol 1991:44:273-283.

34. Greenberg ER. Baron JA, Stukel TA, et al. A clinical irial of $\beta$-carotenc to prevent basal-cell and squamous-cell cancers of the skin. N Engl J Med 1900:323:789-795.

35. Manson JE. Hunter DJ, Buring JE. Hennekens CH. B-carotene to prevent skin cancer. N Engl J Med $1991: 324: 924$ 


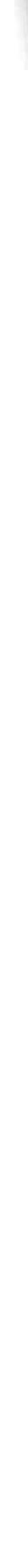




\title{
Effect of beta-carotene on immunological indices in healthy male smokers
}

Geert van Poppel, Steven Spanhaak, Theodore Ockhuizen

\begin{abstract}
To evaluate the immunomodulatory effects of $\beta$-carotene we performed a randomized, double-blind trial in healthy male cigarette smokers. Lymphocyte subsets in peripheral blood were assessed by using double labeling with monoclonal antibodies before and after 14-weeks $\beta$-carotene $(20 \mathrm{mg} /$ day; $n=21)$ or placebo $(n=24)$ supplements. In addition we measured the $e x$ vivo phytohemagglutinin and concavalin $A$ induced lymphocyte proliferation in a separate group (23 placebo, $24 \beta$-carotene). The $\beta$-carotene and placebo groups were comparable on all initial characteristics. During the intervention plasma concentrations of $\beta$-carotene increased 13 -fold in the treatment groups whereas retinol concentrations remained constant. $\beta$-carotene had no effect on lymphocyte subpopulations in peripheral blood. After treatment the $\beta$-carotene group showed $12 \%$ higher PHA-induced lymphocyte proliferations than the placebo group $(p=0.02)$. For ConA induced proliferations no significant difference was observed. These results suggest that supplementary $\beta$-carotene can moderately enhance certain aspects of immune response in healthy male cigarette smokers.
\end{abstract}

\section{Introduction}

Within the past few years there has been an increasing interest in the potential of $\beta$-carotene to provide protection against human cancers. ${ }^{1.2}$ Epidemiological studies have reported inverse relationships between plasma or dietary $\beta$-carotene and the incidence of cancer at several sites, especially the lung. ${ }^{3,4}$ The putative cancer preventing potential of $\beta$-carotene may be explained by its antioxidant capacity to quench free radicals, thus preventing DNA damage and neoplastic transformation. ${ }^{5}$ In addition, immunomodulatory effects of $\beta$-carotene have been proposed as a mechanism for tumor prevention and several animal as well as human studies have shown immunomodulatory effects of $\beta$-carotene."

Immunological studies in humans on the effect of $\beta$-carotene so far have focused on assessment of lymphocyte subsets in peripheral blood and these studies have yielded inconsistent results. Smaller studies in elderly subjects ${ }^{7}$ and in patients with premalignant lesions ${ }^{8}$ have demonstrated positive effects of $\beta$-carotene supplementation, whereas a larger 
study in healthy volunteers ${ }^{9}$ failed to demonstrate any effect. Possibly, effects of $\beta$-carotene are only found in subjects with suboptimal immune or $\beta$-carotene status. Moreover, these studies are difficult to interpret as alterations in lymphocyte subsets may only have limited implications for the effectiveness of the immune response in vivo.

For further elucidation of the involvement of $\beta$-carotene in human immune function, measurements of functional indexes of immune response may be more informative than quantitation of lymphocyte subsets. In addition, studies in humans with low $\beta$-carotene status seem warranted. Cigarette smokers are known to have a marginal $\beta$-carotene status, ${ }^{10}$ and the epidemiological evidence for a cancer preventive potential of $\beta$-carotene is especially consistent for smoking-induced lung cancer. ${ }^{3.4}$ We therefore performed a randomized, double-blind, placebo-controlled trial in healthy male smokers. In addition to quantitation of lymphocyte subsets, we assessed the influence of $\beta$-carotene supplementation on mitogen-induced lymphocyte proliferative response.

\section{Subjects and methods}

\section{Study design}

For this study, immunological indexes were assessed in two separate subgroups of subjects who participated in an intervention trial on $\beta$-carotene and biomarkers for cancer risk." Healthy male employees of the AMEV Insurance Company, the Taxation Office, and the Power Company at Utrerht, the Netherlands were asked to volunteer for the intervention trial, which was approved by an External Review Board for experiments with human volunteers. All participants (total $n=163$ ) had smoked $\geq 15$ cigarettes $/$ day for $>2$ years, did not use preparations containing retinol or carotenoids, and did not report exposure to xenobiotic chemicals during working or leisure time. The volunteers were prestratified by age, duration, and quantity of smoking and randomly assigned to either $\beta$-carotene (20 mg capsules, Hoffmann - La Roche Lid, Basel, Switzerland) or placebo treatment.

Blood samples were collected before and after the 14-weeks treatment. The participants were instructed to take capsules daily with the evening meal: 2 capsules per day during the first 2-weeks, followed by I capsule/day for the next 12-weeks. Every 4 weeks, the participants were sent their next packet of 28 capsules and were asked to return the used strips with the remaining capsules to monitor compliance. In addition, $\beta$-carotene was determined in a blood sample taken after 7-weeks treatment.

Lymphocyte subsets were initially assessed in a subset of 52 participants (26 placebo, $26 \beta$-carotene). Of these 52 participants, 5 subjects ( 2 placebo, $3 \beta$-carotene) withdrew during the trial. One $\beta$-carotene participant was omitted from the data analysis because his plasma $\beta$-carotene concentrations did not increase. For this subject, pill counts to evaluate compliance were not available. In addition, one $\beta$-carotene participant was unable to donate blood on the scheduled final day, leaving 45 subjects (24 placebo, $21 \beta$-carotene) for analysis of lymphocyte-subset data. To minimize influences of between-run variations, placebo and $\beta$-carotene subjects for the lymphocyte subset study were equally divided over 
four initial and six final measurement days.

Lymphocyte stimulation tests were initially performed in a subsct of 51 participants (25 placebo, $26 \beta$-carotene). Of these 51 participants, one placebo and one $\beta$-carotene subject withdrew during the trial. In addition, one placebo and one $\beta$-carotene participant were not able to donate blood on the scheduled final day, leaving 47 subjects ( 23 placebo, $24 \beta$-carotene) for analysis of the lymphocyte proliferation data. For the lymphocyte proliferation study, placebo and $\beta$-carotene subjects were equally divided over six initial and five final measurement days.

\section{Lymphocyte subsets}

Quantitation of lymphocyte subsets was performed by double labeling in whole blood with potassium EDTA as an anticoagulant. Within 3 hours after venipuncture, $100 \mu \mathrm{l}$ blood was incubated for $15 \mathrm{~min}$ in the dark at room temperature with one of the following combinations of monoclonal antibodies. Red blood cells were lysed by addition of $2 \mathrm{ml}$ FACSlysing solution (Beckton Dickinson, San Jose, CA) and subsequent incubation in the dark during $10 \mathrm{~min}$ at room temperature. After centrifugation $(5 \mathrm{~min}, 400 \mathrm{x} \mathrm{g}$ ) the cell pellet was washed with $3 \mathrm{ml}$ of phosphate-buffered saline. The cells were then immediately fixed in $0.5 \mathrm{ml} 0.5 \%$ paraformaldehyde solution and stored at $4^{\circ} \mathrm{C}$ until flowcytometric analysis on the following day. The samples were measured on a FACStar plus (Beckton Dickinson). The following combinations of monoclonal antibodies were used: CD4(leu-3a) fluorescein isothiocyanate (FITC) conjugated/CD8(leu-2a) phytocrythin (PE) conjugated, for the detection of $\mathrm{T}$ helper/inducer (CD4+/CD8-) and $\mathrm{T}$ suppressor/ cytotoxic (CD8+/CD4-) cells. CD3(leu-4)FITC conjugated/human leukocyte antigen (HLA)-DR PE conjugated, for the detection of mature T cells (CD3+/HLA-DR-) and activated T cells (CD3+/HLA-DR+). CD3(leu-4)FITC conjugated/CD16(leu-11c) and CD56(leu-19) PE conjugated, for the detection of non-major histocompatibility complex (MHC) restricted cytotoxic $\mathrm{T}$ cells (CD3+/CD16 and 56+) and natural killer (NK) cells (CD3-/CD16 \& 56+). CD45RA(leu-18) FITC conjugated/CD4(leu-3a) PE conjugated, for the detection of $T$ naive (CD4+/CD45RAt) and T memory (CD4+/CD45RA-) cells. CD2(leu-5b) FITC conjugated/CD19(leu-12) PE conjugated, for the detection of $T$ (CD2+/CD19-)) and $B$ (CD2-/CD19+) cells. All monoclonal antibodies were purchased from Beckton Dickinson.

\section{Lymphocyte stimulation tests}

Within 3 hours after venipuncture, mononuclear cells (MNC) were separated from heparinized whole blood by means of a Ficoll-Paque (Pharmacia, Uppsala, Sweden) density gradient. ${ }^{12}$ A volume of $200-\mu \mathrm{l}$ was placed in a flat-bottom microtiter well (Nunc, Roskild, Denmark) containing $10^{5} \mathrm{MNC}$ and mitogen in RPMI- 1640 with $2 \mathrm{mmol} / \mathrm{l}$ glutamine $/ 0.5 \mathrm{~g} / \mathrm{l}$ gentamycin, and $0.25 \mathrm{mg} / \mathrm{l}$ Fungizone (Flow, Irvine, Scotland). The culture medium was supplemented with either $20 \%$ fetal calf serum (FCS) (Flow) or $20 \%$ autologous heparin plasma, which was freshly prepared from the same blood sample that was used for MNC separation. The mitogen concentrations were 20,50 and $80 \mathrm{mg} / /$ for phytohemagglutinin 
(PHA) (Wellcome, Dartford, England) and 5,20 and $30 \mathrm{mg} / \mathrm{l}$ for concanavalin A (ConA) (Sigma, St Louis, MO). The microtiter plates were incubated during 96 hours at $37^{\circ} \mathrm{C}$ and $5 \% \mathrm{CO}_{2}$. Detection of cell proliferation was performed by using the MTT $(3-4,5$ dimethylthiazol-2-yl-2,5-diphenyl tetrazoliumbromide) method described first by Mosmann. ${ }^{1.3}$ MTT (20 $\mu \mathrm{l} 5 \mathrm{~g} / \mathrm{l}$, Sigma) was added 6 hours before the end of the incubation period. The formed crystals were dissolved by addition of a $25 \%$ sodium-dodecyl-sulphate solution. Increases in optical density at $550 \mathrm{~nm}$ are a measure for increases in cell number. Increases in cell numbers were only measured once, after 96 hours culture.

\section{Blood parameters}

After venipuncture, nonfasting blood samples containing sodium EDTA as anticoagulant were stored overnight in the dark at $4^{\circ} \mathrm{C}$ for $20-23$ hours. Immediately after opening the evacuated tubes, the sum of L-ascorbic + dehydro-L-ascorbic acid (vitamin C) was assessed in whole blood by HPLC with fluorimetric detection. ${ }^{14}$ All-trans retinol, $\alpha$-tocopherol, $\beta$-carotene, and tolal carotenoids were assayed in plasma (stored at $-80^{\circ} \mathrm{C}$ ) by HPLC with colorimetric detection. ${ }^{15}$ Plasma cotinine concentrations were determined by gas chromatography. ${ }^{\text {th }}$

\section{Data analysis}

Initial baseline values and changes in these values during the intervention period were compared between the placebo group and the $\beta$-carotene group using the unpaired t-test. We used multiple-linear regression to quantify differences in final values between the placebo and treatment group after adjustment for initial values and residual confounding. Analyses of covariance was used for statistical testing. All data were analysed by using the BMDP package. ${ }^{17}$ Two-sided p values $<0.05$ were considered statistically significant.

\section{Results}

\section{Lymphocyte subset study}

Tabie 1 shows that the placebo and $\beta$-carotene group in the lymphocyte subset study are comparable for all characteristics, and that except for plasma concentrations of $\beta$-carotene, only minor changes occurred during the intervention trial. After 7-weeks of supplementation mean plasma $\beta$-carotene had increased 13 -fold in the $\beta$-carotene group (from 0.30 to $3.94 \mu \mathrm{mol} / \mathrm{l}$ ) and this increase remained stable until the end of the trial (table 1). Typical chromatograms from a $\beta$-carotene treated and a control subject are shown in figure 1. The minimum increase in plasma $\beta$-carotene was 3.3 -fold. Pill counts showed that a mean of $91 \%$ of all capsules were taken (data for 40 subjects). Skin yellowing was reported by three supplemented subjects. Three subjects reported taking vitamin supplements (one from the placebo, two from the $\beta$-carotene group); they occasionally took vitamin $\mathrm{C}$. Their blood vitamin $\mathrm{C}$ concentration, however, were not very high $(12.6,63.5$, and $43.8 \mu \mathrm{mol} / 1$, respectively). 
Table 1. Baseline characteristics (SD) and changes in these characteristics during a 14-weeks trial on lymphocyte subsets in male smokers, assigned to either $\beta$-carotene ( $20 \mathrm{mg} /$ day) or placebo treatment*

\begin{tabular}{|c|c|c|c|c|}
\hline & \multicolumn{2}{|c|}{ Placebo group $(n=24)$} & \multicolumn{2}{|c|}{$\beta$-carotene group $(n=21)$} \\
\hline & Baseline & Change & Baseline & Change \\
\hline Age (yrs) & $39.1 \pm 9.1$ & n.a. & $39.8 \pm 8.9$ & n.a. \\
\hline Cigarettes/day & $20.8 \pm 5.7$ & n.a. & $20.8 \pm 4.5$ & n.a. \\
\hline Blood vitamin $C(\mu \mathrm{mol} / \mathrm{l})$ & $29.8 \pm 14.8$ & $4.8 \pm 11.7$ & $32.9 \pm 15.3$ & $-0.3 \pm 9.4$ \\
\hline Plasma retinol $(\mu \mathrm{mol} / \mathrm{l})$ & $2.36 \pm 0.85$ & $-0.08 \pm 0.49$ & $2.49 \pm 0.52$ & $0.09 \pm 0.41$ \\
\hline Plasma $\alpha$-tocopherol $(\mu \mathrm{mol} / \mathrm{l})$ & $29.5 \pm 6.4$ & $1.8 \pm 4.3$ & $32.2 \pm 7.5$ & $1.8 \pm 3.7$ \\
\hline Plasma $\beta$-carotene $(\mu \mathrm{mol} / \mathrm{h})$ & $0.33 \pm 0.22$ & $-0.02 \pm 0.16$ & $0.30 \pm 0.14$ & $3.64 \pm 1.99 *$ \\
\hline Plasma cotinine $(\mu \mathrm{g} / \mathrm{l})$ & $311 \pm 116$ & $-11 \pm 64$ & $316 \pm 121$ & $0 \pm 75$ \\
\hline Lymphocyte count $\left(\times 10^{9} / 1\right)$ & $2.14 \pm 0.39$ & $-0.01 \pm 0.35$ & $2.11 \pm 0.63$ & $0.05 \pm 0.44$ \\
\hline
\end{tabular}

* $\bar{x} \pm$ SD. n.a. $=$ non applicable.

$\dagger \beta$-carotene group significantly different from placebo groep, $p<0.001$.
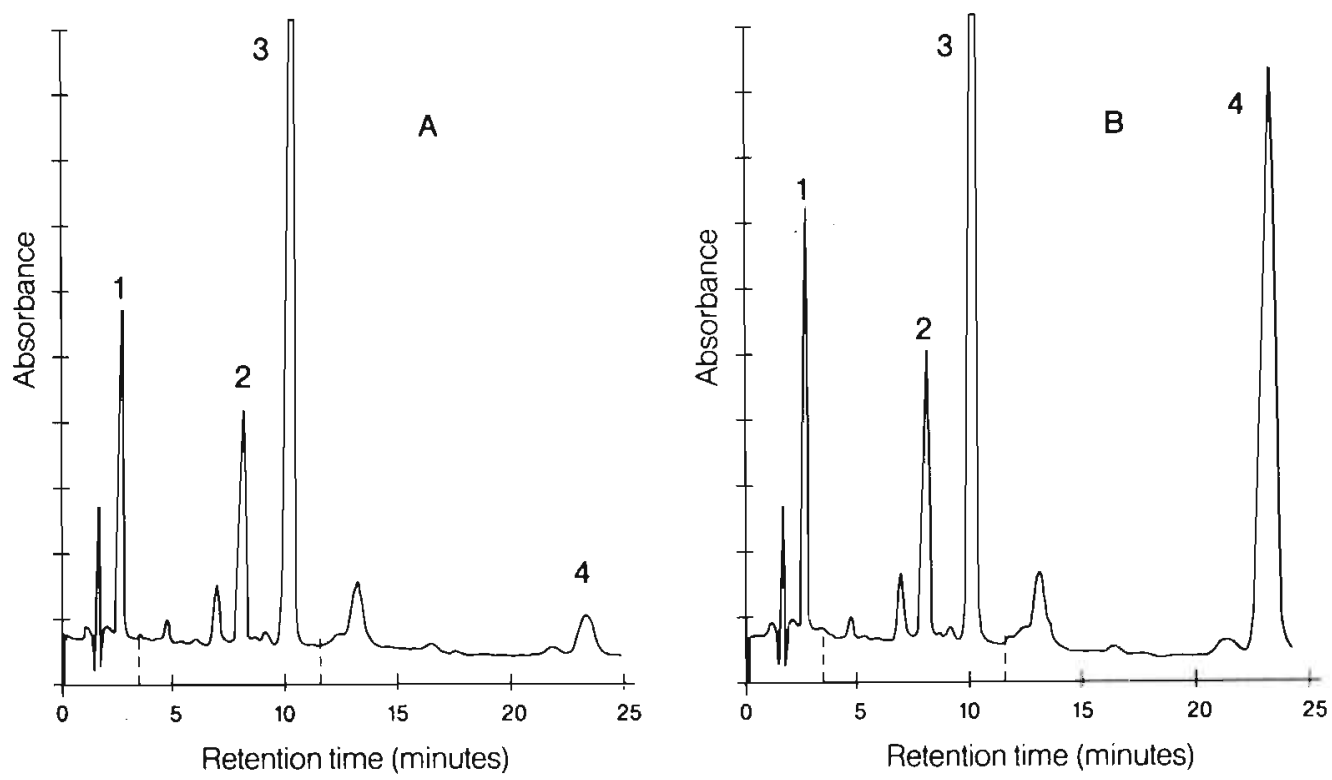

Figure 1. Typical chromatograms from a control subject (A) and a 14-weeks $\beta$-carotene treated subject (B). 1) Retinol 2) $\alpha$-tocopherol 3) Internal standard (tocopheryl acetate) 4) $\beta$-carotene. Dotted lines indicate wavelength shifts (325 nm; $292 \mathrm{~nm} ; 445 \mathrm{~nm}$ respectively). 
The $\beta$-carotene and placebo groups showed similar initial values for lymphocyte subsets (table 2). No effect of $\beta$-carotene supplementation were observed on the lymphocyte subsets (table 2).

Table 2. Lymphocyte subsets as percentage of tolal lymphocyte count during a 14-weeks trial in male smokers, assigned to either $\beta$-carotene (20 mg/day) or placebo treatment.*

\begin{tabular}{|c|c|c|c|c|c|}
\hline & \multicolumn{2}{|c|}{$\begin{array}{c}\text { Placebo group } \\
(n=24) \dagger\end{array}$} & \multicolumn{2}{|c|}{$\begin{array}{c}\beta \text {-carotene group } \\
(n=21) \dagger\end{array}$} & \multirow{2}{*}{$\begin{array}{l}\beta \text {-carotene } \\
\text {-placebo } \\
\text { after study } \\
(95 \% \mathrm{CJ}) \ddagger\end{array}$} \\
\hline & Baselinc & Change & Baseline & Change & \\
\hline CD2+/C.D19- (total T) & $80.7 \pm 5.0$ & $0.7 \pm 4.4$ & $77.9 \pm 5.9$ & $2.3 \pm 5.1$ & $0.3(-3.6: 4.2)$ \\
\hline CD2-/CD19+(total B) & $12.0 \pm 4.7$ & $-0.4 \pm 3.2$ & $13.9 \pm 5.3$ & $-0.3 \pm 3.7$ & $1.2(-0.8: 3.2)$ \\
\hline CD4+/CD8-(T helper/inducer) & $44.3 \pm 5.9$ & $0.3 \pm 4.7$ & $44.8 \pm 7.2$ & $-0.1 \pm 6.3$ & $-1.6(-5.2: 2.0)$ \\
\hline CD4-/CD8+(T suppressor/cytotoxic) & $33.2 \pm 6.8$ & $1.6 \pm 3.5$ & $29.8 \pm 8.1$ & $0.7 \pm 2.6$ & $-1.4(-3.5: 0.8)$ \\
\hline $\mathrm{CD} 3+/ \mathrm{HLADr}-($ mature $\mathrm{T})$ & $66.2 \pm 5.7$ & $-1.9 \pm 5.8$ & $6.5 .1 \pm 7.2$ & $1.0 \pm 4.5$ & $1.8(-1.8: 5.4)$ \\
\hline CD3+/HLADr+) (aclivaled T) & $7.0 \pm 3.4$ & $0.0 \pm 4.0$ & $6.5 \pm 2.7$ & $0.5 \pm 2.9$ & $0.7(-1.4: 2.8)$ \\
\hline CD $3+/ C D 16 \& 56+($ cytotoxic $T)$ & $6.0 \pm 6.2$ & $-0.2 \pm 2.8$ & $4.3 \pm 3.4$ & $0.0 \pm 2.9$ & $0.1(-1.6: 1.7)$ \\
\hline CD $3-/ C D 16 \& 56+(\mathrm{NK})$ & $14.7 \pm 6.6$ & $1.7 \pm 6.0$ & $13.5 \pm 5.1$ & $-0.3 \pm 3.1$ & $-1.8(-5.2: 1.5)$ \\
\hline CD45r+/CD $4+\left(T^{\prime}\right.$ naive $)$ & $17.0 \pm 6.9$ & $-0.2 \pm 4.2$ & $17.0 \pm 6.5$ & $-0.9 \pm 3.4$ & $-0.6(-2.8: 1.7)$ \\
\hline CD4.5r-/CD4+ (T memory) & $30.3 \pm 7.9$ & $0.2 \pm 4.9$ & $32.2 \pm 7.7$ & $0.3 \pm 5.2$ & $0.0(-2.9: 2.9)$ \\
\hline \multicolumn{6}{|l|}{$* \bar{x} \pm \mathrm{SD}$} \\
\hline \multicolumn{6}{|c|}{+ For some individual measurements data are missing. } \\
\hline \multicolumn{6}{|c|}{$\begin{array}{l} \pm \text { Differences in linal values after adjustment for initia } \\
\text { A.C.E, and variation hetween measurement days. }\end{array}$} \\
\hline \multicolumn{6}{|c|}{ Lymphocyte proliferation study } \\
\hline \multicolumn{6}{|c|}{ Baseline characteristics of the lymphocyte-proliferation study are given in table 3 . } \\
\hline \multicolumn{6}{|c|}{$\begin{array}{l}\text { Table 3. Baseline characteristics and changes during a } 14 \text {-weeks trial on lymphocyte-proliferation } \\
\text { respons in male smokers assigned to either } \beta \text {-carotene ( } 20 \mathrm{mg} / \text { day) or placebo treatment.* }\end{array}$} \\
\hline & \multicolumn{2}{|c|}{ Placebo group ( $n=23$ ) } & \multicolumn{3}{|c|}{$\beta$-caroleile group $(n=24)$} \\
\hline & Baseline & Change & & Baseline & Change \\
\hline Agc $(y r s)$ & $40.7 \pm 10.9$ & n.a. & 41. & $1 \pm 10.8$ & n.a. \\
\hline Cigarettes/day & $18.6 \pm 3.5$ & n.a. & 19. & $4 \pm 4.5$ & n.a. \\
\hline Blood vitamin $\mathrm{C}(\mu \mathrm{mol} / \mathrm{l})$ & $40.5 \pm 17.0$ & $3.12 \pm 11.7$ & 41. & $0 \pm 17.4$ & $-3.8 \pm 12.3$ \\
\hline Plasma retinol $(u \mathrm{~mol} / \mathrm{l})$ & $2.49 \pm 0.85$ & $-0.12 \pm 0.49$ & 2.5 & $5 \pm 0.48$ & $-0.03 \pm 0.53$ \\
\hline Plasma $\alpha$-tocopherol $(\mu \mathrm{mol} / \mathrm{l})$ & $31.4 \pm 7.2$ & $1.3 \pm 4.3$ & 32. & $4 \pm 7.0$ & $0.1 \pm 3.6$ \\
\hline Plasma $\beta$-carolene $(\mu \mathrm{mol} / \mathrm{l})$ & $0.28 \pm 0.13$ & $0.01 \pm 0.16$ & 0.3 & $5 \pm 0.16$ & $4.78 \pm 2.51^{*}$ \\
\hline Plasma cotinine $(\mu \mathrm{g} / 1)$ & $306 \pm 112$ & $-3 \pm 64$ & & $7 \pm 108$ & $-10 \pm 75$ \\
\hline
\end{tabular}

$\bar{x} \pm \mathrm{SD}$. n.a. $=$ not applicable.

$\dagger \beta$-carotene group significantly different from placebo grocp, $p<0.001$ 
Here again, the placebo and $\beta$-carotene groups are comparable for all characteristics and, except for plasma concentrations of $\beta$-carotene, only minor changes occurred during the intervention trial. Mean plasma $\beta$-carotene increased 13-fold after 7-weeks supplementation in the $\beta$-carotene group and 14-fold by the end of the trial (table 3). A mean of $90 \%$ of all capsules were taken (data for 42 subjects) and plasma concentrations of $\beta$-carotene increased in all supplemented subjects, the minimum increase being 3.3-fold. Skin yellowing was reported by five supplemented subjects. None of the subjects reported taking vitamin supplements.

Table 4 gives results for lymphocyte proliferation at $80 \mathrm{mg} / \mathrm{l}$ PHA and $30 \mathrm{mg} / \mathrm{l}$ ConA. These concentrations resulted in maximal proliferation in the autologous plasma cultures. $\beta$-carotene supplementation did not have an influence on ConA-induced proliferation either in FCS or in autologous plasma culture. $\beta$-carotene supplementation resulted in an increase in PHA-induced proliferation, but only in lymphocyte cultures supplied with autologous plasma. For the cultures with the other concentrations of mitogens, similar data were obtained (results not shown).

Table 4. Lymphocyte proliferation as increases in optimal density after different incubations during a 14 -weeks trial in male smokers, assigned to either $\beta$-carotene $(20 \mathrm{mg} /$ day $)$ or placcbo treatment.*

\begin{tabular}{|c|c|c|c|c|c|}
\hline & \multicolumn{2}{|c|}{ Placebo group ( $n=23$ ) } & \multicolumn{2}{|c|}{$\beta$-carntene group $(n=24)$} & \multirow{2}{*}{$\begin{array}{c}\text { } \beta \text {-carotene } \\
\text { - placebo after } \\
\text { study }(95 \% \mathrm{Cl}) \dagger\end{array}$} \\
\hline & Baseline & Change & Bascline & Change & \\
\hline PHA (80 mg/l) plasma & $1.12 \pm 0.24$ & $0.04 \pm 0.28$ & $1.01 \pm 0.25$ & $0.22 \pm 0.24 \ddagger$ & $0.14(0.02: 0.26)$ \\
\hline PHA $(80 \mathrm{mg} / \mathrm{l}) \mathrm{FCS}^{1}$ & $1.05 \pm 0.42$ & $0.03 \pm 0.29$ & $1.06 \pm 0.33$ & $-0.11 \pm 0.18$ & $-0.11(-0.3: 0.05)$ \\
\hline ConA $(30 \mathrm{mg} / 1)$ plasma & $0.99 \pm 0.30$ & $0.01 \pm 0.32$ & $1.00 \pm 0.28$ & $0.08 \pm 0.20$ & $0.08(-0.06: 0.21)$ \\
\hline ConA $(30 \mathrm{mg} / \mathrm{l}) \mathrm{FCS}^{2}$ & $0.66 \pm 0.34$ & $-0.05 \pm 0.35$ & $0.62 \pm 0.52$ & $-0.08 \pm 0.57$ & $-0.01(-0.30: 0.29)$ \\
\hline
\end{tabular}

* $\bar{x} \pm$ SD; PHA, Phytohemagglutinin; ConA, concavalin A; FCS, fetal calf scrum.

$\dagger$ Differences in final values after adjustment for initial values, age, blood concentrations of cotinine and vitamins $\mathrm{A}, \mathrm{C}, \mathrm{E}$, and variation between measurement days.

$\ddagger \beta$-carotene group significantly different from placebo group ( $p=0.01$ ).

$1 n=18$ placebo \& $17 \beta$-carotene subjects; $2 n=13$ placebo \& $17 \beta$-carotene subjects.

To obtain an unbiased estimate of the intervention effect, we calculated the difference between the placebo group and the $\beta$-carotene group after intervention, allowing for the small differences that still existed between both groups at the start of the study. After adjustment for age; plasma concentrations of cotinine, vitamins $A, C$ and $E$; variation between measurement days; and initial proliferation response, the after-treatment proliferation induced by PHA $(80 \mathrm{mg} / \mathrm{l})$ was estimated to be $12 \%$ higher in the $\beta$-carotene group than in the placebo group (1.13 vs. $1.27 ; \mathrm{p}=0.02)$. 


\section{Discussion}

This study in healthy male smokers shows that 14 -weeks supplementary $\beta$-carotene has an enhancing effect on ex vivo proliferative $\mathrm{T}$ cell response as induced by the mitogen PHA, whereas marker expression on peripheral blood lymphocytes is not affected by $\beta$-carotene.

The lack of effect of $\beta$-carotene on lymphocyte subsets in this study can hardly be attributed to an inadequate dose of $\beta$-carotene as $20 \mathrm{mg} /$ day is approximately $5-10$-fold the normal intake. In addition, we used $40 \mathrm{mg}$ /day for the first 2 -weeks to saturate tissue concentrations of $\beta$-carotene. Indeed, several participants observed skin discoloration, rendering the study not completely double blind. Plasma concentrations of $\beta$-carotene in the supplemented group dramatically increased to concentrations similar to those reported by Ringer et al. ${ }^{9}$ after $45 \mathrm{mg}$ /day for 1 month and to those reported by Watson et al. ${ }^{7}$ after $30 \mathrm{mg} /$ day for two months. Moreover, we did not observe any effect of $\beta$-carotene on lymphocyte subsets after we excluded supplemented subjects with the lowest quartile $(<1.88 \mu \mathrm{mol} / \mathrm{l})$ of after-treatment $\beta$-carotene concentrations (results not shown).

The absence of an effect of $\beta$-carotene on marker expression is in accordance with a recently reported study in 50 healthy, non-smoking males and females aged 18 - 54 years, who used doses up to $300 \mathrm{mg} /$ day. ${ }^{9}$ Our study thus extends these previous observations to smoking individuals, who are known to have low plasma $\beta$-carotene concentrations. In contrast, three other smaller studies in humans did show effects of $\beta$-carotene on marker expression. The first of these studies, ${ }^{18}$ however, is difficult to compare with ours as the observed increase in CD4+ expression may be attributable to a concomitant increase in plasma retinol, suggesting suboptimal initial vitamin A status. A second, non-placebocontrolled study ${ }^{\wedge}$ likewise does not report plasma retinol concentrations, which precludes evaluation of vitamin deficiencies in the studied subjects. Moreover, this second study used patients with precancerous conditions, which may imply underlying immunological changes. The third study ${ }^{7}$ reported increases in the percentage of cells with markers for NK, $T$ helper, interleukin 2, and transferrin after 2 months supplementation of 16 subjects with $>30 \mathrm{mg} /$ day. In four subjects receiving $15 \mathrm{mg} /$ day, these increases were not observed despite similar increases in plasma $\beta$-carotene. The study, however, did not use double staining, B cells or cell types that decreased were not reported, ${ }^{19}$ and the time elapse between venipuncture and quantitation of lymphocyte subsets was not given. In addition, this last study used elderly subjects. Age has been shown to influences the immune system. $^{20}$ The discrepancies between the studies may be explained if $\beta$-carotene only influences marker expression in people with age- or disease-induced suboptimal immune status.

The increase in PHA-induced lymphocyte proliferation in this study does not seem to be related to a retinol effect of $\beta$-carotene, as plasma retinol concentrations remained unchanged during the study. Likewise, concentrations of the antioxidants $C$ and $E$ were not affected. The increase is remarkable, as we did not observe any influence of $\beta$-carotene on lymphocyte subpopulations to explain increased mitogenesis. The increased PHA-induced 
mitogenesis thus seems to be related to a plasma factor, most probably $\beta$-carotene. This suggestion is supported by our observation that PHA-induced mitogenesis was increased in cultures supplied with autologous ( $\beta$-carotene rich) plasma, but not in cultures supplied with FCS. It is difficult to judge the biological significance of the observed $12 \%$ increase in PHA-induced mitogenesis. However, our ex vivo assay used only $20 \%$ plasma. The in vivo proliferative response, in a $100 \%$ plasma environment, may therefore be substantially more enhanced after $\beta$-carotene supplementation.

The immuno-enhancing mechanism of the antioxidant $\beta$-carotene has been hypothesized $^{6}$ to involve the quenching of free radicals, which could lower the concentration of immunodepressing lipid peroxides, alter arachidonic acid metabolism, stabilize lysosome membranes, or protect nuclear structures. A nonspecific antioxidant mechanism would imply that the same effect should be seen with all mitogens capable of stimulating lymphocyte proliferation. However, we did not observe a significant effect of $\beta$-carotene on ConA-induced proliferation, which could suggest a more specific interaction of $\beta$-carotene with lymphocyte functions. Interestingly, Ringer et al. ${ }^{9}$ mention (without giving data) mildly augmented PHA-induced mitogenesis after $\beta$-carotene supplementation in humans, whereas another mitogen (OTK3) response was not affected. Similarly, Meydani et al. ${ }^{21}$ report enhancement of PHA but not ConA mitogenesis after vitamin $\mathrm{E}$ supplementation in elderly subjects. A study in rats ${ }^{22}$ showed augmented responses to both ConA and PHA after $\beta$-carotene treatment, but in this study retinol concentrations were also increased.

It is tempting to extrapolate our data to the evaluation of a cancer-preventive potential of $\beta$-carotene. Such interpretations, however, can only be very cautiously made. First, because peripheral blood lymphocytes may only partly reflect the distribution and activities of lymphocytes in organs more relevant to carcinogenesis. ${ }^{23}$ For instance, it is notable that lymphocyte subsets in broncheo-alveolar lavage differ from those in peripheral blood. ${ }^{24}$ Second, because the $\mathrm{T}$ cell responses studied may have only limited relevance in immunomodulation of carcinogenesis. Several forms of non-T cell mediated immunity may also be important. ${ }^{25}$ Though we did not observe an effect of $\beta$-carotene on the number of peripheral NK cells (CD3-/16 and 56+), an effect on NK activity may exist. Finally, it should be noted that a substantial number of human tumors do not exhibit any immunogenic properties. ${ }^{26}$ The concept of immune surveillance in the regulation of carcinogenesis may therefore only apply to certain forms of cancer.

We conclude that this study yields evidence that supplementary $\beta$-carotene can moderately enhance certain aspects of immune response in healthy male smokers. The significance of this finding for the putative cancer-preventive potential of $\beta$-carotene remains to be established. In our study's group of smokers had marginal $\beta$-carotene status, we did not observe an effect of $\beta$-carotene on marker expression in peripheral lymphocytes. However, it cannot be excluded that $\beta$-carotene may exhibit cancer preventive properties by modifying marker expression in subjects with suboptimal immune status. 


\section{References}

1. Editorial. A carrot a day keeps cancer at bay? Lancet 1991;337:81-82.

2. Meyskens FL. Coming of age - the chemoprevention of cancer. N Engl J Med 1990;323:825-827.

3. Willell WC. Vilamin A and lung cancer. Nutr Rev 1990;48:201-211.

4. Ziegler RG. A review of epidemiologic evidence that carotenoids reduce the risk of cancer. J Nutr 1989;119:116-122.

5. Krinsky NI. Carotenoids as chemopreventive agents. Prev Med 1989;18:592-602.

6. Bendich A. Carotenoids and the immune response. I Nutr 1989;119:112-115.

7. Watson RR, Prabhala RH, Plezia PM, Alberts DS. Effect of $\beta$-carotene on lymphocyte subpopulations in elderly humans: evidence for a dose-response relationship. Am J Clin Nutr 1991;53:90-94.

8. Prabhala RH, Garewal HS, Hicks MJ, Sampliner RE, Watson RR. The effects of 13-cis retinoic acid and $\beta$-carotene on cellular immunity in humans. Cancer 1991:67:1556-1560.

9. Ringer TV, De Loof $M J$, Winterrowd $G E$, et al. $\beta$-carotene's effect on serum lipoproteins and immunologic indices in humans. Am J Clin Nutr 1991;53:688-694.

10. Gerster H. $\beta$-carorene and smoking. J Nutr Growth Cancer 1987;4:45-49.

11. Van Poppel G, Kok FJ, Duijzings P, De Vogel $N$. No influence of $\beta$-carotene on smoking induced DNA damage as reflected by sister chromatid exchanges. Int J Cancer 1992,51:355-358.

12. Boyum A. Isolation of leucocytes from human blood. Scand J Clin Lab Invest 1968;21 (Suppl.97):77-90.

13. Mosmann T. Rapid colorometric assay for ccllular growth and survival: application to proliferation and cytotoxicity assays. J Immunol Methods 1983:65:55-63.

14. Speck AJ, Schrijver J, Schreurs WHP. Fluorimetric determination of total vitamin $C$ in whole blood by high performance liquid chromatography with pre-column derivatization. J Chromatogr 1984;305: $53-60$.

15. Van Vliet T, Van Schaik F, Van Schoonhoven J, Schrijver J. Determination of several retinoids, carotenoids, and E vitamers by HPLC. Application to plasma and tissues of rats fed a diet rich in either $\beta$-carotene or canthaxanthin. J Chromatogr 1991:55:3:179-186.

16. Feycrabend ( $:$ Bryant A, Jarvis MJ, Russell MAH. Determination of cotinine in biological fluids of non-smokers by packed column gas-liquid chromatography. J Pharm Pharmacol 1984:38:1075-1078.

17. Dixon WJ (ed). BMDP Statistical Software Manual. University of California Press. Berkeley, 1988.

18. Alexander $M$, Newmark $H$, Miller RG. Oral $\beta$-carotene can increase the number of $O K T 4^{+}$cells in humin blood. Immunol Lelt 1985;9:221-224.

19. Bryant DG. Prasad C. Re; Effect of $\beta$-carotene on lymphocyte subpopulations in elderly humans. Am J Clin Nutr 1991;54:432-433.

20. Schwaab R, Wolters CA, Weksler ME. Host defense mechanisms and ageing. Semin Oncol 1989:16:20-27.

21. Mcydani SN, Barklund MP. Liu S, et al. Vitamin E supplementation enhances cell-mediated immunity in healthy elderly subjects. Am J Clin Nutr 1990;52:557-563.

22. Bendich A, Shapiro SS. Eflect of $\beta$-carotenc and canthaxanthin on the immune responses of the rat. $J$ Nutr 1986:116:2254-2262.

23. Westerman J, Pabst R. Lymphocyle subsets in the blood; a diagnostic window on the lymphoid system? Immunol Today 1990;11:406-410.

24. Hunninghake GW, Crystal RG. Pulmonary sarcoidosis. A disorder mediated by excess helper T-lymphocyte activily at sites of disease activity. N Engl J Med 1981;305:429-434.

25. Kripke ML. Immunorcgulation of carcinogenesis; past, present, and future. J Natl Cancer Inst 1988;80:722-727. 


\section{The effect of beta-carotene on sputum cytology in smokers: a preliminary study}

Geert van Poppel, Anniek van Aspert, Tiny Heynen, G. Peter Vooys, Theodore Ockhuizen

\section{Abstract}

A large body of evidence suggests that $\beta$-carotene may reduce lung cancer risk. Since the use of biomarkers may be a useful approach to human cancer risk, we performed a randomized blinded controlled trial in smokers. This allowed a preliminary evaluation of the effect of 14-weeks $\beta$-carotene $(20 \mathrm{mg} / \mathrm{day})$ on bronchial metaplasia in sputum cytology as a marker for potential premalignancy. In addition, we evaluated determinants of sputum production in healthy asymptomatic smokers.

Initial metaplasia scores were somewhat higher in the $\beta$-carotene group $(n=33)$ than in the placebo group $(n=42)(p=0.06)$. Plasma $\beta$-carotene levels increased 14-fold during treatment. Final metaplasia scores were similar in both groups $(p=0.69)$, and there was no decrease in metaplasia scores in the $\beta$-carotene group $(p=0.75)$. We observed no significant correlation between initial and final metaplasia scores in either the $\beta$-carotene (Spearman $R=0.18, p=0.3$ ) or placebo group (Spearman $R=0.17$, $\mathbf{p}=\mathbf{0 . 3}$ ).

Of the $\mathbf{1 5 0}$ potential participants in this trial 75 were not eligible because they failed to produce sputum samples $(n=29)$, or because samples were unsatisfactory $(n=46)$. The eligible group was older (41 vs. 37 years) and had smoked longer ( 23 vs. 19 years), but had similar cigarette consumption (mean 21 /day) and plasma cotinine levels.

This study provides preliminary evidence that $\beta$-carotene has no influence on minor bronchial metaplastic changes as detected in sputum cytology. Moreover, the results indicate that the performance of future studies can be increased by repeated sampling or use of brushings to diminish variations in cytology, by increasing size and time span, and by pre-selection of subjects with more severe lesions. Therefore, cautious interpretation of the absence of an effect of $\beta$-carotene is warranted.

\section{Introduction}

Several lines of evidence indicate that $\beta$-carotene may reduce lung cancer risk. Epidemiological studies have been remarkably consistent in reporting an association between high consumption of $\beta$-carotene-rich fruits and vegetables and lower risk of lung cancer. ${ }^{1.2}$ Experimental studies indicate that $\beta$-carotene may be protective by providing antioxidant 
protection against free radical induced DNA- and cell-damage. ${ }^{2,3}$ In addition, its provitamin A activity may imply a beneficial effect on cellular differentiation and proliferation. ${ }^{2,3}$

To test the $\beta$-carotene - lung cancer hypothesis, several human intervention studies have been initiated. A limited number of these studies use cancer incidence as an endpoint and are necessarily large scale and lengthy. ${ }^{2,45}$ Several other studies focus on intermediate biomarkers for cancer risk. ${ }^{2,6}$ Though these studies cannot provide definite answers, they do have the merit of providing insight in mechanisms within an efficient study size and time schedule. ${ }^{7}$ Also, these studies yield valuable information for planning and evaluating large scale trials on cancer incidence.

We have previously conducted a double-blind placebo-controlled trial to evaluate the effect of $\beta$-carotene on markers for DNA damage in smokers. ${ }^{89}$ Whereas markers for DNA damage may reflect initiation and earlier stages in carcinogenesis, other markers may bear relevance on later stages of carcinogenesis. A promising marker in this respect is degree of bronchial metaplasia observed in cytological evaluation of expectorated sputum. ${ }^{10.11}$ Since sputum samples were routinely collected in the previously conducted study, we performed a preliminary evaluation of the effect of $\beta$-carotene on bronchial metaplasia in sputum samples. In addition, since methodological information on this marker is scarce, we studied determinants of spontaneous sputum production in healthy asymptomatic smokers and variation in bronchial metaplasia scoring over a 14-weeks period.

\section{Subjects and methods}

\section{Study design}

Healthy male employees of the AMEV Insurance Company, the Taxation Office and the Power Company at Utrecht, the Netherlands were asked to volunteer for the intervention trial, which was approved by an External Review Board for experiments with human volunteers. All participants had smoked at least 15 cigarettes per day for over 2 years, did not use preparations containing retinol or carotenoids, and did not report exposure to chemicals during working or leisure time. The volunteers were prestratified by age, duration and quantity of smoking and randomly assigned to either $\beta$-carotene $(20 \mathrm{mg}$ capsules, F. Hoffmann - La Roche Ltd.) or placebo treatment.

Blood and sputum samples were collected before and after the 14-weeks treatment. The participants were instructed to take capsules daily with the evening meal; two capsules per day during the first 2-weeks, followed by one capsule per day for the next 12-weeks. Each 4 weeks, the participants were sent their next strip of 28 capsules, and were asked to return the used strips with the non-taken capsules to monitor compliance. In addition, $\beta$-carotene was determined in a blood sample taken after 7 -weeks treatment.

Initially, 163 smokers volunteered to participate; 83 were assigned to placebo treatment, 80 were assigned to $\beta$-carotene treatment. During the trial, a total of 13 smokers ( 6 placebo, $7 \beta$-carotene) withdrew their participation because of stopping smoking $(n=4)$, illness or accident $(n=3)$, private circumstances $(n=1)$, forgetting to take capsules $(n=2)$, or without 
giving a reason $(n=3)$. Of the 150 smokers who completed the trial, 75 (35 placebo, 40 $\beta$-carotene) were not eligible for this study on sputum cytology; 29 failed to spontaneously produce sputum samples, whereas samples were unsatisfactory in another 46 subjects. This left 75 subjects (42 placebo, $33 \beta$-carotene) for the study of the effect of $\beta$-carotene on sputum cytology.

\section{Sputum cytology}

Sputum was collected and processed as described in detail by Saccomano et al. ${ }^{12}$ Each participant received a careful individual instruction on how to produce a specimen from 'deep in the lungs'. Sputum was collected at home on three consecutive mornings, directly after rising and after carefully rinsing the mouth. The three, or minimally two samples, collected in preservative $(50 \mathrm{ml} 50 \%$ ethanol with $2 \%$ polyethylene glycol (Carbowax 1540, Merck)), were mixed, homogenized, centrifuged and smeared on slides. The slides were stained using the Papanicolaou technique ${ }^{13}$ and all slides were assessed by a single cytotechnologist (TH). For each subject, 2 slides were screened and scored according to the standard criteria of the International Histological Classification of Tumors. ${ }^{14}$ Based on this classification, a standardized protocol for worsening grades of metaplasia was devised, as follows: (1) Normal cytology (2) Mild metaplasia without atypia (3). Metaplasia without atypia (4) Metaplasia with slight atypia (5) Slight dysplasia (6) Moderate dysplasia (7) Severe dysplasia.

Specimens were considered of unsatisfactory quality if they contained inflammatory elements sufficient to obscure the cells to be examined, or if they contained no alveolar macrophages, indicating that the specimen most likely did not originate from the lower respiratory tract.

Blinded rescoring for 13 samples was performed to evaluate within-observer variability. Agreement was exact in 54\% of the samples, whereas agreement was in the same or an adjacent category in $93 \%$ of the samples. In addition, a chief cytotechnologist (AvA) performed a blinded rescoring of slides from 23 subjects to evaluate variability between scorers. Agreement between the two observers was $39 \%$ for full agreement and $95 \%$ for agreement within the same or an adjacent category.

\section{Blood parameters}

Directly after venapuncture, non fasting blood samples containing $\mathrm{NaEDTA}$ as anti-coagulant were stored overnight in the dark at $4^{\circ} \mathrm{C}$ for $20-23$ hours. Directly after opening the evacuated tubes, the sum of L-ascorbic + dehydro-L-ascorbic acid (vitamin C) was assessed in wholeblood by HPLC with fluorimetric detection. ${ }^{15}$ All-trans retinol, $\alpha$-tocopherol, $\beta$-carotene and total carotenoids were assayed in plasma (stored at $-80^{\circ} \mathrm{C}$ ) by HPLC with colorimetric detection. ${ }^{16}$ Plasma cotinine levels were determined by gas chromatography. ${ }^{17}$

\section{Data analysis}

Initial values, final values, and changes in these values during the intervention were compared between groups using the unpaired Student's t-test and the Mann Whitney rank sum test. Spearman rank correlations were calculated to study associations between metaplasia scores 
and baseline characteristics. The Wilcoxon signed rank test was used to test changes in metaplasia scores within groups. The Chi square test was used to comparc improvement in scores between the placebo and $\beta$-carotene group. All statistics were calculated using the BMDP package. ${ }^{18}$

\section{Results}

Table 1 shows that the $\beta$-carotene and placebo group are comparable on all characteristics and that, except for plasma $\beta$-carotene, only minor changes occurred during the intervention trial. After 7 -weeks, mean plasma $\beta$-carotene levels in the intervention group had increased 14 -fold to $4.46 \mu \mathrm{mol} / 1$, and remained stable up to the end of the trial. Pill counts showed that $93 \%$ of all capsules were taken (data for 68 subjects). All participants but one reported to have taken more than $70 \%$ of the capsules.

Table 1. Characteristics (mean \pm sd) during a 14 -wceks intervention trial in malc smokers. assigned to cither $\beta$-carolene or placebo treatmont.

\begin{tabular}{|c|c|c|c|c|}
\hline & \multicolumn{2}{|c|}{ Placebo group $(n=42)$} & \multicolumn{2}{|c|}{ B-carotenc group $(n=3.3)$} \\
\hline & Initial values & Final values & Inilial values & Final values \\
\hline Age (years) & $41.9 \pm 10.3$ & n.a.: & $40.8 \pm 9.7$ & n.a. \\
\hline Number of cigarctles per diy & $20.5 \pm 6.3$ & n.a. & $23.0 \pm 7.7$ & n.a. \\
\hline Ycars of smoking & $2.3 .1 \pm 11.0$ & n.a. & $2.3 .3 \pm 9.4$ & n.al. \\
\hline Blood vilamin $(\mu \mathrm{mo} / \mathrm{l})^{\prime}$ & $39.2 \pm 19.4$ & $38.4 \pm 17.4$ & $38.9 \pm 20.2$ & $346 \pm 15.8$ \\
\hline Plasma relimol (umol/l) & $2.32 \pm 0.08$ & $2 . .33 \pm 0.50$ & $\therefore .44 \pm 0.6 .3$ & $2.53 \pm 0.0 .5$ \\
\hline Plasma a-tocopherol (umol/1) & $30.5 \pm 7 . .3$ & $32.4 \pm 7.1$ & $31.0 \pm 7.1$ & $32.6 \pm 0.1$ \\
\hline Platsma P-carolene (umol/1) & $0.31 \pm 0.20$ & $0.27 \pm 0.15$ & $0.32 \pm 0.1 .3$ & $4.20 \pm 2.0^{*}$ \\
\hline Plasma lotal carotenoids (amol'l) & $1.50 \pm 0.56$ & $1.60 \pm 0.67$ & $1.58 \pm 0.58$ & $5.27 \pm 2.25 *$ \\
\hline Plasma cotininc $(\mathrm{ng} / \mathrm{ml})$ & $310 \pm 107$ & $315 \pm 131$ & $33(0 \pm 123$ & $322 \pm 110$ \\
\hline
\end{tabular}

one p-carolene participant has a missing valuc.

2n.at. = not applicablc.

* significantly different from placcho group. $p<0.0(0) 1$.

At baseline. metaplasia scores were somewhat. though not signiticantly, higher in the B-carotene group (ligure I; $p=0.06$ ). The worst grade of metaplasia. observed in only one participant, was mild dysplasia. Initial and linal metaplasia scores did not differ in the B-carotene group $(p=0.75)$. In the placebo group final metaplasia scores were somewhat higher than initial scores $(p=0.15)$. linal netaplasia scores were similar in both groups (ligure $2 ; p=0.09$ ). 


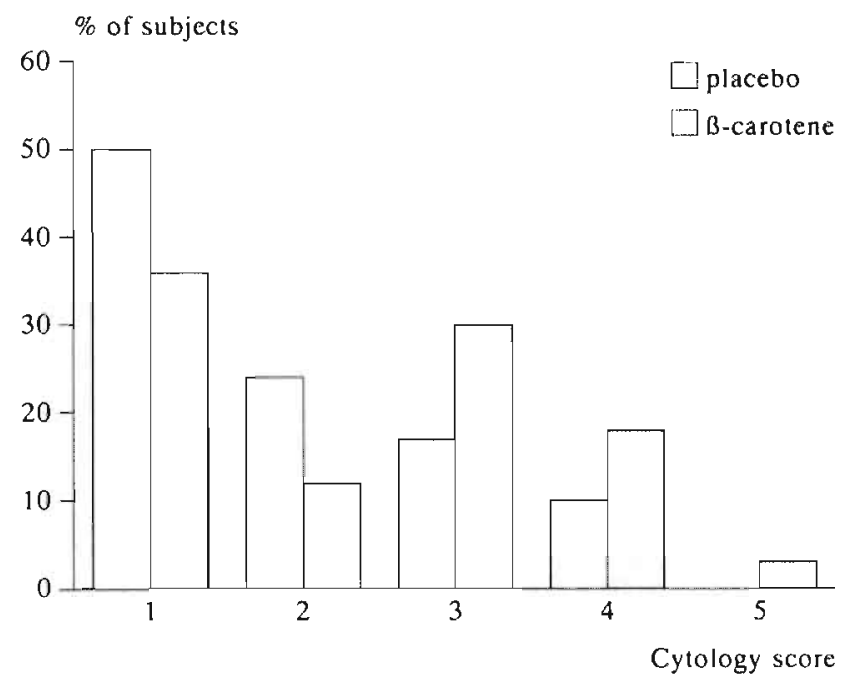

Figure 1 Distribution of cytology scores at the start of a 14-weeks trial in male smokers, assigned 10 cither placebo $(n=42)$ or $\beta$-carotene treatment $(n=33)$.

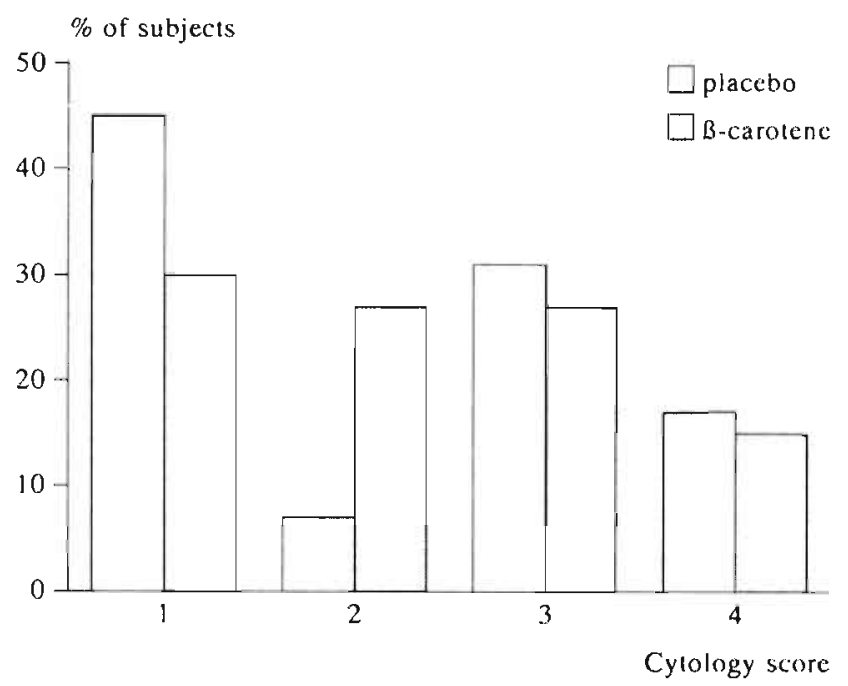

Figure 2 Distribution of cytology scores at the end of a 14-weeks trial in male smokers, assigned to either placebo $(n=42)$ or $\beta$-carotene treatment $(n=33)$. 
Table 2 and 3 shows the relation between initial and final metaplasia scores in both treatment groups. During the intervention, $39 \%$ of the carotene group showed improvement in metaplasia scores, compared with $24^{\prime} ;$ in the placebo group $(p=0.16)$. There was no correlation between the initial and final metaplasia scores either in the $\beta$-carotene group $(R=0.18, p=0.3)$, or the placebo group $(R=0.17, p=0.3)$, or in both groups combined $(R=0.18, p=0.13)$. There was no correlation between any of the baseline characteristics in table 1 and the baseline metaplasia scores (all $\mathrm{R}<0.20$ ).

Table 2. Numbers of subjects in the placebo group with initial and final cylology scores.

\begin{tabular}{lllll}
\hline & \multicolumn{4}{c}{ Initial cytology score } \\
\cline { 2 - 5 } Final cytology score & 1 & 2 & 3 & 4 \\
& $(\mathrm{n}=21)$ & $(\mathrm{n}=10)$ & $(\mathrm{n}=7)$ & $(\mathrm{n}=4)$ \\
\hline $1(\mathrm{n}=19)$ & 12 & 3 & 3 & 1 \\
$2(\mathrm{n}=3)$ & 1 & 0 & 1 & 1 \\
$3(\mathrm{n}=13)$ & 5 & 5 & 2 & 1 \\
$4(\mathrm{n}=7)$ & 3 & 2 & 1 & 1 \\
\hline
\end{tabular}

Table 3. Numbers of subjects in B-carotene group with initial and final cytology scores.

\begin{tabular}{llllll}
\hline & \multicolumn{5}{c}{ Initial cylology score } \\
\cline { 2 - 5 } Final cytology score & 1 & 2 & 3 & 4 & 5 \\
& $(\mathrm{n}=12)$ & $(\mathrm{n}=4)$ & $(\mathrm{n}=10)$ & $(\mathrm{n}=6)$ & $(\mathrm{n}=1)$ \\
\hline $1(\mathrm{n}=10)$ & 3 & 3 & 2 & 1 & 1 \\
$2(\mathrm{n}=9)$ & 5 & 0 & 4 & 0 & 0 \\
$3(\mathrm{n}=9)$ & 3 & 1 & 3 & 2 & 0 \\
$4(\mathrm{n}=5)$ & 1 & 0 & 1 & 3 & 0 \\
\hline
\end{tabular}

Table 4 compares characteristics of the study participants with those of the group who was not eligible because they produced no or unsatisfactory sputum samples. The study group is older and has a longer smoking history. All other characteristics including daily cigarette consumption and plasma cotinine were similar. Also, compliance was similar in both groups ( $93 \%$ vs. $90 \%$ of all capsules taken). 
Table 4. Baseline characteristics of study participants compared with non-cligible subjects.

\begin{tabular}{lcl}
\hline & $\begin{array}{c}\text { Study participants } \\
(n=75)\end{array}$ & $\begin{array}{c}\text { Non-eligible subjects } \\
(\mathrm{n}=75)\end{array}$ \\
\hline Age (years) & $37.4 \pm 9.3$ & $41.4 \pm 10.0^{*}$ \\
Cigarettes per day & $21.1 \pm 6.8$ & $21.6 \pm 7.0$ \\
Years of smoking & $19.4 \pm 9.7$ & $23.2 \pm 10.3^{*}$ \\
Blood vitamin C $(\mu \mathrm{mol} / \mathrm{l})$ & $34.4 \pm 15.9$ & $39.1 \pm 19.6$ \\
Plasma retinol $(\mu \mathrm{mol} / \mathrm{l})$ & $2.31 \pm 0.42$ & $2.38 \pm 0.66$ \\
Plasma $\alpha$-tocopherol $(\mu \mathrm{mol} / \mathrm{l})$ & $30.7 \pm 5.7$ & $31.0 \pm 7.2$ \\
Plasma $\beta$-carotene $(\mu \mathrm{mol} / \mathrm{l})$ & $0.31 \pm 0.18$ & $0.31 \pm 0.17$ \\
Plasma total carotenes $(\mu \mathrm{mol} / \mathrm{l})$ & $1.54 \pm 0.62$ & $1.58 \pm 0.57$ \\
Plasma cotinine $(\mathrm{ng} / \mathrm{ml})$ & $333 \pm 118$ & $322 \pm 114$ \\
\hline
\end{tabular}

${ }^{*} p<0.005$.

\section{Discussion}

This study shows no effect of $\beta$-carotene on the degree of bronchial metaplasie in heavy smokers. Bronchial metaplasia may be a potential marker of pre-malignancy, since the development of carcinoma of the lung has been considered to proceed along the several increasing stages of atypical metaplasia. ${ }^{19}$ Therefore, our results do not seem to lend support to the hypothesis that $\beta$-carotene may protect against lung cancer risk in smokers. Scveral precautions, however, should be considered when interpreting our results.

First, it should be realized that our study was not specifically designed to test a hypothesis with regard to bronchial metaplasia. Sputum samples were routinely collected as part of a trial to evaluate the effect of $\beta$-carotene on several markers for DNA-damage in smokers. ${ }^{\text {H.9 }}$ We therefore did not perform a pre-screening, e.g. to select subjects producing satisfactory sputum samples or subjects showing metaplasia on several sampling occasions. As a result the sample size in our study is rather moderate, which precludes the drawing of definitive conclusions. However, Heimburger et al. ${ }^{10}$ have reported a similar study in only 37 smokers supplemented with folate and B-12, and 36 placebo subjects. These numbers were sufficient to provide preliminary evidence for a beneficial effect. In contrast, our results do not even provide a tendency towards a positive result since there was essentially no change in average metaplasia scores in the treatment group, and no difference in after-treatment metaplasia scores between the placebo and the $\beta$-carotene group.

Though our trial was not specifically designed to study metaplasia, the lack of effect of $\beta$-carotene can hardly be attributed to methodological shortcomings, since the trial was fully randomized and placebo controlled and compliance was very good. Table 1 shows, that randomization was successful, even though the subjects were randomized without knowing whether they would be eligible for a cytology study. Moreover, the eligible and non eligible group are very similar, (table 2) with the exception of a difference in age and duration of 
smoking. Therefore, a selection bias influencing our conclusions seems improbable. The only point at which randomization was not completely successful, was the average degree of initial metaplasia since the placebo group contained more lower initial cytology scores (figure 1), though not statistically significant. Regression to the mean following the 'accidentally' lower initial scores probably explains the insignificant increase in average metaplasia scores in the placebo group during the trial. It therefore does not seem justified to compare this increase with the 'unchanged' metaplasia scores in the $\beta$-carotene group, more so because initial and final metaplasia scores showed no significant correlation. Initial scores thus have little value in predicting final scores, due to large variations over time.

Large variations in cytology scores over time have been previously observed. ${ }^{10.11}$ In our study, observer variations will have had some, but not a major contribution to this variation over time, since both inter- and intra-observer agreement upon repeated scoring were satisfactory. Degrees of observer agreement comparable to ours have been reported by Heimburger, ${ }^{10}$ whereas somewhat better agreement was reported by Browman et al ${ }^{20}$ In this respect, it is noteworthy that our classification would be expected to yield less exact agreement since we use 5 categories where the other studies use only three. Though we used three pooled samples, sampling variation thus seems to have a major influence on the variation in sputum cytology scores over time. This sampling variation may be inherent to the use of sputum, since samples may originate from all locations in the tracheobronchial tree. Our results thus suggest that interpretations of sputum cytology scores are only useful at group level, and that interpretation of changes in individual scores over time is not warranted. Repeated sputum sampling and scoring may reduce this within person variation. Alternatively, studies using bronchial bushings or biopsies are more invasive but can be expected to be more site specific and yield less variations.

Possibly, our study may have been to short to demonstrate an effect, or the dose of $\beta$-carotene may have been insufficient. Though the total cellular turnover of the tracheobronchial epithelium is 30 days, ${ }^{12}$ the time span that is relevant for progression or regression is uncertain. However, Heimburger's study demonstrated effects within a four months period. As for the dose of $\beta$-carotene, this is equivalent to 5 to 10 times the normal intake, and plasma levels dramatically increased. Other studies in humans have used higher doses $\left(50-300 \mathrm{mg} /\right.$ day) but report similar after-treatment plasma $\beta$-carotene levels. ${ }^{21.22}$ This suggests that our $20 \mathrm{mg} /$ day dose is sufficient for a maximal increase of $\beta$-carotene in plasma and tissue. The dose in our study is similar to the doses used in two large scale cancerprevention studies. ${ }^{4.5}$

With regard to metaplastic changes, a retinol-mediated effect of $\beta$-carotene, possibly through conversion at tissue level ${ }^{23}$ seems more plausible than an antioxidant mediated effect. Retinoids have an important role in cellular differentiation and proliferation. ${ }^{24}$ The maintenance of a normal bronchial epithelial pattern is partially dependent upon vitamin $A,{ }^{24}$ and vitamin A deficiency can induce metaplasia. ${ }^{25}$ In this respect it is noteworthy that Arnold et al. ${ }^{11}$ recently demonstrated no effect of a synthetic retinoid on sputum cytology in a carefully designed placebo-controlled trial in 150 smokers. Arnolds study ${ }^{11}$ thus did not substantiate 
preliminary findings from a previous smaller and uncontrolled trial ${ }^{26}$ and seems in accordance with our observation of no effect of the pro-vitamin $A \beta$-carotene.

Our study cannot exclude an effect of $\beta$-carotene on more severe stages of bronchial atypia, since only 11 subjects $(15 \%)$ in our study showed minor or mild atypia at the entry of our study. Interestingly, Heimburgers folate and B-6 study ${ }^{10}$ suggests that the observed effect in their study was primarily confined to the 8 subjects $(11 \%)$ showing atypia on entry. On the other hand, Arnolds retinoid study ${ }^{11}$ showed no effect in a trial with all subjects showing atypia at study entry.

It is tempting to interpret this study using a putative biomarker as indicating no influence of $\beta$-carotene on cancer risk. However, the predictive value of mild atypia for later development of lung cancer is only modest, ${ }^{27}$ and other biomarker studies have shown effects of $\beta$-carotene. In this same study group, we recently demonstrated beneficial effects of $\beta$-carotene on DNA damage as reflected by micronuclei in sputum cells. ${ }^{9}$ Likewise, Stich et al. ${ }^{28.29}$ demonstrated beneficial effects of $\beta$-carotene on micronuclei in buccal mucosa cells in tobacco chewers, whereas Garewal ${ }^{30}$ reported evidence for a beneficial effect on oral leukoplakia. Possibly, $\beta$-carotene does indeed effect human carcinogenesis, but not at all stages of carcinogenesis or at all cancer sites.

This study provides preliminary evidence that $\beta$-carotene has no influence on minor bronchial metaplastic changes as detected in sputum cytology. Moreover, the results indicate that the performance of future studies can be increased by repeated sampling or use of brushings to diminish variations in cytology, by increasing size and time span, and by preselection of subjects with more severe lesions. Therefore, cautious interpretation of the absence of an effect of $\beta$-carotene is warranted.

\section{References}

1. Willett WC. Vitamin A and lung cancer. Nutr Rev 1990;48:201-211.

2. Van Poppel G. Carotenoids and cancer: An update with emphasis in human intervention studies. Eur J Cancer 1993:29A:1335-1344.

3. Krinsky NI. Carotenoids as chemopreventive agents. Prev Med 1989;18:592-602.

4. Hennekens $\mathrm{CH}$, Eberlein K. A randomized urial of aspirin and $\beta$-carotene among US pysicians. Prev Med 1985:14:165-168.

5. Albanes D, Virtamo J, Rautalahti M, Pikkarainen J, Taylor PR, Greenwald P, Heinomen OP. Pilot sludy: The US-Finland lung cancer prevention trial. J Nutr Growth Cancer 1986:3:207-214.

6. Boone CW, Kelloff GJ, Malone WE. Identification of candidate chemoprevention agents and their evaluation in animal models and human clinical trials; a review. Cancer Res 1992:50:2-9.

7. Greenwald P, Witkin KM, Malone WF, et al. The study of markers of biological effect in cancer prevention research trials. Int J Cancer 1992;52:189-196.

8. Van Poppel G, Kok FJ, Duijzings P, De Vogel N. No influence of $\beta$-carotene on smoking-induced DNA damage as reflected by sister chromatid exchanges. Int J Cancer 1992;51:355-358.

9. Van Poppel G, Kok FJ, Hermus RJJ. $\beta$-Carotene supplementation in smokers reduces the frequency of micronuclei in sputum. Br J Cancer 1992;66:1164-1168.

10. Heimburger DC, Alexander CB, Birch R, Butterworth CE, Bailey WC, Krumdieck CL. Improvement in bronchial squamous metaplasia in smokers treated with folate and vitamin B-12. JAMA 1988;259:15251530 .

11. Arnold AM, Browman GP, Levine MN, D'Souza D, Johnstone B, Skingley P, Turner-Smith L, Cayco R, Booker L, Newhouse M, Hryniuk WM. The effect of the synthetic retioid etretinate on sputum cytology: 
rcults from a randomised trial. Br J Cancer 1992;65:737-743.

12. Saccomanno G. Diagnistic pulmonary cytology. ISBN 0-89189-050-5. American Society of Clinical Pathologists, Chicago, 1978.

13. Bruck HC. Histologische Technik. Leitfaden für die Herstellung mikroskopischer Präparate in Unterricht und Praxis. ISBN 3-13314304-2. Georg Thieme Verlag, Stuttgart New York, 1981.

14. Riolton G, Christopherson WM, Lunt R. Cytology of non-gynaecological sites (international Histological Classification of Tumors, no 17). Geneva, World Health Organization, 1977.

15. Speek AJ, Schrijver J, Schreurs WHP. Fluorimetric determination of total vitamin C in whole blood by high performance liquid chromatography with pre-column derivatization. J. Chromatogr 1984;305:53-60.

16. Van Vliet T, Van Schaik F, Van Schoonhoven J, Schrijver J. Determination of several retinoids, carotenoids, and E vitamers by HPLC. Application to plasma and tissues of rats fed a diet rich in either ß-carolene or canthaxanthin. J Chromatogr 1991;553:179-186.

17. Feyerabend C, Bryant A, Jarvis MJ, Russell MAH. Determination of cotinine in biological fluids of nonsmokers by packed column gas-liquid chromatography. J Pharm Pharmacol 1984;38:1075-1078.

18. Dixon WJ (ed). BMDP Statistical Software Manual. University of California Press, Berkeley, 1988.

19. Saccomanno G, Archer VE, Auerbach O, Saunders RP, Brennan LM. Development of carcinoma of the lung as reflected in exfoliated cells. Cancer 1974;33:256-270.

20. Browman GP, Arnold A, Levine MN, D'Souza T, Tumer-Smith LM, Cayco R, Johnstone B, Birse R. Use of screening phase data to evaluate observer variation of sputum cytodiagnosis as an outcome measure in a chemoprevention trial. Cancer Res 1990;50:1216-1219.

21. Nierenberg DW, Bayrd GT, Stukel TA. Lack of effect of chronic administration of oral $\beta$-carotene on serum cholesterol and triglyceride concentration. Am J Clin Nutr 1991;53:652-654.

22. Ringer TV, De Loof MJ, Winterrowd GE, et al. $\beta$-carotene's effects on serum lipoproteins and immunologic indices in humans. Am J Clin Nutr 1991;53:688-694.

23. De Vet HCW. The puzzling role of vitamin A in cancer prevention (review). Anticancer Res 1989;9:145152.

24. Sporn MB, Roberts AB, Roche NS, Kagechika H, Shudo K. Mechanism of action of retinoids. J Am Acad Dermatol 1986;15:756-764.

25. Lippman S, Kessler J, Meyskens F. Retinoids as preventive and therapeutic anticancer agents (part I). Cancer Treat Rep 1987;71C:391-405.

26. Gouveia J, Mathé G, Hercend T, et al. Degree of bronchial metaplasia in heavy smokers and its regression after treatment with a retinoid. Lancet 1982:i:710-712.

27. Vine MF. Schocnbach VJ, Hulka BS. Koch GG, Samsa G. Atypical metaplasia and incidence of bronchogenic carcinoma. Am J Epidemiol 1990;131:781-793.

28. Stich $\mathrm{HF}$, Hornby $\mathrm{P}$, Dunn $\mathrm{BC}$. A pilot $\beta$-carotene intervention trial with inuits using smokeless tobacco. Int J Cancer 1985;36:321-327.

29. Stich HF, Rosin MP, Hornby AP, Matthew B, Sankaranarayanan R, Nair MK. Remission of oral leukoplakias and micronuclei in tobacco/betel quid chewers treated with $\beta$-carotene and with $\beta$-carotene plus vitamin A. Int J Cancer 1988;42:195-199.

30. Garewal HS, Meykens FL, Killen D, et al. Response of oral leukoplakia to $\beta$-carotene. J Clin Oncol 1990;8:1715-1720. 


\section{Epilogue}

This Chapter evaluates the contribution that the studies in this thesis have made to our scientific knowledge. In the first part of this Chapter methodological issues are considered to evaluate the validity of the studies for further interpretation. In the second part, the contribution of the studies to our understanding of biological mechanisms regarding carcinogenesis and the role of $\beta$-carotene is discussed. Implications and expectations for future research are discussed in the third part of this epilogue.

\section{Validity issues}

The studies discussed in the overview in Chapter 2 as well as the "new" studies presented in this thesis all have a common aim; 10 contribute to our knowledge of what is happening in the human body during the development of human cancer, and elucidating the role of $\beta$-carotene in this process. In interpreting studies, it is therefore good scientific practice to evaluate the validity of studies. Two aspects of validity can be distinguished. Internal validity refers to the question whether effects observed within a given study are really true, or whether these effects may have been distorted by flaws in the study design, conduct or analysis. External validity refers to the question whether the effects observed in a given study can be extrapolated or generalized to what is really happening in humans in the general population. ${ }^{1.2}$ In this thesis, two types of studies are reported, i.e. observational studies (Chapter $3 \& 4$ ) as well as experimental studies (Chapter 5-8). For both study types, issues regarding validity are discussed below.

\section{Validity of observational studies}

The internal validity of observational or non-experimental studies may be hampered by three forms of bias. ${ }^{1,2}$

Selection bias refers to a distortion of the measured effect introduced by the procedures used to select the study population. For instance, in a case-control study on diet and cancer, selection bias can occur if controls having "healthy" eating habits are more willing to participate and thus are overrepresented in the study group. For the associations between biological markers that we report within the group of smokers, a selection bias seems highly improbable. In the comparisons between smokers and non-smokers in Chapter 3 and 4 , however, selection bias could attribute to the observed differences in vitamin levels if health-consciousness was a stronger motivation to participate in non-smokers than in the smokers. However, the contrasts in vitamin levels between smokers and non-smokers in our study correspond closely to those in surveys that did not use smoking behaviour as a factor in subject selection. 
Information bias refers to misclassification of study subjects, e.g. with regard to plasma levels of antioxidants or levels of intermediate endpoints. If this misclassification is random or non-differential all study groups that are being compared will be misclassified to an equal degree and associations will be attenuated. This is called bias towards the null. The misclassification can however also be differential and may lead to over- or underestimation in certain study groups. The phenomenon of information bias is illustrated by the observer and run variation in the SCE measure that we observed in Chapter 3 . For the analyses within the group of smokers, results were not biased, since smokers were randomly divided over runs and observers. Nonsmokers, however, were differentially misclassified following their unequal distribution over runs and observers. In the comparison between smokers and nonsmokers multivariate adjustment was used to account for this information bias. Chapter 3 thus demonstrates that differential misclassification can either be avoided by study design or can be accounted for by adjustment in multivariate analyses. However, for a number of markers presented in this study, we also observed a large amount of error of yet unknown origin. Presumably, this error will be random and will therefore attenuate or obscure associations. Therefore, as we emphasize in Chapter 3, the absence of significant associations in the cross-sectional studies should only be interpreted with great caution as evidence of a complete absence of a relation in a biological sense.

Confounding bias is the phenomenon that the observed effect of a factor is mixed with the effect of a second factor. This bias occurs if the confounding factor is associated with both the factor of interest, as well as with the biological effect (e.g. disease) under study. In our study in Chapter 3, alcohol consumption could possibly be a confounder in the association between smoking and SCE levels, since smokers consume considerably more alcohol than non-smokers. However, the association between alcohol consumption and SCE level, if present, is very weak. Adjustment for differences in alcohol consumption therefore does not materially alter the difference in SCE levels between smokers and non-smokers. In Chapter 3 and 4 , possible confounders have been discussed in detail. It seems improbable that the associations reported in these Chapters suffer from confounding bias since possible confounding factors were measured and accounted for in the analyses.

With regard to the external validity of an observational study, this clearly can only be good if the internal validity is also satisfactory. The external validity of a study can also be affected otherwise, since findings in a study group of a given age, sex, and race cannot necessarily be generalized to the entire human population. The effect of a factor may thus be different or not present in the entire human population. For the studies in Chapter 3 and 4 , this cannot be ruled out, since the studies were carried out in a select group, i.e. male administrative volunteers. However, it seems improbable that the biological associations that we report will be different in other age groups or in females in the general population, or in people who were not willing to volunteer. 


\section{Validity of experimental studies}

The concepts of information bias, confounding and selection bias can also be applied to experimental epidemiological studies, and can even be extended to other experimental work, e.g. animal or laboratory experiments. In experimental work, the influences of confounding, information and selection bias on internal validity can be eliminated by appropriate study design. In a randomized placebo controlled trial, as reported in this thesis, the placebo and treatment group can be expected to be comparable with regard to known or unknown confounding factors. To further ensure this comparability, prestratification on known confounding factors before randomization was used. Randomization and pre-stratification in trials can also be expected to eliminate possible differential information errors. In this case, however, the placebo and treatment group should be comparable with regard to the influence of measurement errors. Thus, in the studies in this thesis placebo and treatment group were equally divided over laboratory runs, measurements days, observers, or other sources of variation. With regard to nondifferential information errors, i.e. misclassification leading to bias lowards the null, randomization does not offer a solution. Even properly randomized studies will fail to demonstrate associations if random error dilutes true associations and the study size is inadequate. In the design of our studies inevitable random error has been incorporated, since power calculations based on known random errors were performed to ensure an adequate study size. For the sputum cytology study in Chapter 8 , however, there was no prior estimate of error or spontaneous variation. Chapter 8 therefore emphasizes that the limited study size and the large spontaneous variations warrant cautious interpretation of the lack of an effect.

Experiments such as those described in this thesis, in contrast with observational studies, can thus be designed to have an optimal internal validity. This optimal internal validity is an important reason why we chose to perform the experiments in this thesis. However, the external validity of experiments often poses problems. In animal or laboratory experiments, the external validity is hampered by uncertainties in extrapolation from in vitro to in vivo situations, between species, and from short term high dose exposures to more chronic and low dose exposures. In human experiments, uncertainties regarding external validity still exist since it is not feasible to perform a life-time lasting experiment in a free living group of humans completely representative of the general population. Studies on cancer incidence thus necessarily focus on relatively short term trials in often elderly high risk groups, and may only have a bearing upon events in the late stages of carcinogenesis. Studies using biomarkers for cancer risk, such as those presented in this thesis, do not have this limitation. Biomarker studies may thus be the only opportunity to obtain valid information in earlier stages of carcinogenesis in humans. However, the external validity is uncertain for other reasons, since the predictive value of the applied markers for cancer development has not been established. Also, in the studies that we report, findings in male heavy smokers are described that may not apply to the general population. The results described 
in this thesis therefore cannot be directly translated to human cancer risk, given the uncertainties regarding external validity. However, the studies do contribute to our understanding of the biological truth in humans, since they provide us with otherwise not obtainable information on biological mechanisms as measured in humans. In combination with other scientific work such as animal experiments, observational studies and trials on cancer incidence, biomarker studies thus provide a more complete picture to allow for a scientific judgement on the role of $\beta$-carotene in cancer prevention.

\section{Biological mechanisms}

In the studies reported in this thesis, we tested several hypotheses regarding the biological mechanisms of human carcinogenesis and the involment of $\beta$-carotene in this process. These hypotheses and their verification or falsification are discussed in detail in each separate Chapter. In this Chapter, we will try to integrate these results into a single conceptual framework. Moreover, this integrated interpretalion will allow us to consider the mplication of the sudy resuls fis sech regarding carcinogenesis and $\beta$-carotene. In Chapter 2 , we described the current concepts of huma carcinogenesis as a multistage process involving multiple genetic and epigenetic events. This concept of carcinogenesis, as depicted in Chapter 2, figure 1, shows conceptual similarities with the framework for the classification of biomarkers, as given by the US National Research Council' (figure 1).

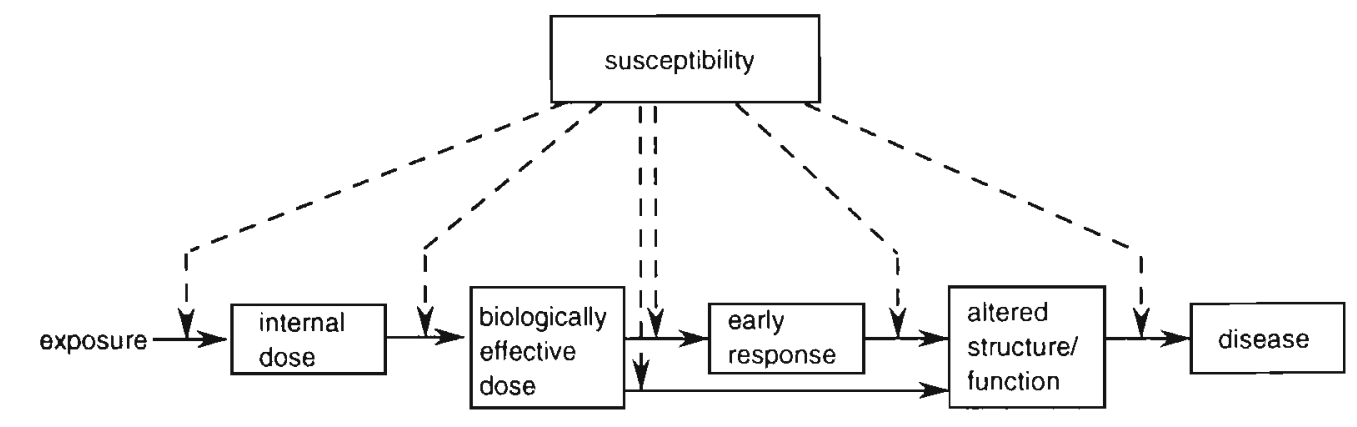

Figure 1. The relationship of biological markers to exposure and disease.

In analogy with this figure, it is tempting to categorize the biomarkers we used in this study as reflecting the different stages of carcinogenesis (initiation, promotion, conversion, progression) as given in Chapter 2, figure 1. ${ }^{4}$ Following this analogy, SCE and micronuclei could be considered markers of early biological effects that reflect DNA damage; these markers would then be relevant in the initiation phase of carcinogenesis. Likewise, measurements of immune response would bear relevance to the promotional stages of carcinogenesis, since immune surveillance may prevent the occurrence of altered cell structures that show immunogenic properties. Metaplastic changes in sputum then would reflect altered structures in preneoplastic lesions and would thus bear relevance to the late (conversion/progression) stages of carcinogenesis. This categorization of the biomarkers within the framework of carcinogenesis is conceptually attractive and may indeed be helput for an ineged interse helpful for an inged is intere however, that reality is more complex tha our concepts. For inster probably indeed involved in early initiation stages of carcinogenesis, but may also significantly contribute to the later stages of carcinogenesis. ${ }^{4}$

With regard to biological mechanisms, the results in this thesis seem to indicate that the two markers for DNA damage (micronuclei in sputum vs SCE in lymphocytes) may in fac reflect different hiological phenomena. Firstly, because we did not observe a correlation between SCE levels and micronuclei counts. Secondly, because we did observe an berween SCE levels and mic associalion beteen the epoxide derxify

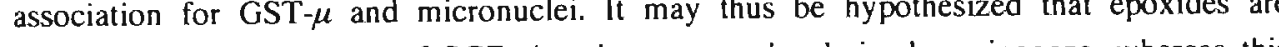
important in the induction of SCEs by cigarelte smoke derived carcinogens, whereas this may not be the case for micronuclei. This hypothesis regarding the role of epoxides in SCE and micronuclei induction is also supported by the differential results with regard to the B-carotene supplement: we observed no effect upon SCE levels, as contrasted with a considerable reduction in micronuclei counts. Free radicals probably play an important role in several forms of DNA damage, but not in the in vivo production of epoxide intermedites inter mex an antioxidan neer this would explain the diffrent response of $m$ ictong supplements. Following the arguments given above, the different responses of SCEs and micronuclei after $\beta$-carotene also seems to support the hypothesis that $\beta$-carotene is effective as an antioxidant, and not as a pro-vitamin A. This notion is also supported by the unchanged plasma retinol levels during the trial. Results regarding buccal micronucle as reported by Stich ${ }^{\mathrm{B}}$ also seem to support a non-retinol mediated effect of $\beta$-carotene since subjects in this latter trial had normal retinol levels, though retinol levels were no subects in his monitored ding ing subsets, also without changes in plasma retinol levels. However, our study failed to confirm these results (Chapter 7), possibly because of differences in age between the study groups.

Apart from differences in molecular mechanisms contributing to SCES versus micronuclei, the different effects of $\beta$-carotene may also be explained by site-specificity. Biomarke studies that have so far shown positive effects of $\beta$-carotene (e.g. oral leucoplakia ${ }^{10}$ and micronuclei ${ }^{8.11}$ all relate to tissues directly in contact with tobacco components. This may 
measurements of immune response would bear relevance to the promotional stages of carcinogenesis, since immune surveillance may prevent the occurrence of altered cell structures that show immunogenic properties. Metaplastic changes in sputum then would reflect altered structures in preneoplastic lesions and would thus bear relevance to the late (conversion/progression) stages of carcinogenesis. This categorization of the biomarkers within the framework of carcinogenesis is conceptually attractive and may indeed be helpful for an integrated interpretation of the results in this thesis. It should be realised, however, that reality is more complex than our concepts. For instance, DNA damage is probably indeed involved in early initiation stages of carcinogenesis, but may also significantly contribute to the later stages of carcinogenesis. ${ }^{4}$

With regard to biological mechanisms, the results in this thesis seem to indicate that the two markers for DNA damage (micronuclei in sputum vs SCE in lymphocytes) may in fact reflect different biological phenomena. Firstly, because we did not observe a correlation between SCE levels and micronuclei counts. Secondly, because we did observe an association between the epoxide detoxifying enzyme GST- $\mu$ and SCEs, in contrast with no association for GST- $\mu$ and micronuclei. It may thus be hypothesized that epoxides are important in the induction of SCEs by cigarette smoke derived carcinogens, whereas this may not be the case for micronuclei. This hypothesis regarding the role of epoxides in SCE and micronuclei induction is also supported by the differential results with regard to the $\beta$-carotene supplement: we observed no effect upon SCE levels, as contrasted with a considerable reduction in micronuclei counts. Free radicals probably play an important role in several forms of DNA damage, but not in the in vivo production of epoxide intermediates nor in the reaction of epoxides with DNA. ${ }^{5.6 .7}$ Thus, if $\beta$-carotene functions as an antioxidant neutralizing free radicals, whereas SCEs are primarily induced by epoxides, this would explain the different response of micronuclei and SCEs after $\beta$-carotene supplements. Following the arguments given above, the different responses of SCEs and micronuclei after $\beta$-carotene also seems to support the hypothesis that $\beta$-carotene is effective as an antioxidant, and not as a pro-vitamin A. This notion is also supported by the unchanged plasma retinol levels during the trial. Results regarding buccal micronuclei as reported by Stich $^{8}$ also seem to support a non-retinol mediated effect of $\beta$-carotene since subjects in this latter trial had normal retinol levels, though retinol levels were not monitored during the trial. Likewise, Watson ${ }^{9}$ reports effects of $\beta$-carotene on lymphocyte subsets, also without changes in plasma retinol levels. However, our study failed to confirm these results (Chapter 7), possibly because of differences in age between the study groups.

Apart from differences in molecular mechanisms contributing to SCEs versus micronuclei, the different effects of $\beta$-carotene may also be explained by site-specificity. Biomarker studies that have so far shown positive effects of $\beta$-carotene (e.g. oral leucoplakia ${ }^{10}$ and micronuclei ${ }^{8.11}$ all relate to tissues directly in contact with tobacco components. This may 
also be considered to support an antioxidant mediated effect of $\beta$-carotene, since it is likely that the directly exposed (oral and tracheobronchial) tissues suffer most from oxidant stress. However, it is also possible that carcinogens from cigarette smoke induce localized retinol deficiencies that are more efficiently neutralized by (putative) $\beta$-carotene conversion at tissue level ${ }^{12,13}$ than by supply of retinol from the circulation. In this respect, it is of interest to note that a similar theory on localized deficiency due to cigarette smoke exposure has recently been formulated with regard to folic acid. ${ }^{14}$ Since we did not measure retinol levels in sputum cells, an effect of $\beta$-carotene on micronuclei through conversion to retinol following localized tissue deficiencies cannot be excluded. However, antioxidant effects of $\beta$-carotene are at this moment supported by ample experimental evidence, ${ }^{15}$ whereas localized conversion to retinol remains to be established.

From the results for the micronuclei and SCE measures, we may thus conclude that $\beta$-carotene seems to protect against certain, but not all, forms of cigarette smoke induced DNA damage, especially in target tissue exposed to cigarette smoke components. This is in line with previous results for buccal micronuclei. ${ }^{8,11}$ Following the previously discussed classification of biomarkers in the pathway of carcinogenesis, this may imply a protective effect of $\beta$-carotene in the early or initiation stages of carcinogenesis. Since we observed no influence of $\beta$-carotene on metaplastic changes in bronchial sputum cells, our results may thus be construed as indicating an effect of $\beta$-carotene primarily in these early phases. For several reasons, however, this interpretation must be cautiously viewed, and may not be fully warranted. Firstly, because we also observed an effect of $\beta$-carotene, though moderate, on aspects of immune functioning. The relevance of increased $T$ cell mutagenesis for cancer immune surveillance remains uncertain, but these results may indicate an involvement of $\beta$-carotene in later stages of carcinogenesis through immune modulation. Secondly, it should be realized that DNA damage has been implied in cancer initiation, but may also contribute to later promotional stages of carcinogenesis (see Chapter 2). Finally, our metaplasia results do not provide a tendency for a beneficial effect, but the limited size of the trial and the large variations in sputum cytology warrant cautious interpretation of these metaplasia results.

The hypothesis that $\beta$-carotene is indeed primarily effective in the earlier stages of carcinogenesis has attractive aspects since it may, apart from site specificity, help to explain the recently reported lack of an effect of $\beta$-carotene in triais on cervical dysplasia ${ }^{16}$ and second skin cancers. ${ }^{17}$ On the other hand the preliminary evidence for effects on oral leucoplakia ${ }^{10}$ may not correspond with early stage effectiveness. Further information to test this hypothesis can be expected from the ongoing trials in cancer incidence: if $\beta$-carotene is primarily effective in earlier stages, then an effect would only be detected after a longer follow-up. Indeed, the Physicians Health Study has recently been extended to more than 10 years-follow. ${ }^{18}$ This illustrates that results and hypotheses from biomarker research can have important implications for design and conduct of future studies on disease incidence. 


\section{Implications for future research}

\section{Intermediate endpoint research}

Biomarkers are increasingly being used in epidemiology to estimate exposure, susceptibility, early biological effects and pre-malignant disease stages. ${ }^{19.20}$ Markers for biological effects and pre-malignant stages are of special interest, since they can be considered as "intermediate endpoints" for cancer risk. These intermediate endpoints will be distinguishable earlier and will be less rare than clinical malignancies. Therefore, intermediate endpoints may permit quicker, smaller and less costly investigations that also provide more insight in biological mechanisms. ${ }^{21.22,23}$ Though the concept of intermediate endpoints is attractive, methodological and practical information on the application of such endpoints is relatively scarce. For application in future studies, we therefore discuss this information for the three putative intermediate endpoints used in this thesis; SCEs in lymphocytes, micronuclei in sputum cells, and metaplastic changes as observed in sputum cytology.

For the application of SCEs, it should be rearized that they show only limited sensitivity towards variations in cigarette smoke exposure. Indeed, we observed only a 10-20\% increase among smokers as compared with non-smokers (Chapter 3). Moreover, we observed considerable variation between laboratory runs and between two scorers, despite our efforts for standardization. In our study, almost $50 \%$ of the variation in SCEs was explained by variation between runs and observers. Also, we observed a very large variation over the 14-weeks period, that may have resulted from (a combination of) seasonal variation, diurnal variation, between run variation, as well as random variation of unknown origin. This biological and technical variability in the SCE measure implies that valid conclusions can only be drawn from carefully designed studies of sufficient size in which sources of variation are accounted for in design or analysis. The application of the SCE measure in epidemiological studies also has logistic constraints, since viable lymphocytes and a rather laborious cell culture process are necessary. Also possibilities for quality control are hampered by the inability to include a pool sample in each laboratory run. A better understanding of the sources of variation may lead to further standardization of the SCE determination, diminished random and non random error, and increased study power. Ideally, this standardization should also be applied over several laboratorics to facilitate comparability of results of several studies.

For the micronuclei measurement, we observed no sensitivity towards the fluctuations in cigarette smoke exposure within our rather homogeneous group of heavy smokers. We did not have non-smoker data for comparisons since we found out that healthy nonsmokers do not spontaneously produce sputum. Other studies in a clinical setting have shown a 3-fold 
increase in micronuclei in sputum ${ }^{24}$ and bronchial brushings ${ }^{25}$ in smokers compared to nonsmokers. Despite inherent sampling variability, there was a moderate association ( $R=0.3-0.4$ ) between micronuclei counts in the same subjects sampled 14-weeks apart. Within-observer agreement was good, and there was no discernable between-run variation, possibly because the micronuclei parameter does not require in vitro cultivation of sampled cells, as contrasted with SCE. These results for the micronuclei determination indicate, that it may be a more attractive marker than SCEs in future studies. More so, because the logistics of the micronuclei marker are less complicated than the SCE parameter. Cells can be collected in fixative at participants homes and samples can be sent by mail. However, our data were obtained by scoring 3000 cells for each sample, which implies a major effort for a single observer. In the future, the prospect of automated scoring ${ }^{26}$ therefore deserves further study. Also, future studies could be strengthened by repeated sputum sampling. Bronchial brushings are more site specific but have the drawback of being more invasive.

For the bronchial metaplasia marker, we again observed no association with cigarette consumption within our rather homogeneous group of heavy smokers. Agreement between and within observers was satisfactory, and comparable to agreements reported in other studies. We observed no association between sputum cytology scores in the same subjects measured 14-weeks apart, probably due to inherent sampling variability. This large withinperson variability implies, that interpretations of sputum cytology scores are only useful at group level, and that interpretation of changes in individual scores over time is not warranted. A certain amount of observer and sampling variability, as in our study, seems inevitable for this marker. Future studies may decrease sampling variability by repeated sampling or by the use of bronchial brushing or biopsies. Also, future studies may benefit from a pre-screening to select subjects showing more severe stages of metaplasia on repeated sampling.

The intermediate endpoints described in this thesis are among those more frequently used. ${ }^{27}$ For these markers, the biological and molecular mechanism underlying the marker are not exactly known. In terms of the potential of interpretation of results and contribution to understanding of mechanisms, markers at a more molecular level may prove useful in future studies on carcinogenesis. The GST- $\mu$ phenotype characterization reported in this thesis can be considered as a marker for susceptibility (see figure 1) at a molecular level. In this respect, recent developments in the measurement of specific DNA adducts, ${ }^{28}$ oncogenes and tumor suppressor genes ${ }^{29}$ and molecular markers for cellular differentiation and proliferation ${ }^{2.3}$ may offer exciting opportunities for future molecular epidemiological studies. With regard to $\beta$-carotene and cancer risk in smokers, assessment of aromatic

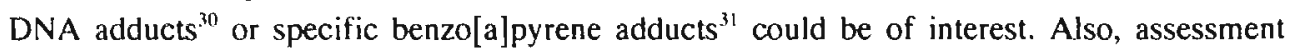
of 8-hydroxylation of the guanosine base could be a measure as an indication of in vivo oxidative DNA damage. ${ }^{32}$ Since carotenoids have been reported to up regulate gap junction communication by stimulating connexin 43 gene expression, ${ }^{33}$ measurements of tissue levels 
of this protein ${ }^{34}$ could provide a molecular marker for regulation of cell proliferation. For cancer at other sites, expression of ras-oncogene ${ }^{35}$ or accumulation of P53 tumor suppressor protein $^{36}$ have been suggested as intermediate markers for carcinogenesis. A final and very important issue in the future of intermediate endpoint research will clearly be the assessment of their validity in predicting cancer. As discussed in detail by Schatzkin, ${ }^{21}$ this involves the incorporation of biomarkers in either prospective cohort studies or in intervention studies on cancer incidence.

\section{Carotenoid and antioxidant research}

The results in this thesis are a contribution to the ongoing research into the possible cancer preventive properties of carotenoids. With regard to $\beta$-carotene research, a number of desirable future epidemiologic studies that could be mentioned after performing our studies need not to be elaborated here, since several intervention studies on cancer incidence or intermediate endpoints are currently being conducted (see Chapter 2). Moreover, in Chapter 9.2 we have discussed several suggestions for intermediate endpoints at a molecular level that could be relevant to $\beta$-carotene research. Results from the ongoing intervention studies, especially with regard to cancer incidence, are eagerly awaited and can be expected to yield more definite answers regarding the putative cancer preventive potential of $\beta$-carotene. As we have discussed, the results described in this thesis may imply the need for a longer follow up in the trials on cancer incidence. Also, our studies may imply that an effect of $\beta$-carotene may be more readily discernable in smokers, being a high risk group with regard to DNA damage and cancer occurence.

If $\beta$-carotene does indeed prove to be beneficial in the ongoing trials, further laboratory study of the mechanisms of action will still be very meaningful for future possibilities for prevention of cancer. If the mechanism is primarily dependent upon conversion to retinol, this would imply that only carotenoids with pro-vitamin A activity will be beneficial. If, however, the mechanism of action (also) involves other, e.g. antioxidant, pathways, this would increase the scope to other potentially protective carotenoids that deserve further epidemiological and laboratory study. Moreover, the scope would then not be limited to carotenoids, but also to other antioxidant compounds (e.g. tocopherols, flavonoids and polyphenols) that are present in fruits and vegetables. ${ }^{37.3 x}$ Future studies could then face the challenge to study not only individual antioxidant components, but also the effects of synergism and interaction between antioxidants. From the results of our studies, an antioxidant mediated pathway for $\beta$-carotene seems plausible, though it has not been proven. The further study of both nutritive and non-nutritive antioxidants in cancer prevention therefore remains a promising field for future research. 


\section{Conclusions}

This thesis has evaluated a number of studies on cancer risk in humans using biomarkers with emphasis on the role of $\beta$-carotene. Regarding the application of biomarkers, the work in this thesis indicates that sources of variation in biomarker assessment need to be carefully incorporated into study design and analysis to allow internally valid conclusions to be drawn from biomarker studies. Moreover, logistic constraints may presently limit the applicability of a number of biomarkers in epidemiological study designs.

Though the predictive value of the biomarkers in this thesis is not established yet, these markers can provide information on biological mechanisms that would otherwise not be available from human studies. The data thus suggest, that increases in certain forms of DNA damage in GST- $\mu$ deficient smokers may explain the reported association between GST $-\mu$ deficiency and lung cancer risk. The results also indicate, that SCE and micronuclei, both markers of DNA damage, may in fact reflect different biological phenomena. With regard to $\beta$-carotene, the results suggest that $\beta$-carotene may indeed reduce cancer risk in humans by preventing cigarette smoke induced DNA damage. Also, $\beta$-carotene may enhance certain aspects of immune function. Moreover, the data are suggestive that $\beta$-carotene is effective per se, and not through conversion to retinol: this supports an antioxidant mediated mechanism for $\beta$-carotene. However, the data also indicate that $\beta$-carotene is not effective against all forms of cigarette smoke induced DNA damage and that $\beta$-carotene may not be effective in later stages of carcinogenesis as reflected by metaplasic changes. Our data thus substantiate and extend the implications from previous human studies, that $\beta$-carotene can affect human carcinogenesis, but not at all stages of carcinogenesis nor at all cancer sites.

\section{References}

1. Rolhman KJ. Modern epidemiology. Isı ed. Little Brown \& Co. Boston/Toronto, 1986.

2. Kleinbaum DG, Kuppert LL. Morgenstern H. Epidemiologic Research. Principles and quantitative methods. Van Nostrand Reinhold Co, New York, 1982.

3. National Research Council, Committee on Biological Markers. Biological Markers in Environmental Health Research. Environ Health Perspect 1987;74:3-9.

4. Harris CC. Chemical and physical carcinogenesis: advances and perspectives for the 1990s. Cancer Res 1991:51 suppl:50235-5044S.

5. Gelboin HV. Benzola]pyrene metabolism, activation and carcinogenesis: Role and regulation of mixed function oxidases and related enzymes. Physiol Rev 1980;60:1107-1166.

6. Hernandez O. Bend JR. Metabolism of epoxides. In: Mannervik B (ed.). Metabolic basis of deloxication, Academic Press, New York, 1982.

7. Pryor WA. Cigarelle smoke and the involvement of free radical reactions in chemical carcinogenesis. Br J Cancer 1987;55 suppl VIII;19-23.

8. Stich HF, Homby AP. Dunn BP. A pilot $\beta$-carotene intervention trial with inuits using smokeless tobacco. Ini J Cancer 1985;36:321-327.

9. Watson RR, Prabhala RH, Plezia PM, Alberts DS. Effect of $\beta$-carotene on lymphocyte subpopulations in elderly humans: evidence for a dose-response relationship. Am J Clin Nutr 1991;53:90-94.

10. Garewal HS, Meyskens FL, Kitlen D, et al. Response of oral leucoplakia to $\beta$-carotene. J Clin Oncol $1990 ; 8: 1715-1720$. 
11. Stich HF, Rosin MP, Vallejera MO. Reduction with vitamin $A$ and $\beta$-carotene administration of proportion of micronuclealed buccal mucosal cells in Asian betel nut and robacen chewers. Lancel $1984 ; \mathrm{i}: 1204-1206$.

12. De Vet HCW. The puzzling role of vitamin $A$ in cancer prevention (review). Anticancer Res 1989;9:145-152.

13. Edes TE, Gysbers DG, Buckley CS, Thornton WH. Exposure to the carcinogen benzopyrene depletes tissue vitamin A: $\beta$-carotenc prevents depletion. Nutr Cancer 1991:15:159-166.

14. Heimburger DC. Krumdicck CL. Alexander CB, Birch R. Dill SR, Bailey WC. Localized folic acid deficiency and bronchial metaplasia in smokers: hypothesis and preliminary report. Nutr Int 1987;3:54-60.

15. Krinsky NI. Antioxidant functions of carotenoids. Free Radical Biol Med 1989;7:617-635.

16. De Vet HCW, Knipschild PG, Willebrand D, et al. The effect of $\beta$-carotene on the regression and progression of cervical dysplasia: a clinical experiment. J Clin Epidemiol 1991;44:273-283.

17. Greenberg ER, Baron JA, Stukel TA. et al. A clinical trial of $\beta$-carotene to prevent basal-cell and squamous-cell cancers of the skin. N Engl J Med 1990;323:789-795.

18. Manson JE, Hunter DJ, Buring JE, Hennekens $\mathrm{CH}$. $\beta$-Carotene to prevent skin cancer. $N$ Eng J Med $1991 ; 324: 924$.

19. Perera F. Molecular cancer epidemiology: a new $100 \mathrm{l}$ in cancer prevention. J Natl Cancer Inst 1987:78:887-898.

20. Van Poppel G, Verhagen H, Van 't Veer P. Biomerkers in epidemiologisch en loxicologisch voedingsonderzoek. Voeding 1992;9:222-229.

21. Schatzkin A, Freedman LS, Schiffman MH. Validation of intermediate end points in cancer research. J Natl Cancer Inst 1990;82:1746-1752.

22. Greenwald P. Witkin KM, Malone WF, et al. The study of markers of biological effect in cancer prevention research trials. Int J Cancer 1992;52:189-196.

23. Lippman SM, Lee JS, Lotan R, et al. Biomarkers as intermediate end points in chemoprevention trial. J Natl Cancer Inst 1990;32:555-560.

24. Fontham E, Correa $P$, Rodriguez E, Lin Y. Validation of smoking history with the mictonuclei test. In: Hoffmann D. Harris CC (eds): Mechanisms in tobacco carcinogenesis. Banbury Report 23, 113 118, Cold Spring Harbor Laboratory, New York 1986.

25. Lippmann SM, Peters EJ, Wargovich MJ, et al. Bronchial micronuclei as a marker of an early stage of carcinogenesis in the human tracheobronchial epithelium. Int J Cancer 1990;45:811-815.

26. Fenech M, Jarvis LR. Morley AA. Preliminary słudies on scoring micronuclei hy computerized image analysis. Mutat Res 1988;203:33-38.

27. Hulka BS, Wilcosky TC, Griffith JD (eds.) Biological Markers in Epidemiology, Oxford University Press, New York. Oxford 1990.

28. Bartsch $\mathrm{H}$, Hemminki K, O'Neill IK (eds.). Methods for detecting DNA damaging agenis in humans:

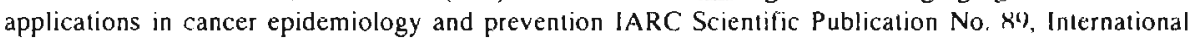
Agency for Research on Cancer, Lyon 1988.

29. Schwartz GG. Oncogenes: a primer for epidemiologists. In: Hulka BS, Wilcosky TC, Griffith JD (eds.) Biological Markers in Epidemiology, Oxford University Press, New York. Oxford 1900.

30. Jones NJ, McGregor AD. Waters R. Detection of DNA adducts in human oral lisuuc: correlation of adduct Icicls with tobacco smoking and differential enhancement of adducts using the butanol extraction and nuclease P1 versions of "P posilabeling. Cancer Res 1993;53:1522-1528.

31. Van Schooten FJ, Van Lecuwen FE, Hillebrand MJ, el al. Determination of benzola]pyrenc diol epoxide-DNA adducts in white blood cell DNA from cokc-oven workers: the impact of smoking. J Natl Cancer Inst 1990;82:927-933.

32. Loft S, Vistisen K, Ewertz M, Tjønneland A, Overvad K. Poulsen HE. Oxidative DNA damage estimated by 8-hydroxydeoxyguanosine excretion in humans: influence of smoking, gender and body mass index. Carcinogenesis 1992;13:2241-2247.

33. Zhang LX, Cooney RV, Bertram JS. Carotenoids up-regulate connexin43 gene expression independent of their provitamin a or antioxidant properties. Cancer Res 1992;52:5707-57I2.

34. Guo H, Acevedo P, Parsa FD, Bertram JS. The gap junctional protein connexin 43 is expressed in dermis and epidermis of human skin: differential modulation by retinoids. J Invest Dermatol $1992 ; 99 ; 460-467$.

35. Singh J, Kelloff G, Reddy S. Intermediate biomarkers of colon cancer: modulation of expression of ras oncogene by chemopreventive agants during azoxymcthane induced colon carcinogencsis. Carcinogenesis 1993;14:699-704. 
36. Wang LD, Hong JY, Qiu SL, Gao H, Yang CS. Accumulation pf pS3 protein in human esophageal precancerous lesions: a possible early biomaker for carcinogenesis. Cancer Research 1993;53:1783. 1787.

37. Namiki M. Antioxidants/antimutagens in Food. CRC Critical Reviews in Food Science and Nutrition 1990;29:273-300.

38. Steinmetz KA, Potter JD. Vegetables, fruits and cancer. II. Mechanisms. Cancer Causes \& Control $1991 ; 2: 427-442$. 


\section{Summary}

Carotenoids are yellow to red pigments that occur in vegetables and fruits. Carotenoids, especially $\beta$-carotene, have been hypothesized to decrease human cancer risk. The current state of knowledge regarding the cancer-preventive properties of carotenoids is summarized in Chapter 2. Epidemiologic studies have shown consistent inverse relations between intake of carotenoid-rich fruits and vegetables and risk of cancer at a number of common sites. For other sites, however, the evidence is not consistent. Mechanisms that could explain a protective action of carotenoids include conversion to retinol, antioxidant functions. immunomodulatory effects, as well as modification of carcinogen metabolism and cell-to-cell communication. Since observational epidemiology cannot resolve causal associations, human intervention studies on cancer incidence or on biomarkers related to cancer risk are necessary.

The hypothesis that $\beta$-carotene may decrease cancer risk is addressed in this thesis using an intervention trial in a high-risk group of heavy smokers. The trial evaluates the effect of $\beta$-carotene supplementation on several putative markers or intermediate endpoints for cancer risk. Two markers reflect DNA damage, which is a crucial event in carcinogenesis. These cytogenetic markers are sister chromatid exchanges (SCE) in peripheral lymphocytes, and micronuclei in sputum as expectorated from the respiratory tract. As indices for immune function lymphocyte subsets in peripheral blood as well as mitogen-induced lymphocyte proliferation response were used. Sputum cytology was used to evaluate bronchial metaplastic changes as a potential marker of later stages of carcinogenesis. Plasma levels of $\beta$-carotene, retinol and antioxidant vitamins were monitored during the trial, as well as plasma cotinine as a measure of smoking behaviour. In addition, we assessed deficiency of the detoxification enzyme glutathione S-transferase $\mu$ (GST $-\mu$ ) as a potential marker of genetic susceptibility to cancer. All participants in the study were healthy male employees, who reported not to be exposed to xenobiotic chemicals and who volunteered for the study. Smokers were selected for the trial if they had smoked more than 15 cigarettes per day for over 2 years. For comparisons, a group of non-smokers (never smokers) was selected for a baseline measurement without participation in the $\beta$-carotene trial.

In Chapters 3 and 4, data from the baseline measurements are used to evaluate the application of a number of biomarkers in a cross-sectional study involving both the smokers $(n=156)$ and the non-smokers $(n=38)$. For the smokers group, this cross-sectional study also provides the baseline measurement of the intervention trial. As expected, smokers had higher levels of SCE (5.08 vs. 4.71 SCE per lymphocyte) and lower levels of the antioxidants vitamin C (36.6 vs. $54.8 \mu \mathrm{mol} / \mathrm{l})$ and $\beta$-carotene $(0.31$ vs. $0.48 \mu \mathrm{mol} / \mathrm{l})$, indicating increased oxidant stress. Within the group of smokers, the two measures of DNA damage, micronuclei and SCE, were not associated $(\mathrm{R}=-0.025)$ and showed only limited sensitivity to variations in cigarette smoke exposure. SCE were higher in GST- $\mu$-deficient smokers (5.24 vs. 4.97 SCE per lymphocyte). 
For micronuclei a similar GST- $\mu$-reiated difference was not observed (4.3 vs. 4.9 micronuclei per 1000 cells).

The results of the $\beta$-carotene intervention are presented and discussed in Chapters 5 to 8 . The 163 volunteers were prestratified by age, duration and quantity of smoking and randomly assigned to either $20 \mathrm{mg} /$ day $\beta$-carotene $(n=80)$ or placebo treatment $(n=83)$ for 14-weeks. During the trial 13 smokers ( 6 placebo, $7 \beta$-carotene) discontinued participation, whereas biomarkers were inadequate or not obtained in a varying number of participants. The $\beta$-carotene and placebo groups were comparable on all initial characteristics. Plasma levels of $\beta$-carotene in the treatment group increased 14 -fold during the trial whereas plasma levels of vitamins or cotinine remained unchanged in both groups.

The trial showed no protective effect of $\beta$-carotene on DNA damage reflected by SCE in lymphocytes (Chapter 5). Changes in SCE counts were identical in the placebo group $(n=73)$ and the $\beta$-carotene group $(n=70)$, as were SCE values after treatment (4.37 vs. 4.24 SCE per lymphocyte). Micronuclei in sputum, on the other hand, were reduced after $\beta$-carotene treatment; after adjusiment for initial values, the treatment group ( $n=53$ ) had $27 \%$ lower micronuclei counts than the placebo group $(n=61)$ at the end of the trial (Chapter 6). Lymphocyte subpopulations showed that the initial and final distribution over all $\mathrm{B}$ and $\mathrm{T}$ cell subsets was identical in both groups (21 $\beta$-carotene, 24 placebo) (Chapter 7). For ex vivo mitogen response induced by PHA. T cell proliferation was $12 \%$ higher in the $\beta$-carotene group ( $n=24)$ then in the placebo group $(n=23)$. Bronchial metaplasia in sputum cytology was assessed in $33 \beta$-carotene and 42 placebo subjects (Chapter 8). There was no decrease in metaplasia scores in the $\beta$-carotene group during the trial, and final metaplasia scores were similar in the placebo and the $\beta$-carotene group.

The epilogue (Chapter 9) evaluates the contribution that the studies in this thesis have made 10) our scientific knowledge. Sources of variation in biomarker assessment need to be carefully incorporated in study design and analysis to eliminate various sources of bias and thus to allow intermally valid conclusions to be drawn. The randomized placebo-controlled intervention studies in this thesis fultil these requirement, but the external validity is not certain since the predictive value of the biomarkers is not established yet. The markers can, however, provide information on biological mechanisms that would otherwise not be available from human studies.

In conclusion, the results indicate that increases in certain forms of DNA damage in GST- $\mu$ deficient smokers may explain the reported association between GST- $\mu$ deficiency and lung cancer risk. The results also suggest that SCE and micronuclei, both markers of DNA damage, may in fact reflect different biological phenomena. With regard to $\beta$-carotene, the results indicate that $\beta$-carotene may indeed reduce cancer risk in humans by preventing cigarette smoke-induced DNA damage. Also, $\beta$-carotene may enhance certain aspects of immune 
function. Moreover, the data suggest that $\beta$-carotene is effective per se, and not through conversion to retinol; this supports an antioxidant mediated mechanism for $\beta$-carotene. However, the data also indicate that $\beta$-carotene is not effective against all forms of cigarette smoke-induced DNA damage and that $\beta$-carotene may not be effective in later stages of carcinogenesis as reflected in metaplastic changes. Our data thus substantiate and extend the implications from previous human studies, that $\beta$-carotene can affect human carcinogenesis, but not at all stages of carcinogenesis nor at all cancer sites. 



\section{Samenvatting}

Carotenoïden zijn gele, oranje en rode kleurstoffen die voorkomen in groenten en fruit. Er zijn aanwijzingen dat carotenoiden, en in het bijzonder $\beta$-caroteen, bij zouden kunnen dragen aan een verminderd risico op kanker. In dit proefschrift is het verband tussen $\beta$-caroteen en kankerrisico bestudeerd in een aantal epidemiologische onderzoeken bij gezonde vrijwilligers. $\mathrm{Bij}$ deze vrijwilligers zijn een aantal zogenaamde biomerkers gemeten die bedoeld zijn om een indruk te krijgen van het mogelijke kankerrisico.

In hoofdstuk 2 van het proefschrift wordt een overzicht gegeven van de huidige stand van de wetenschappelijke kennis op het gebied van carotenoiden en kanker. Epidemiologische onderzoeken hebben een consistent verband aangetoond tussen een hogere consumptie van groenten en fruit die rijk zijn aan carotenoiden en een lager risico op een aantal veel voorkomende vormen van kanker. Voor een aantal andere vormen van kanker zijn de aanwijzingen echter niet eenduidig. Een aantal werkingsmechanismen zouden een beschermende werking van carotenoiden kunnen verklaren, zoals omzetting in vitamine $A$, antioxidant werking, beïnvloeding van het immuunsysteem, een invloed op de ontgifting van kankerverwekkende stoffen en een werking op de communicatie tussen de lichaamscellen. Uit de studies tot nu toe kan echter nog geen oorzakelijk verband worden geconcludeerd. Hiervoor is interventie-onderzoek nodig, waarbij nagegaan wordt of consumptie van extra caroteen invloed heeft op het voorkomen van kanker of op biomerkers voor kankerrisico.

In dit proefschrift worden de resultaten beschreven van zo'n interventie-onderzoek met biomerkers bij een groep mensen met een hoog risico op kanker, namelijk rokers. Twee van de biomerkers die gemeten zijn geven een indruk van DNA beschadigingen, omdat schade aan DNA een belangrijke stap is in het ontstaan van kanker. De eerste merker voor DNA schade is het aantal sister chromatid exchanges (SCE), gemeten in bepaalde witte bloedcellen, de lymfocyten. De tweede merker voor DNA schade is het aantal micronuclei, gemeten in opgehoest longslijm. Als merker voor het immuunsysteem is in het bloed de verdeling van lymfocyten over subgroepen met een bepaalde functie bepaald. Daarnaast is de groeireactie van de lymfocyten in celkweek gemeten na toevoeging van stoffen die tot celdeling aanzetten. Als mogelijke merker voor de latere stadia in het kankerproces is sputum cytologie gebruikt; hicrbij zijn metaplastische veranderingen in opgehoest longslijm beoordeeld. Behalve de merkers voor kankerrisico zijn een aantal andere biomerkers bepaald, waaronder bloedwaarden voor $\beta$-caroteen, vitamine $A$ en antioxidant vitamines, en bloedwaarden voor cotinine als een maat voor het rookgedrag. Verder is in bloed de aan of afwezigheid van het ontgiftingsenzym glutathion S-transferase $\mu$ (GST- $\mu$ ) bepaald; dit zou een merker kunnen zijn voor een erfelijk bepaalde gevoeligheid voor het krijgen van kanker.

Alle vrijwilligers voor het onderzoek waren gezonde mannelijke werknemers. De rokers in het interventie-onderzoek hadden allemaal gedurende twee jaar meer dan 15 sigaretten per dag 
gerookt. Ter vergelijking is aan het begin van het onderzoek ook een groep mensen gemeten, die nooit gerookt hadden. Deze laatste groep heeft geen extra $\beta$-caroteen gekregen.

In hoofdstuk 3 en 4 worden de gegevens van de beginmeting bij 156 rokers en 38 niet-rokers gebruikt om de toepassing van biomerkers in een cross-sectioneel onderzoek te evalueren. Zoals verwacht, hadden rokers meer SCE's (5,08 vs. 4,71 SCE per lymfocyt) en lagere bloedwaarden voor de antioxidanten vitamine $C(36,6 \mathrm{vs} .54,8 \mu \mathrm{mol} / \mathrm{l})$ en $\beta$-caroteen $(0,31 \mathrm{vs}$. $0,48 \mu \mathrm{mol} / \mathrm{l})$. Dit geeft aan dat bij roken grotere oxidatie-stress bestaat. Binnen de groep rokers werd geen verband gevonden tussen de twee maten voor DNA schade, micronucleï en SCE's $(\mathrm{R}=-0,025)$, terwijl deze merkers slechts in beperkte mate gevoelig waren voor verschillen in blootstelling aan tabaksrook. De rokers zonder het enzym GST- $\mu$ hadden hogere SCE waarden (5,24 vs. 4,97 SCE per lymfocyt), maar niet duidelijk verschillende micronucleï waarden ( 4,3 vs. 4,9 micronucleï per 3000 cellen).

De resultaten van de interventie met $\beta$-caroteen worden besproken in hoofdstuk $5 \mathrm{t} / \mathrm{m} 8$. De 163 rokers werden door het toeval toegewezen aan een groep die gedurende 14 weken $20 \mathrm{mg}$ extra $\beta$-caroteen per dag kreeg $(n=80)$, of aan een placebogroep die gedurende dezelfde tijd een pil zonder werkzame stof kreeg $(n=83)$. Bij deze toewijzing werd rekening gehouden met de leeftijd en het rookgedrag van de rokers. Tijdens de studie hebben 13 deelnemers ( 6 placebo, 7 B-caroteen) zich teruggetrokken uit het onderzoek, terwijl bij een wisselend aantal personen niet alle biomerkers gemeten konden worden. De placebo en $\beta$-caroteen groep waren bij de aanvang van het onderzoek vergelijkbaar voor wat betreft bloedwaarden voor antioxidanten en vitamines. Tijdens de interventie werden de bloedwaarden in de $\beta$-caroteen groep 14 keer zo hoog, terwijl de bloedwaarden voor de antioxidanten en cotinine gelijk bleven in beide groepen.

In het onderzoek werd geen beschermend effect van $\beta$-caroteen gevonden op DNA schade in de vorm van SCE's (hoofdstuk 5). De veranderingen in SCE's tijdens het onderzoek waren gelijk in de placebo groep $(n=73)$ en de $\beta$-caroteen groep $(n=70)$, evenals de eindwaarden voor SCE's (4,37 vs. 4,24 SCE per lymfocyt). Voor de micronucleï werd wél een afname door $\beta$-caroteen gevonden; na correctie voor de beginwaarden had de $\beta$-caroteen groep $(n=53)$ $27 \%$ lagere eindwaarden dan de placebo groep $(n=61)$. De verdeling van lymfocyten over een groot aantal subgroepen was zowel bij de aanvang als aan het eind van de studie identiek in beide groepen (21 $\beta$-caroteen, 24 placebo) (hoofdstuk 7). Voor de groeireaclie van lymfocyten na toediening van de stof phytohaemagglutinine werd een $12 \%$ hogere waarde gevonden in de $\beta$-caroteen groep $(n=24)$ in vergelijking met de placebo groep $(n=23)$. Metaplastische veranderingen in longslijm werden beoordeeld in $33 \beta$-caroteen en 42 placebo deelnemers. Er was geen verbetering waarneembaar in de $\beta$-caroteen groep gedurende de interventie, en de uiteindelijke scores waren ook niet verschillend tussen de placebo en de $\beta$-caroteen groep. 
In de epiloog van dit proefschrift (hoofdstuk 9) word besproken, wat de bijdrage is van de onderzoeksresultaten aan onze wetenschappelijke kennis. Er wordt geconcludeerd dat bij het opzetten en interpreteren van studies terdege rekening gehouden moet worden met allerlei redenen voor variaties in biomerker bepalingen, zodat de onderzoeksresultaten niet vertekend worden. In de dubbel-blinde, placebo gecontroleerde onderzoeksopzet in dit proefschrift lijkt zo'n vertekening van de onderzoeksresultaten onwaarschijnlijk. Bij het interpreteren van de resultaten moet echter wel bedacht worden dat we nog niet zeker weten of de biomerkers voor kankerrisico in het onderzoek inderdaad iets zeggen over het later krijgen van kanker. De biomerkers geven ons in elk geval wel een goed inzicht in de biologische werkingsmechanismen bij mensen.

De conclusies van dit proefschrift zijn allereerst dat een toename in bepaalde vormen van DNA schade bij rokers zonder het ontgiftings enzym GST- $\mu$ een verklaring kan zijn voor het verband in eerdere onderzoeken tussen erfelijk bepaalde afwezigheid van dit enzym en het optreden van longkanker. Verder lijken verschillende biologische mechanismen verantwoordelijk voor de twee merkers voor DNA schade, SCE's dan wel micronucleï. Voor wat betreft $\beta$-caroteen laten de onderzoeksresultaten zien, dat $\beta$-caroteen inderdaad het kankerrisico in mensen zou kunnen verlagen omdat $\beta$-caroteen bepaalde vormen van DNA schade door roken vermindert. Ook zou $\beta$-caroteen bepaalde aspecten van het immuunsysteem kunnen stimuleren. Bovendien suggereren de resultaten, dat $\beta$-caroteen deze effecten heeft zonder dat het omgezet wordt in vitamine $A$. Dit maakt het waarschijnlijker dat $\beta$-caroteen als antioxidant beschermend zou werken. De resultaten van het onderzoek geven tegelijkertijd echter ook aan, dat $\beta$-caroteen zeker niet werkt tegen alle vormen van DNA schade door roken, terwijl ook geen effecten aangetoond konden worden op metaplastische veranderingen die optreden in de latere fasen van het kankerproces. De resultaten van dit onderzoek zijn hiermee een onderbouwing en uitbreiding van de eerdere onderzoeken die wijzen op een invloed van $\beta$-caroteen op het proces van kanker, maar niet op alle vormen of stadia van kanker. 



\section{Nawoord}

De bibliotheek van TNO Voeding in Zeist is gunstig gelegen met grote ramen op het zuiden en uitzicht op een park met oude beuken. Dit nodigt uit tot een langer verblijf dan strikt noodzakelijk, en de eerste ideeën voor de studies in dit proefschrift werden dan ook geboren in deze bibliotheek. Ideeën is één ding, en een helder projectvoorstel en dit ook nog uitvoeren is iets heel anders; hiervoor waren vruchtbare en soms verhitte discussies met Prof.Dr. Frans J. Kok onontbeerlijk. Frans, mijn dank voor jouw betrokkenheid en begeleiding bij 'ons' onderzoek. Ben je nu promotor in plaats van co-promotor omdat ik langzaam was, of omdat jij snel was? Ook Prof.Dr. Ruud J.J. Hermus, als promotor van het eerste uur, wil ik graag danken voor de steun die hij aan het onderzoek gegeven heeft.

Voor een epidemiologisch onderzoek zijn onderzoeksdeelnemers onmisbaar. Ik heb bewondering voor de vele vrijwilligers die nauwgezet supplementen hebben geslikt, en soms geduldig een wintersport kleur zonder hoogte-stage hebben doorstaan. Ook de instellingen die bereid waren hun deuren te openen ben ik veel dank verschuldigd. Bij het Centraal Belastinggebouw Utrecht was Fred van den Bosch altijd paraat om een onderzoeksruimte te regelen, terwijl bij het Energiebedrijf Utrecht Ton de Zwart een onaangenaam vroege start telkens weer mogelijk maakte. Bij AMEV gaven de bedrijfsartsen G.K.M. Maat en M.Th.J. Atjak hun steun, terwijl Trudy Hermans, Janna Middag en natuurlijk Alice van Zijl zorgden voor een grote hoeveelheid praktische en sociale ondersteuning. Alice, volgens mij deden een flink aantal vrijwilligers meer voor jou dan voor de wetenschap mee!

Bij de praktische uitvoering van een project wordt een onderzoeker geconfronteerd met fundamentele biologische beperkingen. Zo heeft ieder mens maar twee handen, terwijl veelal 90\% van de hersencellen niet gebruikt wordt. Veel dank daarom aan Hanny Leezer, die deze beperkingen niet schijnt te hebben en die bovendien blijmoedig bestand is tegen de chaos die mijn actieve $10 \%$ weet te produceren. Hanny, ik weid verder niet uit, want we hebben maar twee pagina's voor het nawoord. Een ander rustpunt was natuurlijk Wim Gorgels, die nu vee! meer ervaring met veldwerk heeft dan de doorsnee epidemioloog (sorry Wim).

Biomerkers betekent laboratoriumbepalingen. Tijdens het project heb ik precies één keer een pipet in $m$ 'n handen gehad, dus 'de uitbesteder' als bijnaam lijkt wel terecht. De micronucleï en SCE bepalingen door de Afdeling Biologische Toxicologie waren een tour de force voor rekening van Wilma Stenhuis, Truus Bruyntjes en Nico de Vogel. Het onmogelijke deden zij direct, op wonderen moest ik iets langer wachten, en tegenwoordig duiken ze niet meer weg als ik in de gang loop. Verder dank aan van André Tielemans en Bep van Tuijl, aan Jan Bogaards voor de GST- $\mu$ bepalingen en aan Jan Catsburg voor de 'difjes'. Bij de Afdeling Experimentele Biologie waren de vitaminebepalingen, een perfect systeem van opslag bij -80 , en een mondsnoerend systeem van humor in goede handen bij Anneke Rademaker, Gonnie 
Pieters, Jan van Schoonhoven, Jan Knijff, Freek Schrander en Frank van Schaik. Jolanda van Os en Lia Velthuizen waren bovendien altijd bereid om bloed te prikken (mooi werk hè, Lia, zo'n motor met zijspan). Mocht er na een bezoek aan EB nog een restje babbels over zijn dan was er altijd het Voedingslab met een prachtige eigen variatie op het mondsnoeren; veel dank aan Steven Spanhaak en Hillie Pellegrom voor de subsets, de stimuleringstesten, en de broodnodige uitleg hierbij.

Ondanks de vele laboratoria in Zeist zijn er ook nog essentiële bepalingen elders gedaan. I would like to thank Dr. Martin Jarvis of the Institute of Psychiatry in London for the cotinine assays. Voor de sputumcytologie is zeer prettig samengewerkt met de Afdeling Pathologie van de Katholieke Universiteit Nijmegen. Tiny Heynen deed de cytologische beoordelingen en heeft zo ervaren dat epidemiologie vooral veel betekent, terwijl Anniek van Aspert enthousiast een scoringsprotocol opstelde en de aanvullende scores deed. Mijn dank dat jullie ondanks het monnikenwerk toch telkens enthousiast waren als ik weer binnen kwam vallen!

Mijn allereerste idee van epidemiologie in een grijs verleden was dat het iets met computers was en dit bleek tijdens dit onderzoek weer waar. Voor hulp bij de data-invoer en verwerking dank aan Paul Duijzings, Evelien Aarnink en Ria KJokman, en aan Arthur van Aken voor de figuren. Verder natuurlijk dank aan Cor Kistemaker en Eric Schoen voor verkoelende statistische adviezen in tijden van cerebrale oververhitting.

Mocht de oplettende lezer nu denken dat deze promovendus niet veel zelf heeft gedaan, dan is dit het moment om te bekennen dat ik ook lang niet alles zelf bedacht heb. Voor de toxicologische advisering vanuit de afdeling Biologische Toxicologie zorgde Dr. Jan Wilmer tijdens de beginfasen van het project, terwijl Prof.Dr. Peter van Bladeren tijdens de latere fasen ook al te snel bleek om copromotor te blijven. Voor vitamine- en caroteen-expertise kon ik altijd terecht bij Dr. Jaap Schrijver van de afdeling Experimentele Biologie. Verder dank aan Dr. Theo Ockhuizen, destijds hoofd van de afdeling Voeding, voor de immunologische inbreng en de steun voor dit promotie-onderzoek. Prof.Dr. G.P. Vooijs van de afdeling Pathologie, KU Nijmegen was een onmisbaar adviseur op het gebied van sputumcytologie. Van Dr. Riekie de Vet van afdeling Epidemiologie, RL Maastricht, kreeg ik goede adviezen en haar proefschrift was tot voor kort het enige dat ik ooit helemaal gelezen heb.

Het menselijk geheugen is kort en lijkt een voorkeur te hebben voor irrelevante zaken. Daarom wil ik hier iedereen bedanken die niet met name genoemd is en die direct of indirect heeft bijgedragen aan het proefschrift. Anonieme referenten, wiens commentaren mijn adrenaline omhoogjoegen, mijn collega's die dat moesten opvangen, mijn klim- en skievrienden voor zeer positieve adrenaline buiten werktijd, mijn huisgenoten voor de late borrels. Tot slot wil ik mijn ouders bedanken, die mij leerden dat de dingen misschien wel anders zijn, en dat de horizon ver weg is. Ik hoop dat ze dit een mooi boekje vinden. 


\section{Bibliography}

Strik JJTWA. Mensink JA, Vos GJ, Van Poppel G, Topp RJ. Porphyrinogenic action of tetrachloroazobenzene. Chemosphere 1983:12:573.

Deurenberg P, Van Poppel G, Hautvast JGAJ. Morbiditeit en subjeclief welbevinden bij jonge volwassenen met overgewicht. Ned Tijdschr Geneeskd 1984;128:940-944.

Van Staveren WA, West CE, Hoffmanns MDAF, Bos P, Kardinaal AFM, Van Poppel GAFC, Schipper HJA, Hautvast JGAJ, Hayes RB. Comparison of contemporaneous and retrospective estimalcs of food consumplion made by dietary history method. Am J Epidemiol 1986;123:884-893.

Knuiman JT, Van Poppel G, Burema J, Van der Heijden L. Hautvast JGAJ. Multiple overnight urinc collections may be used for estimating the excretion of electrolytes and creatinine. Clin Chem 1988;34:135-138.

Van Poppel G, Schneijder P, Maas IAM, Schrijver J, Sluiter-van Nies AAM, Kok FJ. Sociaal-economische verschillen in voeding en voedingstoestand bij 10-11 jarige jongens. Ned Tijdschr Geneeskd 1989;133:1223-1227.

Maas IAM, Van Poppel G, Bambang Oetomo S, Kok FJ. Antropometrie en sociaal economische status bij 10-I1 jarige jongens. T Soc Gezondheidsz 1989;67:179-182.

Schrijvers CTM, Van Poppel G, Schrijver J, Hulshof KFAM, Kok FJ, Bambang Oetomo S. Bezuinigen op voedingsmiddelen en de voedingstoestand van tien- en elfjarige jongens: een verkennende siudie. Ned Tijdschr Diëtisıen 1989;44:89-93.

Van Poppel G. Schrijver J, Meulmeester JF, Kempen-Voogd N. Biochemical and anthropometric evaluation of the nutritional stalus of 35 -year-old Dutch men with reference to smoking and Jrinking habits. Int J Vit Nutr Res 1989;59:381-387.

Schrijvers CTM. Van Poppel G, Tersteeg W. Kok FJ. Determinanten van de gebitsstatus bij 10 - 11 jarige jongens. T Soc Gezondheidsz 1989;67:416-4I8.

Schneijder P, Hulshof KFAM, Van Poppel G, Kistemaker C. Vocding van 10-11 jarige jongens. Ned Tijdschr Diëtisten 1990;45:136-140.

Löwik MRH, Van Poppel G, Wedel M. Van den Berg H. Schrijver J. Dependence of vitamin B-6 status assessment on alcohol intake among elderly men and women (Dutch Nutrition Surveillance System). J Nutr 1990:120:1344-1351.

Kok FJ, Van Poppel G. Melse J, Verheul E, Schouten EG, Kruyssen DHCM, Holman A. Do antioxidants and polyunsaturated fatty acids have a combined association with coronary atherosclerosis? Atherosclerosis $1991 ; 31: 85-90$.

Van Poppel G, Schneijder P, Löwik MRH. Schrijver S, Kok FJ. Nutritional status and food consumption in 10-11 year old Dutch boys. Br J Nutr 1991;66:16!-169.

Van Poppel G, Kok FJ. Gorgels WJMJ, Schrijver J. Lung cancer and exposure to tobacco in the household. (letter) N Engl J Med 1991:324:413-414.

Van Poppel G, De Vogel N, Van Bladeren P, Kok FJ. Increased cylogenetic damage in smokers deficient in glutathione S-transferase isozyme $\mu$. Carcinogenesis 1992;13:303-305.

Gorgels WJMJ, Van Poppel G, Jarvis MJ, Stenhuis W, Kok FJ. Passive smoking and sister chromatid exchanges in lymphocytes. Mut Res 1992;279:233-238. 
Van Poppel G, Kok FJ, Duijzings P, De Vogel N. No influence of $\beta$-carotene on smoking induced DNA damage as reflected by sister chromatid exchanges. Int I Cancer 1992:51:355-358

Brussaard JH, Van Dis SJ, Van Poppel G. Anti-oxidantia en preventie van hart- en vaatziekten. Ned Tijdschr Geneeskd 1992;136:2110-2114.

Van Poppel G. Carotenoids and Cancer. Voeding 1992;53:195-199

Princen HMG, Van Poppel G, Vogelezang C, Buytenhek R, Kok FJ. Supplementation of vitamin E, but not of $\beta$-carotene in vivo protects LDL from peroxidation in vitro. Effect of cigarette smoking. Areriosclerosis an Trombosis 1992;12:554-562

Bos RP, Van Poppel G, Theuws JLG, Kok FJ. Decreased excetion of thiothers in urine of smokers after the use of $\beta$-carotene. Int Arch Occup Environ Health 1992;64:189-193.

Kardinaal AFM, Van Poppel G, Kok FJ. Antioxidanıs and coronary hearth disease. J Myocard Ische 1992:4:64-78.

Van Poppel G. Verhagen H, Van 't Veer P. Biomerkers in epidemiologisch en toxicologisch voedingsonderzoek. Voeding 1992;53:222-229.

Van Poppel G, Kok FJ, Hermus RJJ. $\beta$-carotene supplementation in smokers reduces the frequency of micronucle in spulum. Br J Cancer 1992;66:1164-1168.

Verhagen H, Van Poppel G, Willems MI, Bogards JJP, Rompelberg CIM, Van de Kerkhof MCA, Van Bladeren J. Cancer-preventing potential of nalural food constituents. Confernce Proceedings Food Ingredients Europe 992:246-250. Expoconsulı Publishers, Maarssen, the Netherland.

verhagen H, Van Poppel G, Willems MI, Bogards JJP, Rompelberg CJM, Van Bladeren PJ. Cancer preventio by natural food constiluents. Int Food Ingredients 1993;1/2:22-29.

Van Poppel G, Spanhaak S. Ockhuizen Th. Effect of $\beta$-carotene on immunological indices in healthy male mokers. Am J Clin Nutr 1993:57:402-407.

Brug J. Van Poppel G. Voeding en kanker: chemopreventieve voedselbestanddelen. Ned Tijdschr Genees 1993:137:799-803.

Van Poppel G. Carotenoids and cancer. An update with emphasis on human intervention studies. Eur J Cancer 1993:29: 1335-1344.

Van Poppel G. Verhagen H. Van 't Veer P. Van Bladeren PJ. Markers for cylogenetic damage in smokers: ssociations with plasma antioxidants and glutathione-S-transferase $\mu$. Cancer Epidemiol Biomark Prev 1993:2:441-447

Van Poppel G. Kardinaal AFM. Princen HMG. Antioxidanten en coronaire harziekten. Hart Bulletin 1994, in press

Kenmeren JM. Van Poppel G. Verhoef P. Jarvis MJ. Plasma cotinine: stability in smokers and validation of self reported smoke exposure in non smokers. Environmental Research 1994, in press.

Boogaards JJP, Verhagen H. Willems MI, Van Poppel G, Van Bladeren PJ. Consumplion of Brussels sprouts results in elevaled $\boldsymbol{\alpha}$-class glutathione S-Iransferase levels in human blood plasma. Carcinogenesis 1994, in press.

\section{About the author}

Geert van Poppel was born in Riethoven on 10 July 1960. After graduating from Gymnasium- $\beta$ at the Rythovius College in Eersel, he started to study Human Nutrition at the Agricultural University in Wageningen in 1978. The MSc program was focused on nutrition (in particular nutritional epidemiology) and toxicology and included a project at the Tanzania Food and Nutrition Center in Dar Es Salaam. After obtaining his MSc degree in 1985, he worked at the International Course in Food Science and Nutrition in Wageningen. From 198. to 1986, he worked as a research associate on an EC project at the Department of Human Nutrition, Aricultural University Wageningen During this period, he also obtained a teachers

degree.
In 1986, he started working as a nutritional epidemiologist at the Department of Nutrition, TNO Nutrition and Food Research in Zeist. From 1986 to 1989 research was done within the framework of the Dutch Nutrition Surveillance program. During that time he wrote the grant proposal for the intervention study described in this thesis. In 1988, he attended the New England Epidemiology Summer Program at Boston/Medford, USA. From 1989 onward research activities include the studies in this thesis, several case-control studies on dietary factors and cardiovacular disease, and the role of non nutritive dietary compounds in disease prevention. Since 1993, he is head of the Epidemiology Section of the Department of Nutrition of TNO Nutrition and Food Research. 


\section{About the author}

Geert van Poppel was born in Riethoven on 10 July 1960. After graduating from Gymnasium- $\beta$ at the Rythovius College in Eersel, he started to study Human Nutrition at the Agricultural University in Wageningen in 1978. The MSc program was focused on nutrition (in particular nutritional epidemiology) and toxicology and included a project at the Tanzania Food and Nutrition Center in Dar Es Salaam. After obtaining his MSc degree in 1985, he worked at the International Course in Food Science and Nutrition in Wageningen. From 1985 to 1986 , he worked as a research associate on an EC project at the Department of Human Nutrition, Agricultural University Wageningen. During this period, he also obtained a teachers' degree.

In 1986, he started working as a nutritional epidemiologist at the Department of Nutrition, TNO Nutrition and Food Research in Zeist. From 1986 to 1989 research was done within the framework of the Dutch Nutrition Surveillance program. During that time he wrote the grant proposal for the intervention study described in this thesis. In 1988, he attended the New England Epidemiology Summer Program at Boston/Medford, USA. From 1989 onward research activities include the studies in this thesis, several case-control studies on dietary factors and cardiovascular disease, and the role of non nutritive dietary compounds in disease prevention. Since 1993, he is head of the Epidemiology Section of the Department of Nutrition of TNO Nutrition and Food Research. 


\section{Worteltjestaart}

400 gram zelfrijzend bakmeel

I eetlepel kaneel

I theeleepel nootmuskaat

1 theelepel zout

3 kleine eieren

300 gram suiker

150 gram mayonaise

100 gram ananasstukjes

300 gram geraspte wortelen

75 gram walnoten

75 gram rozijnen

voor glazuar

100 gram roomkaas

50 gram poedersuiker

2 eetlepels water

Meng zelfrijzend bakmeel, kaneel, nootmuskaat en zout in een kom. Meng de eieren, suiker en mayonaise in een aparte kom en voeg dit aan het bloemmengsel toe. Kort mixen of roeren tot het deeg goed gemengd is. Roer vervolgens de ananas, wortelen, noten en rozijnen door het deeg en breng dit over in een ingevette tulbandvorm. Bakken in 60 minuten in een voorverwarmde oven op $190^{\circ} \mathrm{C}$. Laat de taart afkoelen, keer op een schaal en glazuur de bovenkant met het mengsel van roomkaas, suiker en water. 